Aus der Klinik für Nephrologie und Rheumatologie (Prof. Dr. med. G. A. Müller) im Zentrum Innere Medizin der Medizinischen Fakultät der Universität Göttingen

\title{
Prognose von Patienten mit Alport-Syndrom unter Berücksichtigung einer medikamentösen Intervention und verschiedener Nierenersatzverfahren
}

\author{
INAUGURAL-DISSERTATION \\ zur Erlangung des Doktorgrades \\ der Medizinischen Fakultät der \\ Georg-August-Universität zu Göttingen
}

vorgelegt von

Angela Assmann, geb. Coordes

aus Osnabrück

Göttingen 2014 
Dekan: Prof. Dr. rer. nat. H. K. Kroemer

I. Berichterstatter: Prof. Dr. med. O. Gross

II. Berichterstatter/in: Prof. Dr. med. M. Lakomek

III. Berichterstatter/in: Prof. Dr. hum. biol. Margarete Schön

Tag der mündlichen Prüfung: 21.01.2015 


\section{Inhaltsverzeichnis}

Abbildungsverzeichnis

Tabellenverzeichnis

Abkürzungsverzeichnis

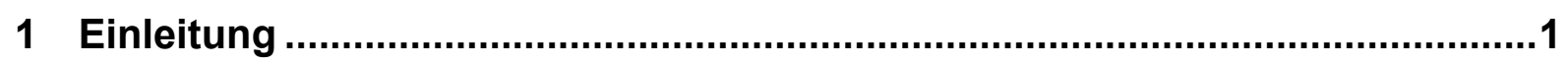

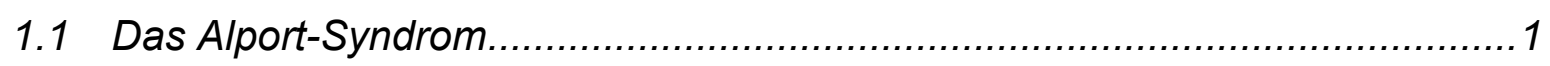

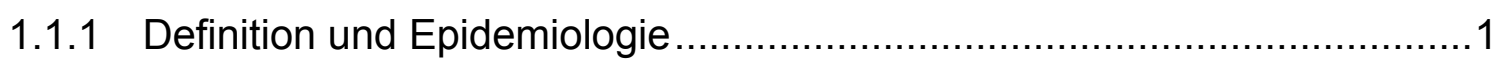

1.1.2 Mutationen im Kollagen Typ IV als Ursache des Alport-Syndroms..........2

1.1.3 Pathophysiologie des Alport-Syndroms .........................................4

1.1 .4 Klinische Manifestation...............................................................

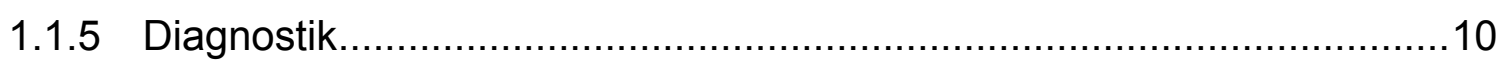

1.2 Therapie des Alport-Syndroms ............................................... 12

1.2.1 Pharmakotherapie mit ACE-Hemmern ........................................... 13

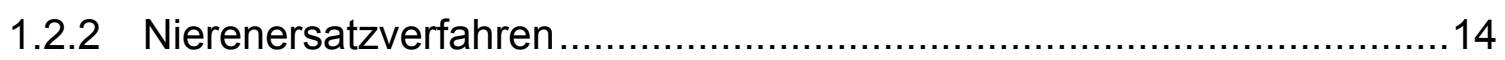

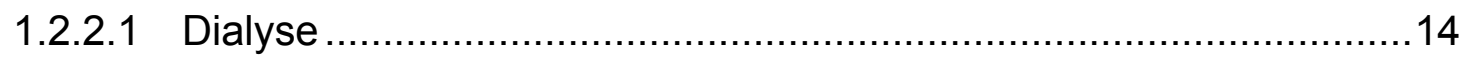

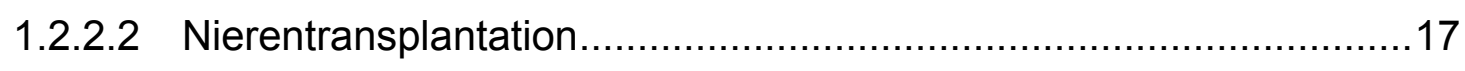

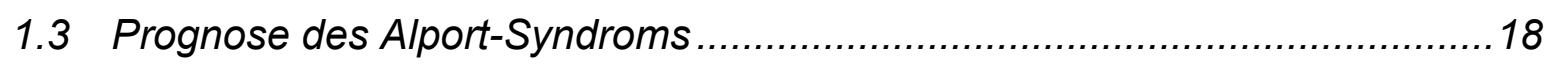

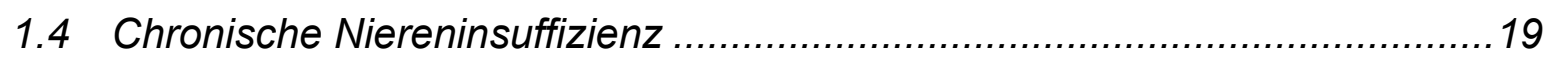

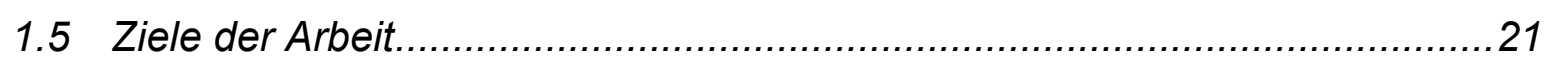

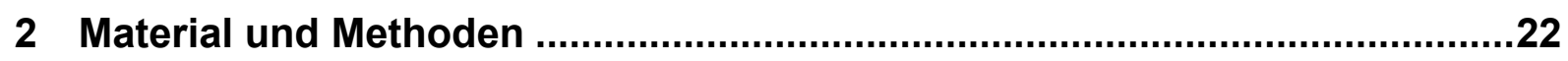

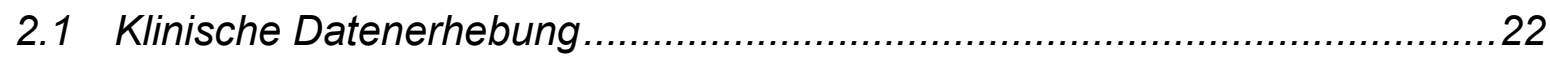

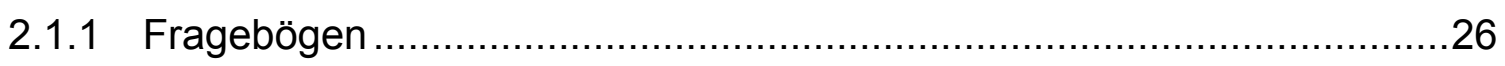

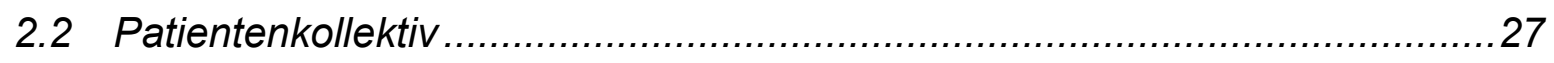

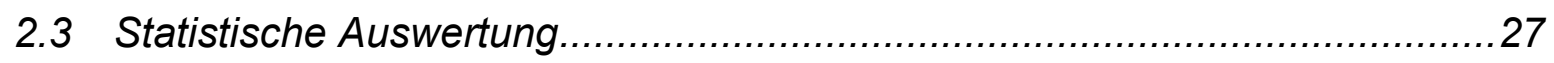

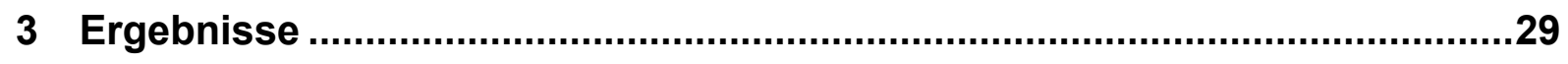

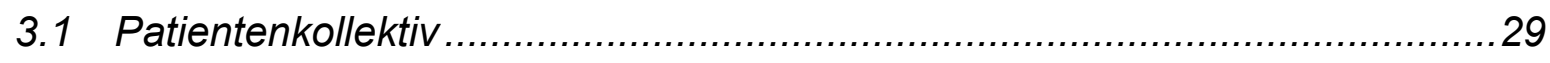

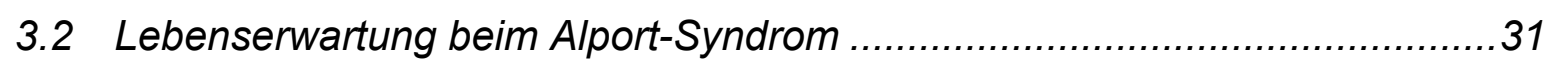

3.3 Auswirkungen von ACE-Hemmern auf die Lebenserwartung von Patienten

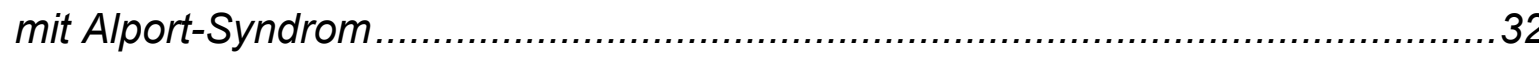


3.4 Alter bei Dialysebeginn

3.4.1 Einfluss einer ACE-Hemmer-Therapie auf das Alter bei Dialysebeginn .35

3.4.2 Einfluss des Erbgangs beim Alport-Syndrom auf das Alter bei

Dialysebeginn

3.5 Dauer der Transplantatfunktion 39

3.5.1 Dauer der Transplantatfunktion unter Berücksichtigung einer ACE-

Hemmer-Therapie.

3.5.2 Dauer der Transplantatfunktion unter Berücksichtigung des Erbgangs ..41

4 Diskussion

4.1 Datenerhebung

4.2 Lebenserwartung beim Alport-Syndrom im Vergleich zu anderen

Nierenerkrankungen .

4.3 Auswirkungen von ACE-Hemmern auf die Lebenserwartung von Patienten mit Alport-Syndrom.

4.4 Auswirkungen einer ACE-Hemmer-Therapie auf das Alter bei Dialysebeginn ..

4.5 Auswirkungen des Erbgangs auf den Dialysebeginn bzw. die

Transplantatfunktionsdauer.

4.6 Auswirkungen von ACE-Hemmern auf die Dauer der Transplantatfunktion..49

4.7 Dauer der Transplantatfunktion beim Alport-Syndrom im Vergleich zu anderen Patienten mit Nierentransplantation.... .50

4.8 Ausblick. .54

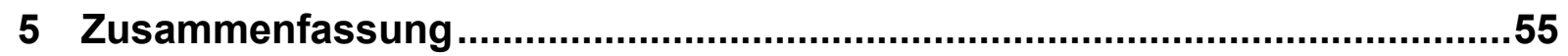

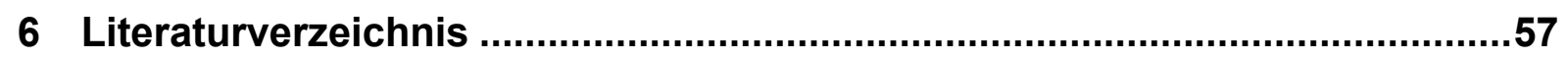

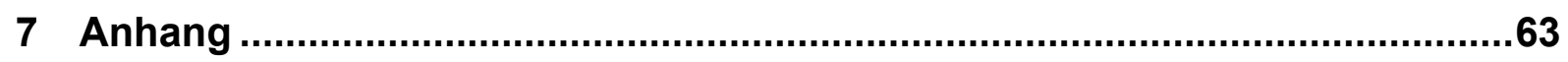

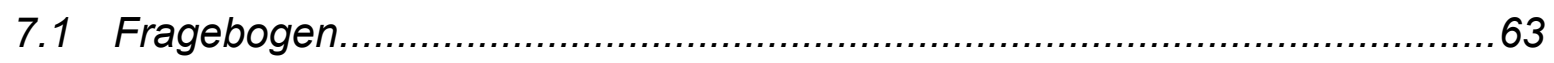




\section{Abbildungsverzeichnis}

Abbildung 1: Organisation von Tripelhelices der Kollagenfamilie Typ IV ..................3

Abbildung 2: Struktur des Kollagen Typ IV ...............................................

Abbildung 3: Elektronenmikroskopische Aufnahme eines normalen Glomerulus ........5

Abbildung 4: Elektronenmikroskopische Aufnahme eines Glomerulus beim Alport-

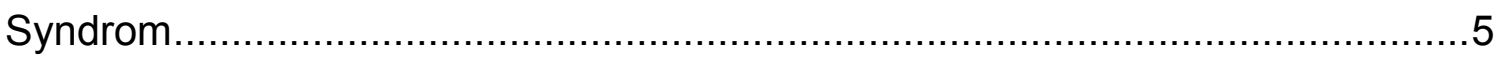

Abbildung 5: Verteilung der Geschlechter in den Erbgängen ...............................30

Abbildung 6: Lebenserwartung beim Alport-Syndrom.................................. 32

Abbildung 7: Verteilung einer ACE-Hemmer-Therapie im untersuchten Patientenkollektiv

Abbildung 8: Auswirkungen von ACE-Hemmern auf die Lebenserwartung von Patienten mit Alport-Syndrom 34

Abbildung 9: Anzahl an nicht-dialysepflichtigen Alport-Patienten zum Zeitpunkt der Datenerhebung 35

Abbildung 10: Anzahl an nicht-dialysepflichtigen Alport-Patienten zum Zeitpunkt der Datenerhebung unter Berücksichtigung einer stattgefundenen oder unterbliebenen ACE-Hemmer-Therapie .... 36

Abbildung 11: Einfluss des Erbgangs auf das Alter bei Dialysebeginn ....................38

Abbildung 12: Transplantatfunktionsdauer in Jahren 39

Abbildung 13: Auswirkung einer ACE-Hemmer-Therapie auf die Dauer der Transplantatfunktion

Abbildung 14: Dauer der Transplantatfunktion unter Berücksichtigung des Erbgangs

Abbildung 15: Funktionsdauer der Nierentransplantate in Deutschland im internationalen Vergleich 


\section{Tabellenverzeichnis}

Tabelle 1: Darstellung der klinischen Symptomatik beim Alport-Syndrom.................9

Tabelle 2: Diagnostischer Wert von klinischen und pathologischen Charakteristika

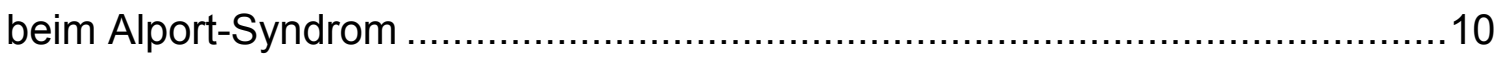

Tabelle 3: Immunhistochemie beim Alport-Syndrom ....................................12

Tabelle 4: Stadieneinteilung der chronischen Niereninsuffizienz nach der K/DOQI ..20

Tabelle 5: Aufteilung der Mutationen in den Erbgängen von Dialyse-Patienten ........38

Tabelle 6: Aufteilung der Mutationen in den Erbgängen von Patienten mit Nierentransplantation 


\section{Abkürzungsverzeichnis}

\begin{tabular}{|c|c|}
\hline Abb. & Abbildung \\
\hline ACE & angiotensin converting enzyme \\
\hline AS & Alport-Syndrom \\
\hline $\mathrm{BC}$ & Bowman-Kapsel \\
\hline BM & Basalmembran \\
\hline BMdT & Basalmembran distaler Tubulus \\
\hline bzw. & beziehungsweise \\
\hline ca. & circa \\
\hline CAKUT & congenital anomalies of the kidney and urinary tract \\
\hline CAPD & continuous ambulatory peritoneal dialysis \\
\hline DSO & Deutsche Stiftung Organtransplantation \\
\hline EBM & epidermale BasImembran \\
\hline ESCAPE & $\begin{array}{l}\text { effect of strict blood pressure control and ace inhibition } \\
\text { on the progression of chronic renal failure in pediatric } \\
\text { patients }\end{array}$ \\
\hline ERA-EDTA & $\begin{array}{l}\text { European Renal Association - European Dialysis and } \\
\text { Transplant Association }\end{array}$ \\
\hline et al. & und andere (lat. et alii) \\
\hline etc. & und so weiter (lat. et cetera) \\
\hline g & Gramm \\
\hline GBM & glomeruläre Basalmembran \\
\hline GFR & glomeruläre Filtrationsrate \\
\hline J. & Jahren \\
\hline K/DOQI & Kidney Disease Outcomes Quality Initiative \\
\hline KHK & koronare Herzkrankheit \\
\hline $\mathrm{KI}$ & Konfidenzintervall \\
\hline Lj. & Lebensjahr \\
\hline $\mathrm{m}^{2}$ & Quadratmeter \\
\hline $\min$ & Minute \\
\hline $\mathrm{ml}$ & Milliliter \\
\hline $\mathrm{n}$ & Anzahl \\
\hline
\end{tabular}


NAPRTCS North American Pediatric Renal Trials and Collaborative Studies

NC non collagenous

$\mathrm{NI} \quad$ Niereninsuffizienz

$\mathrm{p} \quad$ probability

QuaSi-Niere Qualitätssicherung in der Nierenersatztherapie

TGF transforming growth factor

US United States

vs. versus

z.B. zum Beispiel

zw. $\quad$ zwischen 


\section{Einleitung}

\subsection{Das Alport-Syndrom}

\subsubsection{Definition und Epidemiologie}

Das Alport-Syndrom (AS), auch progressive hereditäre Nephritis genannt, ist eine vererbte Nephropathie mit progredienter Niereninsuffizienz, die sich in Form von Hämaturie und Proteinurie äußert. Im Endstadium der Niereninsuffizienz, dem terminalen Nierenversagen, kommt es zur Urämie. Diese endet ohne Behandlung letal. Nach den aktuellen Leitlinien ist das "terminale Nierenversagen" durch eine glomeruläre Filtrationsrate von unter $15 \mathrm{ml} / \mathrm{min} / 1,73 \mathrm{~m}^{2}$ und der Notwendigkeit einer Nierenersatztherapie definiert (Levey et al. 2003). Zu möglichen Nierenersatztherapien zählen die Hämodialyse, die Peritonealdialyse und die Nierentransplantation. Zusätzlich zu den genannten nephrologischen Symptomen liegt bei $60-80 \%$ der Erkrankten eine Innenohrschwerhörigkeit vor. Ferner weisen 25 - 40\% der Patienten für das AS typische Augenveränderungen auf (Alport 1927, Flinter et al. 1988). Generell gibt es drei verschiedene Vererbungsmodi des AS: X-chromosomal, autosomal-rezessiv und autosomal-dominant. Die Prävalenz des X-chromosomalen AS wird auf 1:5.000 geschätzt, die des autosomal-rezessiven AS auf 1:50.000 (Atkin 1988). Das autosomal-dominant vererbte AS nimmt nur einen sehr geringen Anteil von circa $5 \%$ ein (Pescucci et al. 2004).

Das AS macht einen Anteil von 0,3 bis $2,3 \%$ an den zum terminalen Nierenversagen führenden Erkrankungen aus (Hudson et al. 2003). Von allen Dialysepatienten sind 1 - $2 \%$ am AS erkrankt (NAPRTCS 2008).

Das AS ist, nach dem Krankheitsbild der polyzystischen Nieren, die zweithäufigste erbliche Erkrankung, die zum terminalen Nierenversagen führt (Geiger et al. 2003). 


\subsubsection{Mutationen im Kollagen Typ IV als Ursache des Alport-Syndroms}

Das AS ist eine diffuse Funktionsstörung spezialisierter Basalmembranen, die sich durch die Expression bestimmter Isoformen des Kollagen Typ IV charakterisieren lassen (Kashtan und Michael 1996).

Das Protein Kollagen Typ IV ist ein wesentlicher Bestandteil der glomerulären Basalmembran (GBM) und spielt bei der Entstehung des AS die entscheidende Rolle (Gunwar et al. 1998).

Sechs verschiedene alpha (IV)-Ketten, $\alpha 1$ - $\alpha 6$, des Kollagen Typ IV sind bekannt. Diese werden von den Genen COL4A1 - COL4A6 codiert. Während die $\alpha 1$ - und $\alpha 2-$ Ketten ubiquitär in Basalmembranen anzutreffen sind, zeigen die $\alpha 3-, \alpha 4-, \alpha 5-$ und a6-Ketten organspezifische Verteilungen (Hudson et al. 1993). Die $\alpha 3-, \alpha 4-$ und $\alpha 5-$ Ketten kommen in der Niere in der glomerulären Basalmembran vor. Außerdem findet man die $\alpha 5-K e t t e$ noch in der Bowman-Kapsel der Niere. Im Auge sind die $\alpha 3-$, a4- und $\alpha 5$-Ketten in der Linsenkapsel, der Descemet-Membran, der BruchMembran und in der Membrana limitans interna anzutreffen. Im Innenohr findet man sie im Limbus spiralis, in der Prominentia spiralis und in der Basilarmembran. Die $\alpha 6-$ Kette ist ebenfalls in der Bowman-Kapsel und im distalen Tubulus vorhanden, allerdings ist ein Vorkommen im Auge und im Ohr bislang nicht bekannt. Eine Besonderheit ist, dass diese Kette und die $\alpha 5$-Kette außerdem in der Basalmembran der Epidermis vorhanden sind (Gunwar et al. 1998, Kashtan und Michael 1996, Ninomiya et al. 1995).

Die Grundstruktur des Kollagens ist eine aus drei alpha-Ketten bestehende triplehelikale Struktur (Trimer), die als Protomer bezeichnet wird. Jede alpha-Kette besitzt drei Domänen: eine kurze 7S-Domäne an ihrem N-terminalen Ende, eine lange triple-helikale Kollagen-Domäne mit mehr als 1000 Glycin-X-Y-Wiederholungen und eine nicht kollagene Domäne (NC1) an ihrem C-terminalen Ende. Es gibt drei verschiedene Möglichkeiten, wie sich die alpha-Ketten zu einem Protomer zusammenfügen: $\alpha 1 \alpha 1 \alpha 2, \alpha 3 \alpha 4 \alpha 5$ und $\alpha 5 \alpha 5 \alpha 6$. Zwei Trimere treten über die NC1Domäne am C-terminalen Ende zusammen und bilden ein Hexamer. Über die 7SDomäne findet eine Verbindung mit drei weiteren Protomeren statt. Das Kollagennetzwerk wird weiter verdrillt und durch Disulfidbrücken zusätzlich stabilisiert (Kleppel et al. 1992, Hudson et al. 2003) (Abb. 1 und Abb. 2). 
Kollagen Typ IV Ketten

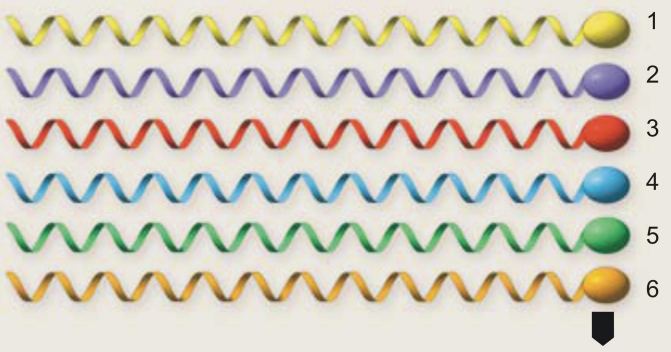

NC1-Monomer
Protomere

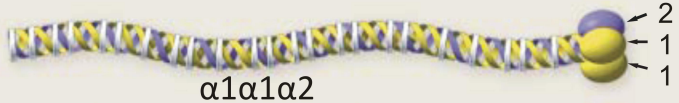
$\alpha 1 \alpha 1 \alpha 2$

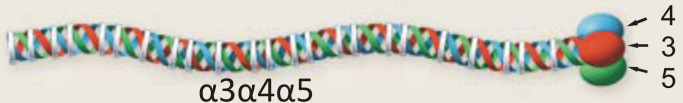

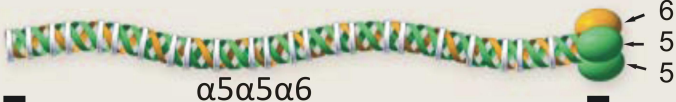

NC1-Trimer

Abbildung 1: Organisation von Tripelhelices der Kollagenfamilie Typ IV. (modifiziert nach Hudson et al. 2003). Auf der linken Seite sind die sechs unterschiedlichen alpha-Ketten des Kollagen Typ IV zu sehen. Auf der rechten Seite sieht man die Verbindung von jeweils drei $\alpha$-Ketten (Trimere) zu einem Protomer. Jedes Protomer besitzt eine 7S-Domäne an seinem N-terminalen Ende, eine triple-helikale Kollagen-Domäne und eine NC1-Domäne an seinem C-terminalen Ende.
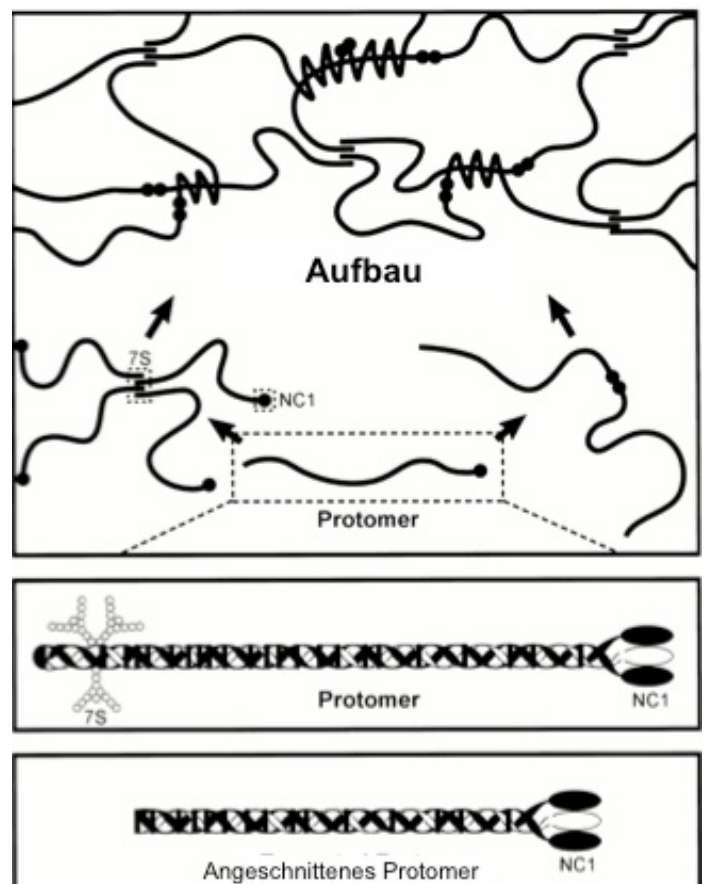

Angeschnittenes Protomer

Abbildung 2: Struktur des Kollagen Typ IV. (modifiziert nach Gunwar et al. 1998). Zwei Protomere (Trimere) verbinden sich über die NC1-Domäne und bilden ein Hexamer. Über die 7S-Domäne verbinden sich vier Protomere und es entsteht ein Tetramer. Durch weitere Verdrillungen entsteht ein stabiles Kollagen-Netzwerk. 


\subsubsection{Pathophysiologie des Alport-Syndroms}

Die Pathophysiologie des AS beruht auf Mutationen in Genen, welche für das Kollagen Typ IV codieren. Diese Mutationen führen zu einem fehlerhaften Aufbau der GBM und schließlich zur Nierenfibrose, die in einem terminalen Nierenversagen endet (Gunwar et al. 1998).

Ursächlich für das AS sind Mutationen in der $\alpha 3-, \alpha 4-$ oder $\alpha 5-$ Kette des Kollagen Typ IV. Eine Mutation im Genlocus q35-36 auf dem Chromosom 2 kann die Gene COL4A3 oder COL4A4 betreffen. Dies führt zu der autosomal-rezessiven Form des AS, die einen Anteil von ca. 10 - 15\% ausmacht. Eine Mutation auf Chromosom Xq22 betrifft dagegen das Gen COL4A5 und ruft die wesentlich häufigere Xchromosomal vererbte Form $(>80 \%$ ) des AS hervor. Fünfzehn Prozent der Fälle beruhen bei beiden Erbgängen auf Neumutationen (Antignac et al. 1994). Außerdem ist eine sehr selten vorkommende autosomal-dominante Form des AS bekannt, welche ebenfalls durch Mutationen in den Genen COL4A3 oder COL4A4 hervorgerufen wird (Pescucci et al. 2004).

Die Mutationen in den genannten Genen führen dazu, dass die $\alpha 3-, \alpha 4-$ und $\alpha 5-$ Ketten nicht in die GBM eingebaut werden (Gunwar et al. 1998). Es werden nur $\alpha 1-$ und $\alpha 2-K e t t e n$ eingebaut, welche nicht in der Lage sind, eine ausgereifte GBM zu bilden (Gunwar et al. 1998). In der normalen Entwicklung der GBM ersetzen die $\alpha 3-$, $\alpha 4-$ und $\alpha 5-K e t t e n$ die $\alpha 1$ - und $\alpha 2-K e t t e n$, um so eine voll funktionstüchtige GBM entstehen zu lassen (Miner und Sanes 1996).

Hierdurch ist der typische Aufbau der GBM, der aus zwei Laminae rarae und einer Lamina densa besteht, gestört. Die Lamina densa imponiert mit netzartigen Strukturveränderungen und die Basalmembran ist insgesamt verdickt (Kashtan und Michael 1996) (Abb. 3 und Abb. 4). Bei sehr jungen Patienten hingegen zeigt sich die GBM verdünnt und unregelmäßig (Gubler et al. 1981). 
Diese Veränderung der glomerulären Basalmembran führt zur Vernarbung der Glomeruli und zum Ausfall der Tubuli, was zur interstitiellen Fibrose der Niere führt. Die genauen Pathomechanismen, die von der Zerstörung der GBM schließlich zur terminalen Niereninsuffizienz führen, sind zur Zeit noch nicht geklärt (Martini und Peters 2009).

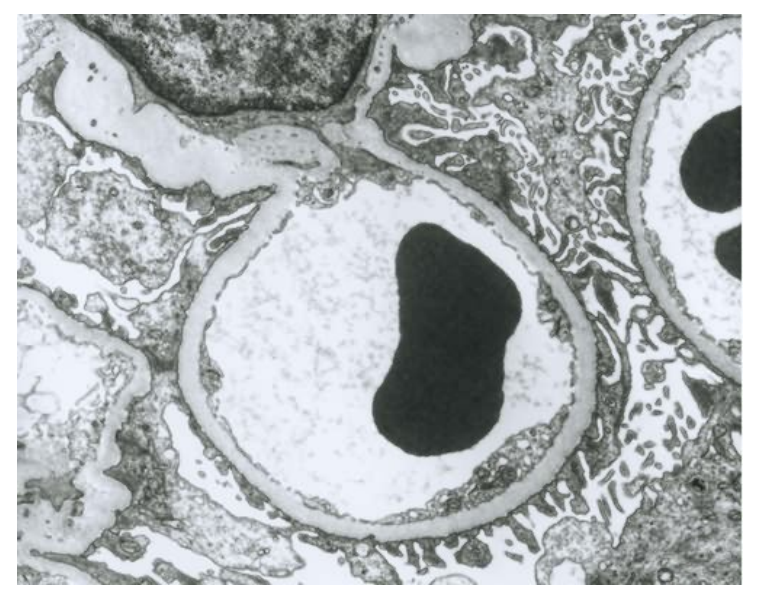

Abbildung 3: Elektronenmikroskopische Aufnahme eines normalen Glomerulus. (modifiziert nach Herbst und Hübner 2000). Im Lumen ein Erythrozyt (schwarz = elektronendichte Masse), eine gleichmäßige, zarte Endothelschicht und eine gleichmäßig breite Basalmembran von homogener Elektronendichte (schwach grau) sowie ein Saum von Podozyten bzw. Podozytenfüßchen. Im linken oberen Quadranten liegt der Kern einer Mesangialzelle (Vergrößerung 15.000-fach).

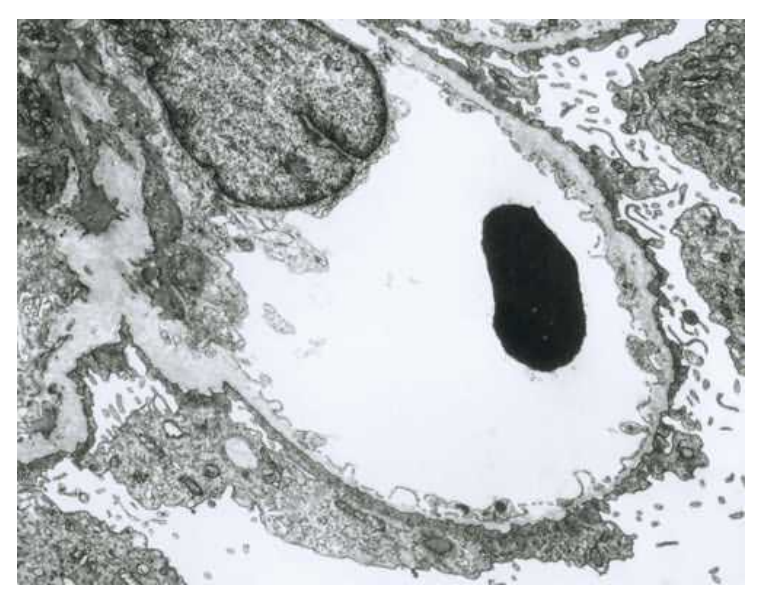

Abbildung 4: Elektronenmikroskopische Aufnahme eines Glomerulus beim AlportSyndrom. (modifiziert nach Herbst und Hübner 2000). Im Lumen ein Erythrozyt (schwarz = elektronendichte Masse), eine wellig konturierte Endothelschicht und eine unregelmäßig breite, überwiegend stark verdünnte, aufgesplitterte Basalmembran mit vermindert elektronendichten $(=$ hellen) Herden unterhalb des Endothels. Die Podozyten zeigen eine villöse Transformation. Im linken oberen Quadranten liegt der Kern einer Endothelzelle (Vergrößerung 15.000-fach). 
Bis heute sind mehrere hundert Mutationen des COL4A5-Gens bekannt, die das Xchromosomal vererbte AS verursachen (Gross et al. 2002). Das Beispiel einer typischen Mutation ist die Missense-Mutation, welche durch den Austausch eines Glycin-Restes im kollagenen Anteil der a5-Kette durch eine andere Aminosäure verursacht wird. Diese Mutation ist die häufigste Ursache, die zum X-chromosomal vererbten AS führt (Kashtan und Michael 1996, Kawai et al. 1996). Sie macht einen Anteil von $40 \%$ aus (Gubler 2008).

\subsubsection{Klinische Manifestation}

Das AS wurde erstmals 1927 von Arthur Cecil Alport beschrieben (Alport 1927). Die klinische Ausprägung sowie die Häufigkeit von Organschäden sind sehr variabel.

Die X-chromosomale Form betrifft hauptsächlich Männer (Hemizygotie). Aber auch Frauen können betroffen sein (Heterozygotie), die als Carrier die Erkrankung dann auf ihre Söhne übertragen (Pirson 1999). Töchter sind zu 50\% ebenfalls latente Überträgerinnen, von denen ca. $10-20 \%$ selbst an die Dialyse kommen (Temme et al. 2012b). Bei dem X-chromosomal vererbten AS sind die Symptome bei den betroffenen Männern wesentlich ausgeprägter als bei betroffenen Frauen (Pirson 1999). Die große Spannweite hinsichtlich des Schweregrads der Erkrankung bei den betroffenen Frauen beruht darauf, dass eines der beiden X-Chromosomen zufällig inaktiviert wird. Dabei ist entweder das mutierte oder das Wildtyp-Allel des COL4A5Gens betroffen (Kashtan 2007).

Als erstes Symptom macht sich in der Regel eine persistierende Hämaturie bemerkbar. Beim X-chromosomal vererbten AS weisen alle Männer und 95\% der Frauen eine mikroskopische Hämaturie auf. Eine Makrohämaturie zeigen 60 - 70\% der hemizygoten Männer und ein Drittel der heterozygoten Frauen (Flinter 1998). Beim autosomal-rezessiven Erbgang leiden alle Patienten an einer Mikrohämaturie, viele an einer Makrohämaturie (Mochizuki et al. 1994).

Das darauf folgende Symptom ist meist eine Proteinurie (Pirson 1999). Diese wird in den ersten Lebensjahren gewöhnlich noch nicht nachgewiesen. Dies ist darauf zurückzuführen, dass sie sich im Laufe der Erkrankung bei den Männern des Xchromosomalen und bei beiden Geschlechtern des autosomal-rezessiven Erbgangs erst noch entwickelt (Grunfeld 1985). Die Proteinurie nimmt ab dem Kindesalter zu. Sie kann zu einem nephrotischen Syndrom führen, welches durch eine große Proteinurie (bei Kindern $>1 \mathrm{~g}$ pro $\mathrm{m}^{2}$ Körperoberfläche in 24 Stunden und bei 
Erwachsenen $>3-3,5$ g pro 24 Stunden), Hypoproteinämie, Ödeme durch Hypalbuminämie und Hyperlipoproteinämie gekennzeichnet ist (Gubler et al. 1981).

Ein weiteres Symptom ist der durch die Erkrankung bedingte Bluthochdruck, der mit zunehmendem Alter typischerweise progredient und stärker bei den betroffenen Männern des X-chromosomalen Erbgangs ausgeprägt ist als bei Frauen. Auch hier gibt es hinsichtlich der Stärke der Ausprägung beim autosomal-rezessiven AS keine geschlechtsspezifischen Unterschiede. Die Hypertonie entsteht durch die kontinuierlich fortschreitende Verschlechterung der Nierenfunktion.

Bei allen betroffenen Männern mit X-chromosomalem Erbgang entwickelt sich ein terminales Nierenversagen. Die Schnelligkeit des Fortschreitens ist jedoch von Patient zu Patient sehr unterschiedlich (Kashtan und Michael 1996). Das Alter zum Zeitpunkt der terminalen Niereninsuffizienz hängt von der zugrundeliegenden Form (adult oder juvenil) ab, die im Folgenden noch näher beschrieben wird. Beim autosomal-rezessiv vererbten AS kommt es bei beiden Geschlechtern in der zweiten bis dritten Lebensdekade zum terminalen Nierenversagen (Gubler 2008).

Die Symptome betroffener Frauen mit X-chromosomalem AS sind milder ausgeprägt. Sie können ein normales Alter erreichen und bis ins Alter von 50 - 70 Jahren ohne eine Einschränkung der Nierenfunktion leben. Eine Makrohämaturie in der Kindheit, ein nephrotisches Syndrom und eine diffuse Verdickung der GBM sind allerdings auch bei den betroffenen Frauen ein prognostisch ungünstiges Zeichen und weisen auf die Entwicklung einer terminalen Niereninsuffizienz hin (Grunfeld et al. 1985).

Ebenfalls zeigen das Auftreten eines Lenticonus anterior (kegelförmige Vorwölbung der Augenlinse) und eine Innenohrschwerhörigkeit einen ungünstigen Verlauf an, da sie meist mit schwereren Mutationen in den $\alpha$-Ketten des Kollagen Typ IV assoziiert sind (Gross et al. 2002, Kashtan und Michael 1996). Als weiteres Krankheitssymptom der Augen können perimakuläre Veränderungen auftreten, die sich durch glänzende weißliche oder gelbliche Flecken auf der Netzhaut äußern (Perrin et al. 1980). Der vordere Lenticonus ist pathognomonisch für das AS, jedoch nur bei $10-$ $30 \%$ der Betroffenen vorhanden. Er deutet auf ein schnelles Fortschreiten der Erkrankung hin und tritt in ca. $75 \%$ der Fälle beidseitig auf. Der Lenticonus tritt auch bei Frauen auf. Jedoch ist er bei Männern wesentlich häufiger. Dieser Defekt tritt in der Regel zwischen der zweiten und dritten Lebensdekade auf (Kashtan und Michael 1996). 
Der Hörverlust zeigt sich meist in der späten Kindheit oder frühen Adoleszenz bei den betroffenen Männern mit X-chromosomalem Erbgang. Die Frauen sind auch hier nicht so stark betroffen. Es leiden ca. $80 \%$ der Männer und 45\% der Frauen an einer Innenohrschwerhörigkeit. Bei der autosomalen Form gibt es keine geschlechtsspezifischen Unterschiede (Jais et al. 2000, Kashtan und Michael 1996).

Das Endstadium der Erkrankung ist die terminale Niereninsuffizienz, die sich in Form einer Urämie bemerkbar macht. Sie hat eine Dialyse oder Transplantation zur Folge. Hinsichtlich des Erreichens des terminalen Nierenversagens muss man beim Xchromosomal vererbten AS zwischen einer adulten und einer juvenilen Form unterscheiden. Bei der adulten Form sind die Patienten bei Erreichen der terminalen Niereninsuffizienz älter als 31 Jahre, bei der juvenilen Verlaufsform unter 31 Jahre (Atkin et al. 1988). In welchem Alter das Stadium der terminalen Niereninsuffizienz erreicht wird, ist auch abhängig von der dem AS zugrundeliegenden Mutation. Patienten mit einer Nonsense- oder Frameshift-Mutation oder größeren Deletionen im Genom entwickeln gewöhnlich vor dem 31. Lebensjahr ein terminales Nierenversagen (juvenile Form). Patienten mit Splicevarianten, Exonskipping oder Missense-Mutationen der $\alpha$-Helixglycine entwickeln meistens erst nach dem dreiBigsten Lebensjahr eine Nierenfunktonseinschränkung (adulte Form) (Kashtan und Michael 1996, Gross et al. 2002).

Zusammenfassend ist festzustellen, dass die klinische Symptomatik bei der Xchromosomalen und autosomal-rezessiven Form des AS identisch ist (Tabelle 1). Bei dem autosomal-rezessiven Erbgang sind beide Geschlechter gleich häufig und gleich stark betroffen. Im Gegensatz hierzu sind beim X-chromosomal vererbten AS die Männer häufiger und auch schwerer betroffen als die Frauen (Savige et al. 2013). 


\begin{tabular}{|c|c|c|}
\hline Symptome beim AS & $\begin{array}{l}\text { Auftreten der Symptome } \\
\text { beim X-chromosomalen } \\
\text { Erbgang }\end{array}$ & $\begin{array}{l}\text { Auftreten der Symptome } \\
\text { beim autosomalen } \\
\text { Erbgang }\end{array}$ \\
\hline $\begin{array}{l}\text { persistierende Hämaturie } \\
\text { - mikroskopische } \mathrm{H} \text {. } \\
\text { - makroskopische } \mathrm{H} \text {. }\end{array}$ & $\begin{array}{l}\text { - } \quad \text { alle } \widehat{\jmath} \text { (meist schon } \\
\text { im 1.Lj.), 95\% der } q \\
-\quad 60-70 \% \curvearrowright, 30 \% \uparrow \\
\text { (Flinter 1998) }\end{array}$ & $\begin{array}{l}\text { - alle Patienten } \\
\text { - viele Patienten } \\
\text { (Mochizuki et al. } \\
\text { 1994) }\end{array}$ \\
\hline Proteinurie & $\begin{array}{l}\text { nach einigen Jahren bei } \widehat{ }{ }^{\top} \\
\text { (Grunfeld 1985) }\end{array}$ & $\widehat{\delta}=q($ Grunfeld 1985) \\
\hline Hypertonie & $\begin{array}{l}\hat{\jmath}>+(\text { Kashtan und } \\
\text { Michael 1996) }\end{array}$ & $\begin{array}{l}\hat{O}=q \text { (Kashtan und Michael } \\
1996)\end{array}$ \\
\hline terminale NI & $\begin{array}{l}\hat{\sigma} \text { alle (juvenile und adulte } \\
\text { Form), zw. 40-50J. 10-15\% } \\
\text { der }+ \text { und } 90 \% \text { der } \widehat{O} \\
\text { (Gubler } 2008 \text { ) }\end{array}$ & $\begin{array}{l}\text { 2.-3. Dekade, } \delta^{\lambda}=\uparrow \text { (Gubler } \\
\text { 2008) }\end{array}$ \\
\hline $\begin{array}{l}\text { Augenveränderungen } \\
\text { (insgesamt } 15-30 \% \text { ) }\end{array}$ & $\begin{array}{l}\text { 2.-3. Dekade, } \widehat{\nearrow}>q \\
\text { (Kashtan und Michael } \\
\text { 1996) }\end{array}$ & nicht typisch \\
\hline $\begin{array}{l}\text { Innenohrschwerhörigkeit } \\
\text { (80\% der } \curvearrowright \text { (Jais et al. } \\
\text { 2000), 45\% der } q \text { (Kashtan } \\
\text { und Michael 1996)) }\end{array}$ & $\begin{array}{l}\widehat{\delta} \text { (späte Kindheit) }>\text { } \\
\text { (später als bei den } \widehat{\jmath} \text { ) }\end{array}$ & $\begin{array}{l}\text { Großteil der Patienten, } \quad \hat{0} \\
=q\end{array}$ \\
\hline
\end{tabular}

Tabelle 1: Darstellung der klinischen Symptomatik beim Alport-Syndrom. Es werden die unterschiedlichen Symptome beider Geschlechter beim AS im Hinblick auf die beiden zugrundeliegenden Erbgänge und den Zeitpunkt ihres Auftretens dargestellt. Abkürzungen: Lj. (Lebensjahr), J. (Jahren), zw. (zwischen). 


\subsubsection{Diagnostik}

Das AS muss als mögliche Diagnose in Betracht gezogen werden, wenn ein Kind an einer persistierenden mikroskopischen Hämaturie glomerulären Ursprungs leidet. Im Rahmen des diagnostischen Prozederes ist es sinnvoll, ein Screening der Verwandten auf mikroskopische Hämaturie durchzuführen. Bei dem Betroffenen selbst sollte eine ausführliche ophthalmologische Untersuchung und ein Audiogramm gemacht werden. Der vordere Lenticonus, der nahezu pathognomonisch für des AS ist, ist nur bei $10-30 \%$ der Betroffenen vorhanden (Kashtan und Michael 1996). Dennoch sind sowohl der vordere Lenticonus als auch die perimakulären Veränderungen gute hinweisende diagnostische Kriterien auf ein AS (Tabelle 2). Sie weisen zusätzlich auch auf ein frühzeitig einsetzendes Nierenversagen hin, da sie meist mit einer schwereren Mutation der $\alpha$-Ketten des Kollagen Typ IV assoziiert sind (Perrin et al. 1980, Zhang et al. 2008).

Folgende Charakteristika sind pathognomonisch für das AS:

- vorderer Lenticonus

- Fehlen (Hemizygotie) oder Unterbrechungen (X-Heterozygotie) der $\alpha 3-\alpha 4-\alpha 5($ IV)-Ketten in der GBM

- Verdickung und Aufsplittung der GBM

Bei folgenden Charakteristika ist das AS höchst wahrscheinlich:

- perimakuläre Veränderungen

Tabelle 2: Diagnostischer Wert von klinischen und pathologischen Charakteristika beim Alport-Syndrom. (modifiziert nach Pirson 1999)

Neben der Klinik spielt die Pathologie in der Diagnosestellung eine entscheidende Rolle. Die Nierenbiopsie mit anschließender elektronenmikroskopischer Analyse ist in der Diagnostik des AS wegweisend. Diffuse Verdickung und Aufsplitterung der GBM sind typisch für das AS (Abb. 4) (Kashtan und Michael 1996).

Als Goldstandard in der Diagnostik des AS gilt die molekulargenetische Untersuchung der AS-Patienten und eine humangenetische Beratung (Kashtan et al. 2012). Dieses Vorgehen ist notwendig, um asymptomatische Überträger zuverlässig erkennen zu können. Des Weiteren wird die molekulargenetische Untersuchung 
genutzt, um in einer Familie, in der bereits eine Mutation identifiziert wurde, das AS pränatal zu diagnostizieren (Kashtan und Michael 1996).

Eine weitere diagnostische Möglichkeit stellt die immunhistochemische Untersuchung einer Hautbiopsie dar, da das $\alpha 5 \alpha 5 \alpha 6$-Trimer auch in der epidermalen Basalmembran exprimiert wird. Dieses Verfahren stellt eine weniger gefährliche und weniger invasive Alternative zur Nierenbiopsie dar, wenn für diese keine zwingende Indikation besteht. Das Fehlen (Hemizygotie) oder ein mosaikartiges Auftreten (XHeterozygotie) der $\alpha 5$-Kette in der epidermalen Basalmembran ist hinweisend für das X-chromosomal vererbte AS (Tabelle 3). Allerdings schließt ein unauffälliger Befund ein AS nicht aus (Pirson 1999). Die immunhistochemische Diagnostik ist aufgrund ihrer niedrigen Sensibilität von zweifelhaftem klinischen Wert. Bei über $50 \%$ der Patienten mit molekulargenetisch nachgewiesenem AS wurde dennoch ein normales COL4A5-Muster immunhistochemisch nachgewiesen. Diese niedrige Sensibilität wird auf die vielen Missense-Muationen, die nur zu einem leicht veränderten Genprodukt führen, zurückgeführt (Kashtan 1998). 


\begin{tabular}{|c|c|c|c|}
\hline & GBM & BC & EBM \\
\hline \multicolumn{4}{|c|}{ X-chrom. AS } \\
\hline$\alpha 3(I V)$ & - & - & $\begin{array}{c}\text { normalerweise } \\
\text { abwesend }\end{array}$ \\
\hline$\alpha 4(\mathrm{IV})$ & - & - & $\begin{array}{c}\text { normalerweise } \\
\text { abwesend }\end{array}$ \\
\hline$\alpha 5(\mathrm{IV})$ & - & - & $-/+$ \\
\hline \multicolumn{4}{|c|}{$\begin{array}{l}\text { autosomal- } \\
\text { rezessives AS }\end{array}$} \\
\hline$\alpha 3(\mathrm{IV})$ & - & - & $\begin{array}{c}\text { normalerweise } \\
\text { abwesend }\end{array}$ \\
\hline$\alpha 4(\mathrm{IV})$ & - & - & $\begin{array}{c}\text { normalerweise } \\
\text { abwesend }\end{array}$ \\
\hline$\alpha 5(\mathrm{IV})$ & - & + & + \\
\hline
\end{tabular}

Tabelle 3: Immunhistochemie beim Alport-Syndrom. (modifiziert nach Kashtan und Michael 1996). An- oder Abwesenheit einzelner Kollagenketten bei den unterschiedlichen Formen des AS. Anhand der $\alpha 5$-Kette lassen sich die beiden Erbgänge immunhistochemisch unterscheiden. $\mathrm{GBM}=$ glomeruläre Basalmembran, $\mathrm{BC}=$ Bowman-Kapsel, $\mathrm{EBM}=$ epidermale Basalmembran.

\subsection{Therapie des Alport-Syndroms}

Die Therapie des AS ist Gegenstand aktueller Forschung (Gross et al. 2012, Kashtan et al. 2012, Temme et al. 2012b). Der sehr lange Krankheitsverlauf (Erreichen der terminalen Niereninsuffizienz etwa in der 2. - 3. Lebensdekade) des AS erschwert es, Interventionsmöglichkeiten zu entwickeln und stellt daher eine Ursache für den Mangel an Therapiemöglichkeiten beim AS dar. Hinzu kommt die noch nicht gänzlich erforschte Pathogenese vom Gendefekt bis zur Entstehung der Nierenfibrose (Gross et al. 2004).

In dieser Problematik ist in den letzten zehn Jahren ein Fortschritt zu verzeichnen. Es wurden COL4A3 ${ }^{--}$-Mäuse entwickelt, die als Tiermodell dem Phänotyp des humanen AS ähneln (Cosgrove et al. 1996). Anhand dieses Tiermodells konnte erstmals der positive Effekt einer ACE-Hemmer-Therapie (Ramipril) auf die Lebenserwartung und die Nierenprotektion dieser Mäuse gezeigt werden (Gross et al. 2003). 


\subsubsection{Pharmakotherapie mit ACE-Hemmern}

ACE-Hemmer werden in erster Linie zur Therapie des Bluthochdrucks eingesetzt. Sie hemmen das Angiotensin-konvertierende Enzym (Angiotensin Converting Enzyme). Dieses ist für die Umwandlung von Angiotensin I in Angiotensin II in der Blutdruck-regulierenden Kaskade des Renin-Angiotensin-Aldosteron-Systems notwendig. Renin wird aus der Niere freigesetzt und sorgt für die Umwandlung des aus der Leber stammenden Angiotensinogen in Angiotensin I. Angiotensin II führt über die Bindung an die spezifischen Rezeptoren zur Vasokonstriktion und damit zum Blutdruckanstieg. Somit führt eine Hemmung dieses Enzyms zur therapeutisch bezweckten Blutdrucksenkung. Des Weiteren bewirkt Angiotensin II eine Ausschüttung von Aldosteron aus der Nebennierenrinde. Hierdurch kommt es zu einer vermehrten Retention von Natrium und Wasser aus dem Tubulus, was ebenfalls eine Erhöhung des Blutdrucks zur Folge hat (Fischler und Follath 1999). Eine weitere Eigenschaft des Angiotensin II ist seine proinflammatorische und profibrogene Wirkung auf die Niere (Wolf 2005). Hierdurch ist es entscheidend an der Pathogenese des AS beteiligt. Neben der Umwandlung von Angiotensin I in Angiotensin II katalysiert ACE den Abbau von Bradykinin in seine inaktiven Produkte. Durch enzymatische Hemmung mittels ACE-Hemmern kommt es zu einer kumulativen Anhäufung von Bradykinin und es kann zu einer für ACE-Hemmer typischen Nebenwirkung, dem trockenen Reizhusten, kommen (Vollert et al. 2009).

Der Nutzen einer ACE-Hemmer-Therapie zur Nephro- und Kardioprotektion bei chronischen Nierenerkrankungen des Menschen konnte bereits in mehreren Studien nachgewiesen werden (Chiurchiu et al. 2005, Lewis et al. 1993, Wühl et al. 2004, Wühl et al. 2009). In der ESCAPE-Studie von Wühl et al. (2004) wurden nierenkranke Kinder mit Bluthochdruck mit dem ACE-Hemmer Ramipril behandelt. Durch dessen antihypertensiven Effekt konnte die Proteinurie verzögert und so die Verschlechterung der glomerulären Filtrationsrate gemindert werden.

In einer Studie von Gross et al. im Jahr 2003 wurde der Effekt von ACE-Hemmern in einem Alport-Mausmodell untersucht. Der ACE-Hemmer Ramipril konnte im Mausmodell eine Verdopplung der Lebensdauer der behandelten Tiere erreichen. Die unbehandelten Alport-Mäuse starben nach 71 +/- 6 Tagen am terminalen Nierenversagen. Die Ramipril-Therapie konnte sowohl das Auftreten der Proteinurie als auch der Urämie und deren Ausmaß verzögern. Außerdem zeigte sich bei einer ACE-Hemmer-Therapie eine Verlangsamung der interstitiellen Fibrosierung durch die 
Downregulation von TGF- $\beta 1$, der als entscheidender Faktor in der Pathogenese der Fibrosierung identifiziert werden konnte (Gross et al. 2003, Sayers et al. 1999). TGF$\beta 1$ ist ein Zytokin, welches über die Induktion von Fibroblasten, die ihrerseits extrazelluläre Matrix synthetisieren, profibrotisch wirkt (LeRoy et al. 1990). Dieses Zytokin konnte vermehrt in der GBM bei Alport-Patienten nachgewiesen werden (Sayers et al. 1999).

\subsubsection{Nierenersatzverfahren}

\subsubsection{Dialyse}

Die Dialyse und die Nierentransplantation stellen die Therapiemöglichkeiten des terminalen Nierenversagens beim AS dar. Laut des Jahresberichts von 2008 der „North American Pediatric Renal Trials and Collaborative Studies“ (NAPRTCS) liegt der Anteil an Alport-Patienten an allen pädiatrischen Dialyse-Patienten bei 1,9\% (NAPRTCS 2008).

Die Dialyse ist ein Nierenersatzverfahren, welches bei terminaler Niereninsuffizienz zumindest solange eingesetzt werden muss, bis es zu einer Nierentransplantation kommt. In Deutschland erhalten zur Zeit ungefähr 70000 Patienten eine chronische Dialysetherapie [Tendenz steigend]. Die Inzidenz des terminalen Nierenversagens liegt bei 175 pro 1 Millionen Einwohner pro Jahr (Valtin et al. 2009). Im Durchschnitt wartet ein Patient von Beginn der Dialysetherapie bis zur Transplantation ca. sechs Jahre (Wenzel et al. 2003).

Die Kriterien für einen Dialysebeginn hängen von unterschiedlichsten objektiven Parametern (Zeichen der Mangelernährung wie z.B. fortschreitender Gewichtsverlust) und subjektiven Parametern (Wahrnehmung der eigenen Lebensqualität) sowohl des Patienten als auch des betreuenden Arztes ab. Absolute Indikationen, eine Dialysetherapie zu beginnen, sind: Perikarditis, diuretikaresistente Überwässerung und Lungenödem, therapierefraktäre Hypertonie, urämische Enzephalopathie und/oder Neuropathie, klinisch relevante Blutungsneigung, Übelkeit und Erbrechen durch die Urämie (Hakim und Lazarus 1995).

In einer Studie von Goldfarb-Rumyantzev et al. (2005) wurde gezeigt, dass je kürzer die Dauer der Dialysetherapie vor einer Transplantation ist, desto besser sowohl die Transplantatfunktionsdauer als auch die Lebenserwartung der Patienten ist. Bei medizinischer Indikation sollte eine Dialysetherapie nicht hinausgezögert werden. 
Aufgrund der langen Wartezeit für ein Nierentransplantat (in Deutschland etwa fünf bis sechs Jahre) (DSO 2013) sind die terminal-niereninsuffizienten Patienten in der Realität allerdings meist auf eine länger andauernde Dialysetherapie angewiesen.

Die am häufigsten verwendete Dialyseform ist die Hämodialyse, bei der eine semipermeable Membran extrakorporal die urämischen Toxine aus dem Blut filtert. Das Dialysat enthält eine individuell für jeden Patienten angepasste Konzentration an Elektrolyten. In der Regel benötigt ein Patient 12 - 15 Stunden Dialyse pro Woche, die meistens in drei gleichlange Zyklen aufgeteilt werden. Da die Effektivität dieser Dialyseform nur gegeben ist, wenn ein ausreichender Blutfluss von $200-300$ ml/min und ein wiederholt erforderlicher Blutzugang vorhanden ist, ist die Anlage eines Shunts notwendig (Böhler 2008a). Ein Nachteil dieser Art von Dialyse ist, dass es sich um ein diskontinuierliches Verfahren handelt und deswegen das Risiko für ausgeprägte Elektrolyt- und Volumenschwankungen besteht (Nowack et al. 2009). Außerdem ist die Gabe von Heparin zur Blutgerinnungshemmung notwendig, da es sonst zu einer Thrombenbildung im System kommen würde (Böhler 2008a). Eine akute Hämodialyse-bedingte Komplikation stellt die Hypotonie dar, die durch unterschiedliche Faktoren begünstigt werden kann. $\mathrm{Zu}$ diesen zählen osmotische Verschiebungen, antihypertensive Medikamente vor Dialysebeginn oder exzessive Ultrafiltration bei inadäquater kompensatorischer Gefäßfüllung (Valtin et al. 2009).

Eine andere Art der Dialyse ist die chronisch ambulante Peritonealdialyse (CAPD), bei der das Bauchfell als Membran dient (Bauchfelldialyse) (Popovich et al. 1978). Um dem Blut nicht nur die harnpflichtigen Substanzen, sondern auch das überschüssige Wasser zu entziehen, wird dem Dialysat Glukose zugesetzt. Hierdurch steigt der onkotische Druck des Dialysats über den des Intravasalraums und das Wasser tritt osmotisch bedingt in den Raum höherer Konzentration gelöster Teilchen über. Die CAPD wird vier bis fünf Mal täglich durchgeführt (Mettang 2008). Dieses Verfahren ist in der Regel dann einsetzbar, wenn noch eine eigene Nierenrestfunktion vorhanden ist und wird daher manchmal als erste Dialyseform gewählt. Vorteile dieses Verfahrens sind, dass der Patient seine Dialyse eigenständig zu Hause oder bei der Arbeit durchführen kann. Außerdem ist dieses kontinuierliche Verfahren hämodynamisch günstiger und weniger belastend für das Herz-Kreislauf-System (Nowack et al. 2009). Des Weiteren ist kein Gefäßzugang nötig und die Restnierenfunktion wird besser erhalten als bei der Hämodialyse. Allerdings hat auch dieses Verfahren Nachteile. Es besteht die Gefahr der Entwicklung einer Peritonitis 
(Mettang 2008). Diese Komplikation konnte durch verschiedene technische Verbesserungen wie den Einsatz von Bakterienfiltern oder besseren Konnektionssystemen substanziell gesenkt werden (Leahy et al. 1980). Sie stellt jedoch immer noch das größte Problem der Peritonealdialyse dar (Nowack et al. 2009). Man geht von 0,3 Peritonitiden pro Patient innerhalb eines Jahres aus. Des Weiteren kann es durch die erhöhte Kalorienzufuhr mit dem Dialysat zu einer Gewichtszunahme kommen (Mettang 2008).

Die Haupttodesursachen bei Patienten mit terminaler Niereninsuffizienz sind die kardiovaskulären Erkrankungen (Collins et al. 2007). US-amerikanische Daten zeigen auf, dass ca. $45 \%$ der Todesfälle bei terminaler Niereninsuffizienz auf kardiovaskulären Erkrankungen beruhen. Ein Fünftel hiervon sterben durch akute Myokardinfarkte, bei 60\% war ein plötzlicher Herztod die Ursache (Foley et al. 2005, KDOQI 2006). Der Zusammenhang zwischen terminalem Nierenversagen und koronaren Erkrankungen ist vielschichtig. Zum einen kann die Niereninsuffizienz als Folge einer generalisierten Arteriosklerose durch Risikofaktoren wie Diabetes mellitus gesehen werden. Zum anderen können diese bestehenden Risikofaktoren (Diabetes mellitus, arterielle Hypertonie und Hyperlipidämie) durch eine chronische Niereninsuffizienz verstärkt werden und so die Ursache einer KHK sein (Kimak et al. 1999). So kann zum Beispiel die Hypertonie, die in $60-100 \%$ bei terminaler Niereninsuffizienz vorhanden ist, sowohl Folge als auch Ursache dieser sein und stellt einen Risikofaktor für alle kardialen Ereignisse dar (Gupta et al. 2004). Zudem ist auch Diabetes mellitus einerseits einer der stärksten Risikofaktoren in der Entstehung einer KHK, andererseits aber auch die häufigste Ursache einer chronischen Niereninsuffizienz. Des Weiteren lässt sich bei Patienten mit Niereninsuffizienz vermehrt eine Dyslipidämie nachweisen. Diese veränderten Lipide werden wiederum mit der Entstehung arterisklerotischer Plaques assoziiert (Kimak et al. 1999). Neben diesen bereits genannten „klassischen“ Risikofaktoren einer KHK, gibt es weitere Risikofaktoren, die bei einer Niereninsuffizienz auftreten und mit der Entstehung von kardiovaskulären Ereignissen verknüpft sind. In diesem Zusammenhang sei zum Beispiel eine inadäquate Behandlung kardiovaskulärer Risikofaktoren (Shlipak et al. 2002) erwähnt. Die zuvor genannten Aspekte erklären den Circulus vitiosus, der zu den häufigen kardiovaskulären Ereignissen bei chronisch nierenkranken Patienten führt. 
Die kardiovaskuläre Mortalität bei jungen Dialysepatienten ist im Vergleich zur Allgemeinbevölkerung ungefähr 1000fach erhöht und außerdem höher als bei nierentransplantierten Patienten (Foley et al. 1998). Die Niereninsuffizienz ist demnach einerseits ein Risikofaktor für die Entstehung kardialer Ereignisse, andererseits verschlechtert sie das Outcome bei stattgefundenen kardialen Ereignissen (Shlipak et al. 2002). Wenn sich die Nierenfunktion allerdings nach erfolgreicher Transplantation normalisiert, nimmt auch das kardiovaskuläre Risiko ab (Valtin et al. 2009).

\subsubsection{Nierentransplantation}

2,3\% aller Nierentransplantierten haben das Alport-Syndrom (NAPRTCS 2008). In der Allgemeinbevölkerung bekommen 27\% aller Patienten mit terminaler Niereninsuffizienz eine Transplantation (Böhler 2008). Die Lebenserwartung nach einer Transplantation ist dreimal so hoch wie bei Verbleib auf der Warteliste und weiterer Dialysetherapie (Levey et al. 1998). Außerdem ist ein deutlicher Gewinn an Lebensqualität durch eine Transplantation gegeben. Zudem sind die kardiovaskuläre Morbidität und Mortalität geringer als bei der Dialysetherapie (Jofre et al. 1998).

Eine gestörte Glukosetoleranz entwickeln ca. 10\% (Kasiske et al. 2003), und 60\% der Patienten leiden unter Hyperlipidämie, ausgelöst durch die Behandlung mit Immunsuppressiva (Kasiske 1998). Außerdem stellt die Urämie als Hauptrisikofaktor für kardiovaskuläre Erkrankungen ein Problem dar. Diese tritt nach einer Transplantation durch Hypertonus, Hyperlipidämie und diabetischer Stoffwechsellage verstärkt auf. Des Weiteren hemmt das Immunsuppressivum Cyclosporin A die Harnsäuresekretion im proximalen Tubulus (Perico et al. 2005). Eine Entwicklung von Tumoren nach Nierentransplantation ist ebenfalls beschrieben (Vajdic et al. 2006). Weitere Komplikationen sind: Katarakt, Osteopenie, peptische Ulzera, Pankreatitis und Divertikulitis (Cohen und Galbraith 2001).

Im Mittel funktionieren Leichennierenorgane ungefähr 13,8 Jahre und Lebendspenden 21,6 Jahre. Das 5-Jahres-Überleben des Transplantates liegt bei postmortaler Spende bei $67 \%$ und bei Lebensspende bei $80 \%$. Das 5-Jahres-Überleben der Patienten liegt bei $81 \%$ bzw. 90\% (Budde und Budde 2009). Über 50\% der Mortalität von Transplantatpatienten ist auf kardiovaskuläre Erkrankungen zurückzuführen.

Das Risiko eines Transplantatverlustes erhöht sich durch folgende Faktoren: Alter, Diabetes mellitus, Hypertonie, männliches Geschlecht und Rauchen (Budde und 
Budde 2009). Wie bereits erläutert, stellt auch die vorangegangene Dialysetherapie einen Risikofaktor dar (Goldfarb-Rumyantzev et al. 2005). Am höchsten ist die Mortalität im ersten Jahr nach der Transplantation. Es besteht die Gefahr der Entwicklung einer chronischen Allograft-Nephropathie (CAN). Hierbei handelt es sich um einen chronischen obliterierenden vaskulären Prozess, bei dem sowohl immunologische als auch nicht-immunologische Faktoren eine Rolle spielen (Stallone et al. 2005).

Alport-Patienten eignen sich in besonderem Maße für eine Transplantation, da bei innen kein Risiko des Wiederauftretens der Erkrankung in der neuen Niere besteht. Auch das mittlere Transplantatüberleben ist besser als bei anderen Erkrankungen. Ein ähnliches Ergebnis zeigte sich bei der Untersuchung des Transplantatüberlebens bei kongenitalen Fehlbildungen der Nieren und ableitenden Harnwege (CAKUT). Hier lag das 2-Jahres-Überleben des Transplantates in einer Untersuchung von Kashtan et al. (1995) zwischen 74 und $89 \%$. Allerdings besteht bei transplantierten AlportPatienten die Gefahr der Entwicklung einer Anti-GBM-Nephritis post transplantationem. Diese Form der Nephritis kann nur beim AS vorkommen und führt innerhalb weniger Wochen bis Monate zum Transplantatversagen (Kashtan 2006). Zu dieser Komplikation kommt es jedoch nur in weniger als 10\% der Fälle (Milliner et al. 1982). Bei der Anti-GBM-Nephritis handelt es sich um eine immunologische Reaktion des Empfängers auf das Transplantat. Durch die transplantierte Niere werden dem Körper Antigene der GBM präsentiert, die in der Alport-Niere nicht vorhanden waren. Bei diesen Antigenen handelt es sich um die NC1-Domäne der $\alpha 3 \alpha 4 \alpha 5$-Kette des Kollagen Typ IV. Auf diese reagiert der Körper mit der Bildung von Antikörpern (Kashtan 1996, Mojahedi et al. 2007).

\subsection{Prognose des Alport-Syndroms}

Allgemein gilt, dass das klinische Bild beim AS stark vom zugrundeliegenden Erbgang bzw. Geschlecht abhängt. Beim X-chromosomal vererbten AS entwickeln alle männlichen Träger ein terminales Nierenversagen. Das Alter bei Erreichen der terminalen Niereninsuffizienz korreliert mit dem zugrundeliegenden Genotyp. Bei

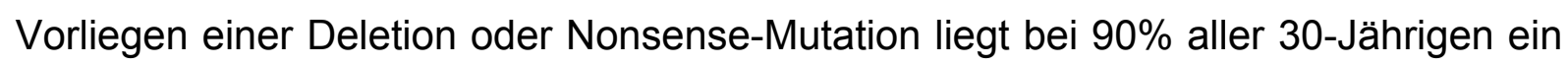
terminales Nierenversagen vor, bei Splicevarianten bei $70 \%$ und bei MissenseMutationen bei $50 \%$ (Jais et al. 2000). Beim weiblichen Geschlecht kann das 
klinische Bild von asymptomatischen Überträgerinnen bis zur frühen terminalen Niereninsuffizienz reichen (Pochet et al. 1989).

Beim autosomalen Erbgang gibt es keine geschlechtsspezifischen Unterschiede. Die Patienten entwickeln in der zweiten bis dritten Lebensdekade ein terminales Nierenversagen (Gubler 2008).

\subsection{Chronische Niereninsuffizienz}

Die chronische Niereninsuffizienz ist heutzutage ein weit verbreitetes Krankheitsbild in der Allgemeinbevölkerung (National Kidney Foundation 2002). Das ansteigende Alter in der Bevölkerung und die stetige Zunahme an Diabetespatienten dürften hier als primär ursächliche Faktoren genannt werden (Mokdad et al. 2001). Der Begriff chronische Niereninsuffizienz wurde 2002 von der Kidney Disease Outcomes Quality Initiative (K/DOQI) der US-amerikanischen National Kidney Foundation neu definiert und hat sich mittlerweile weltweit durchgesetzt. Sie wird definiert als:

- Nierenschädigung über 3 Monate, definiert durch strukturelle oder funktionelle Anomalien mit oder ohne Einschränkung der glomerulären Filtrationsrate (GFR), die sich manifestiert in pathologischen Anomalien oder Markern einer Nierenschädigung inklusive Anomalien in der Zusammensetzung des Blutes oder Urins oder Anomalien in bildgebenden Verfahren

oder

- GFR $<60 \mathrm{ml} / \mathrm{min} / 1,73 \mathrm{~m}^{2}$ für $\geq 3$ Monate, mit oder ohne Nierenschädigung.

Die Stadieneinteilung der Niereninsuffizienz richtet sich nach der glomerulären Filtrationsrate (GFR) (Tabelle 4) (National Kidney Foundation 2002).

Die GFR ist der aussagekräftigste Parameter, um die Nierenfunktion sowohl von Gesunden als auch von Kranken zu beurteilen (Smith 1951). Ihr Wert ist abhängig von Alter, Geschlecht und Körpergröße und nimmt mit dem Alter ab. Die normale GFR bei einem jungen Erwachsen liegt ungefähr zwischen $90-120 \mathrm{ml} / \mathrm{min} / 1,73 \mathrm{~m}^{2}$ (Davies und Shock 1950, Lindeman et al. 1985, Rowe et al. 1976). 


\begin{tabular}{|l|l|l|l|l|}
\hline Stadium & Beschreibung & $\begin{array}{l}\text { GFR } \\
{[\mathbf{m l} / \mathbf{m i n} / \mathbf{1}, \mathbf{7 3}} \\
\left.\mathbf{m}^{2}\right]\end{array}$ & $\begin{array}{l}\text { Prävalenz } \\
{[\%]}\end{array}$ & Vorgehen \\
\hline 1 & $\begin{array}{l}\text { Nierenschädigung } \\
\text { mit normaler oder } \\
\text { erhöhter GFR }\end{array}$ & $\geq 90$ & 3,3 & $\begin{array}{l}\text { Diagnostik und } \\
\text { Therapie der } \\
\text { Grunderkrankung }\end{array}$ \\
\hline 2 & $\begin{array}{l}\text { Nierenschädigung } \\
\text { mit gering } \\
\text { reduzierter GFR }\end{array}$ & $60-89$ & 3,0 & $\begin{array}{l}\text { Verlangsamung der } \\
\text { Progression }\end{array}$ \\
\hline 3 & $\begin{array}{l}\text { mäßig reduzierte } \\
\text { GFR }\end{array}$ & $30-59$ & 4,3 & $\begin{array}{l}\text { Evaluierung und } \\
\text { Behandlung von } \\
\text { Komplikationen }\end{array}$ \\
\hline 4 & $\begin{array}{l}\text { stark reduzierte } \\
\text { GFR }\end{array}$ & $15-29$ & 0,2 & $\begin{array}{l}\text { Vorbereitung zur } \\
\text { Nierenersatztherapie }\end{array}$ \\
\hline 5 & Nierenversagen & $<15$ & 0,1 & Nierenersatztherapie \\
\hline
\end{tabular}

Tabelle 4: Stadieneinteilung der chronischen Niereninsuffizienz nach der K/DOQI (National Kidney Foundation 2002). GFR = glomeruläre Filtrationsrate

Die häufigste Ursache für ein terminales Nierenversagen in Deutschland ist mit $36 \%$ die diabetische Nephropathie, gefolgt von der hypertensiven Nephropathie mit 15\%, Glomerulonephritiden mit 15\%, interstitiellen Nephritiden mit 10\% und polyzystischen Nierenerkrankungen mit 6\% (Valtin et al. 2009). 


\section{$1.5 \quad$ Ziele der Arbeit}

Die Behandlung des AS steht im Mittelpunkt aktueller Forschung. Bisher gibt es keine offiziell zugelassene Therapie. Die Behandlung mit dem ACE-Hemmer Ramipril ist nur eine Therapieempfehlung (Kashtan et al. 2012). Seit Frühjahr 2012 läuft eine vom Bundesministerium für Bildung und Forschung geförderte prospektive, randomisierte, Placebo-kontrollierte, doppel-blinde, multizentrische Deutschlandweite Therapiestudie "EARLY PRO-TECT ALPORT“. Diese Studie hat das Ziel, Nutzen und Risiken einer frühen Therapie mit dem ACE-Hemmer Ramipril bei jungen oligosymptomatischen Alport-Patienten abzuwägen.

Im Rahmen der vorliegenden Arbeit wurde an knapp 300 Alport-Patienten eine Registeranalyse (Europäisches Alportregister) zur Evaluierung der Prognose beim AS unter Berücksichtigung der Off-label-Therapie mit ACE-Hemmern und unterschiedlichen Nierenersatzverfahren durchgeführt, um in Zukunft betroffene Familien besser beraten zu können. Die Patienten wurden auf klinische Prognosefaktoren wie Lebenserwartung, Alter bei Dialysebeginn und Transplantatfunktionsdauer untersucht.

Das AS ist eine Erkrankung, die zwangsläufig in einer terminalen Niereninsuffizienz endet. In der Regel sind die Patienten in der zweiten oder dritten Lebensdekade auf ein Nierenersatzverfahren angewiesen. Ziel der vorliegenden Dissertation war es zu untersuchen, in welchem Alter die Patienten eine Nierenersatztherapie benötigen und ob eine vor Erreichen der terminalen Niereninsuffizienz erhaltene ACE-HemmerTherapie diese Nierenersatzverfahren (Dialyse und Transplantation) hinauszögern und damit auch die Lebenserwartung verbessern kann. Eine weitere Fragestellung hinsichtlich der Dialyse war, ob sich das Alter bei Dialysebeginn bei den unterschiedlichen Erbgänge des AS (X-chromosomal oder autosomal) unterscheidet. Im letzten Teil sollte die Dauer der Transplantatfunktion bei Alport-Patienten untersucht werden. Dabei wurde ebenfalls nachgeprüft, ob eine ACE-HemmerTherapie, welche die AS-Patienten vor Erreichen der Dialysepflichtigkeit erhalten haben, die Dauer der Transplantatfunktion verlängern kann. Zudem war auch hier von Interesse, ob sich die Transplantatfunktionsdauer beim X-chromosomalen oder autosomalen Erbgang unterscheidet. 


\section{Material und Methoden}

\subsection{Klinische Datenerhebung}

Diese Arbeit ist Teil eines europäischen Projektes, welches 2006 begonnen wurde. Das Ziel des Projekts ist es, ein europaweites Datenregister zu erstellen, in dem alle Alport-Patienten erfasst werden. Dieses Projekt wurde durch die Ethik-Kommission der Georg-August-Universität am 20.11.2007 unter der Antragsnummer 10/11/06 und dem Studientitel „European initiative towards delaying renal failure in Alportsyndrome" genehmigt.

Die Datenerhebung für diese Arbeit bzw. die oben genannte Studie fand primär im Rahmen einer Beobachtungsstudie über Fragebögen, alternativ auch über Arztbriefe, statt. Die Ergebnisse wurden dann tabellarisch in Form einer Excel-Tabelle, die im Folgenden genauer beschrieben wird, zusammengefasst.

In dieser Tabelle wurden zuerst demographische Daten, wie das Geburtsdatum (G), das betreuende Zentrum $(E)$, der Erbgang $(P$ und $Q)$, das Alter $(H)$ und das Geschlecht (I) erfasst.

\begin{tabular}{cccccc}
\hline $\mathrm{E}$ & $\mathrm{G}$ & $\mathrm{H}$ & $\mathrm{I}$ & $\mathrm{P}$ & $\mathrm{Q}$ \\
\hline Zentrum & Geb.-Datum & Alter & $\mathrm{m} / \mathrm{f}$ & X-chromosomal & autosomal \\
\hline
\end{tabular}

Danach erfolgte eine Untersuchung klinischer und laborchemischer Parameter: Hat eine Nierenbiopsie $(\mathrm{J})$ und/oder ein Mutationsnachweis $(K)$ stattgefunden und welche Mutation ( $\mathrm{L}$ und $\mathrm{M})$ liegt vor?

\begin{tabular}{cccc}
\hline $\mathrm{J}$ & $\mathrm{K}$ & $\mathrm{L}$ & $\mathrm{M}$ \\
\hline Biopsie & Mutation & Deletion & inframe \\
\hline
\end{tabular}

Die nächsten Spalten beinhalteten genauere Information bezüglich der ACEHemmer-Therapie. Hat eine Therapie stattgefunden $(R)$ und wenn ja, in welchem Krankheitsstadium $(\mathrm{S}-\mathrm{V})$ und mit welchem Alter $(\mathrm{Y})$ wurde sie begonnen?

\begin{tabular}{cccccc}
\hline R & S & T & U & V & Y \\
\hline ACE-Hemmer & ACE 0 & ACE I & ACE II & ACE III & Alter bei Therapiebeginn \\
\hline
\end{tabular}


Dann wurde erhoben, welche nephroprotektiven Medikamente noch eingenommen wurden.

\begin{tabular}{ccc}
\hline$Z$ & $A A$ & $A B$ \\
\hline$A T 1$ & ACE+AT1 & CSE \\
\hline
\end{tabular}

Im Folgenden wurde die Nierenfunktion anhand von Proteinurie (AC - AF) und Kreatinin-Clearance ( $A G$ und $A H)$ vor und nach der Therapie erfasst. Des Weiteren wurde das aktuelle Krankheitsstadium (AI), in dem sich der Patient zum Abfragezeitpunkt befand, angegeben.

\begin{tabular}{lllllll}
\hline \multicolumn{1}{c}{ AC } & \multicolumn{1}{c}{ AD } & \multicolumn{1}{c}{ AE } & \multicolumn{1}{c}{ AF } & AG & AH & Al \\
\hline Proteinurie & Proteinurie & Proteinurie & Proteinurie Rückgang & Crea-Clearance & Crea-Clearance & Aktuelles \\
vor T & nach T & aktuell & & vor T & nach T & Stadium \\
\hline
\end{tabular}

Die nächsten Spalten betrafen die Dialyse: Hat sie stattgefunden (AN)? Wenn ja, in welchem Alter? (AR)

\begin{tabular}{cc}
\hline AN & AR \\
\hline Dialyse & Alter Dialysebeginn \\
\hline
\end{tabular}

Dann wurde als Endpunkt der Befragung die Transplantation berücksichtigt. Hier wurde erfasst, wann die Transplantation stattgefunden hat (AU), ob es ein Transplantatversagen gegeben hat (AW) und die Dauer der Transplantatfunktion $(A X)$.

\begin{tabular}{cccc}
\hline AT & AU & AW & AX \\
\hline Tx & Tx Jahr & Tx Versagen & Dauer Tx Funktion \\
\hline
\end{tabular}

Außerdem kann man der Datenbank entnehmen, ob sich Verwandte ebenfalls an der Dialyse befanden (AY) und wann eventuell betroffene Geschwister eine Therapie begonnen hatten $(B B-B D)$.

\begin{tabular}{cccc}
\hline AY & BB & BC & BD \\
\hline Verwandte an Dialyse & Geschwisterpaar & Geschwister späte T & Geschwister frühe T \\
\hline
\end{tabular}


Zum Schluss gibt die Tabelle noch Auskünfte über etwaige Nebenwirkungen (BG) der ACE-Hemmer-Therapie wie Hyperkaliämie, Husten, Schwindel und Hypotonie (BF).

\begin{tabular}{cc}
\hline BF & BG \\
\hline Art der NW & NW \\
\hline
\end{tabular}

Diesem Register liegen Daten von 310 teilnehmenden Zentren aus drei Generationen von Alport-Patienten zugrunde.

Zur Aktualisierung und Ergänzung dieser Daten wurde für die vorliegende Dissertation im Frühjahr 2010 ein weiterer, standardisierter einseitiger Fragebogen (siehe Anhang) erstellt. Dieser Fragebogen wurde zum Teil den Patienten selbst, dem betreuenden Zentrum und/oder dem niedergelassenen Nephrologen/Pädiater zugesandt. Zusätzlich hat die Abfrage auch per E-Mail, Fax und Telefon stattgefunden. Teilgenommen haben folgende kindernephrologische Zentren bzw. niedergelassene Ärzte:

- Kindernephrologisches Zentrum Heidelberg

- Kindernephrologisches Zentrum München

- Kindernephrologisches Zentrum Köln

- Kindernephrologisches Zentrum Frankfurt

- Kindernephrologisches Zentrum Halle

- Kindernephrologisches Zentrum Münster

- Kindernephrologisches Zentrum Leipzig

- Kindernephrologisches Zentrum Dortmund

- Kindernephrologisches Zentrum MHH

- Kindernephrologisches Zentrum Freiburg

- Kindernephrologisches Zentrum Essen

- Kindernephrologisches Zentrum Marburg

- Priv. Doz. Dr. R. Cremer, Köln

- Prof. Dr. O. Groß, Oberarzt - Facharzt für Innere Medizin und Nephrologie der Uniklinik Göttingen

- PD Dr. med. Martin Marx, SHG-Kliniken Völklingen, Medizinische Klinik III Nephrologie / Dialyse

- $\quad$ Frau OÄ Dr. H. Zappel, Kindernephrologie, Univ.-Kinderklinik Göttingen 
- Prof. Dr. med. Bernd Krumme, Wiesbaden

- Prof. Dr. Hans-H. Neumayer, Charité Universitätsmedizin Berlin

- Dialyse Bochum

- Dialyse Nettetal

- Dialyse Emden

- Nürtingen, Nephrologie

- Emsland, Nephrologie

- Uni Tübingen

- Wuppertal.

- Außerdem haben noch folgende Länder an der Erstellung des Registers mithilfe der Fragebögen mitgewirkt:

- Belgien

- Spanien

- Frankreich

- Russland

- Österreich

- Serbien

- Schweiz

- Rumänien

- Italien

- Türkei.

Die Daten der zurückgesandten Fragebögen wurden anonymisiert und in einer Excel-Tabelle zusammengestellt. Den Patienten wurden jeweils Nummern zugewiesen, die auch das Herkunftsland angaben. Diese Excel-Tabelle enthielt ebenfalls Informationen aus den primär ermittelten Daten des schon oben erwähnten Registers von 2006. Die Aktualisierung der Daten dauerte 12 Monate und wurde von mehreren Medizinstudenten unter der Leitung von Herrn Prof. Dr. Gross durchgeführt. In $86 \%$ der Fälle war die Abfrage erfolgreich, in den übrigen Fällen lagen keine Follow-up Daten vor.

Die Patientendaten waren nur Herrn Prof. Dr. Gross zugänglich. Die Analyse der Daten erfolgte in verschlüsselter Form. Zusätzlich musste zu Beginn der Auswertung eine Verschwiegenheitserklärung unterschrieben werden. 


\subsubsection{Fragebögen}

In dem einseitigen Fragebogen wurden folgende sechs Endpunkte erhoben:

- Dialyse

- Aktuelle Nierenfunktion

- Therapie

- Nebenwirkungen

- Diagnose

- Familie.

Unter dem Endpunkt „Dialyse“ wurde abgefragt, ob diese stattfindet und wenn ja, seit wann. Die aktuelle Nierenfunktion betreffend, wurde gebeten, die KreatininClearance und die Höhe der Proteinurie oder den aktuellen Kreatininwert anzugeben. Im Abschnitt „Nebenwirkungen“ wurde nach eingetretenen Todesfällen, Hyperkaliämie, akutem Nierenversagen, Angioödem und sonstigen Nebenwirkungen wie Hypotonie, Katarakt oder Husten während der Therapie gefragt.

Bei der Diagnostik war es entscheidend zu wissen, ob ein Mutationsnachweis stattgefunden hatte und ob eine Nierenbiopsie durchgeführt worden war. Wenn dieses bejahrt wurde, wurde der Befund eingetragen.

Der letzte Punkt des Fragebogens bezog sich auf die Familie. Gefragt wurde nach Angehörigen, die sich ebenfalls in der Dialyse befinden und eventuell weiteren betroffenen Angehörigen mit AS. 


\subsection{Patientenkollektiv}

In dem Alport-Register, das für die primäre Datenerhebung verwendet wurde, befanden sich 573 Personen, von denen 297 Alport-Patienten und 276 Überträgerinnen waren. Von den 297 Alport-Patienten wurden 285 in die Datenerhebung dieser Dissertation eingeschlossen. Bei den Übrigen handelte es sich um Patienten, von denen entweder keine Folgedaten vorhanden waren oder keine Antworten auf die Fragebögen vorlagen.

Die Voraussetzung für den Einschluss in die Auswertung war ein AS, das durch eine Nierenbiopsie oder eine Mutationsanalyse sicher nachgewiesen worden war. Ausgeschlossen wurden Patienten, sofern die Diagnose nicht eindeutig war oder sie keine Einverständniserklärung abgaben.

\subsection{Statistische Auswertung}

Die statistische Auswertung fand in Zusammenarbeit mit der Abteilung für Medizinische Statistik der Universitätsmedizin Göttingen statt. Außerdem erfolgte zu Beginn der Arbeit ein persönliches Beratungsgespräch bei Frau Dr. Katharina Lange, Mitarbeiterin des Statistischen Instituts.

Eine graphische Darstellung der Daten wurde in Form von Kaplan-Meier-Kurven mit der Statistik-Software STATISTICA Version 10.0 erstellt.

Die statistische Auswertung fand mit SAS Version 9.2 (SAS Institute, Inc., Cary, NC) statt.

Die medianen Überlebenszeiten, das mediane Alter bei Dialysebeginn und die mediane Transplantatfunktionsdauer wurden mit 95\%-Konfidenzintervallen (KI) angegeben. Wenn die Fallzahl zu klein oder die Anzahl an Events zu gering ist, kann kein Median bestimmt werden. Das Fehlen oberer Grenzen der 95\% KIs im Ergebnisteil ist analog zu erklären.

Der Vergleich der Überlebensraten zwischen den unterschiedlichen Gruppen wurde mithilfe des Logrank-Tests durchgeführt (Bland und Altman 2004). Nachgewiesene Unterschiede zwischen zwei Variablen wurden ab einer Irrtumswahrscheinlichkeit von $\mathrm{p} \leq 0,05$ als signifikant gewertet.

Dabei wurden die „Lebenserwartung“, das „Alter bei Dialysebeginn“ und die „Transplantatfunktionsdauer“ als primäre Größen betrachtet. Diese Werte wurden 
jeweils hinsichtlich potenzieller Unterschiede im Bezug auf den Erbgang und auf eine ACE-Hemmer-Therapie hin untersucht.

Wenn, wie in der vorliegenden Dissertation, Beobachtungen hinsichtlich des Zeitpunktes des Eintretens eines bestimmten Events (hier: Tod, Dialysebeginn oder Transplantatverlust) angestellt werden, werden auch zensierte Daten verwendet. Zensiert bedeutet, dass der Patient die Studie verlässt, ohne dass bei inm zum Abfragezeitpunkt das Event eingetreten ist. Der Grund für eine Zensierung war das Fehlen von Follow-up-Daten. 


\section{Ergebnisse}

Die Ergebnisse resultieren aus der Auswertung der Fragebögen. Zunächst erfolgt eine deskriptive Darstellung des Patientenkollektivs. Anschließend werden die Auswirkungen von ACE-Hemmern auf die Lebenserwartung und die Verzögerung des Dialysebeginns dargestellt. Außerdem werden die unterschiedlichen Auswirkungen der beiden beim AS relevanten Erbgänge (autosomal-rezessiv und Xchromosomal) untersucht. Des Weiteren wird die Dauer der Transplantatfunktion im Hinblick auf eine stattgefundene oder unterbliebene ACE-Hemmer-Therapie ermittelt.

\subsection{Patientenkollektiv}

Von den Alport-Patienten, die an der Datenauswertung teilnahmen $(n=285)$, waren $255(89,5 \%)$ männlich und 30 (10,5\%) weiblich. Das Patientendurchschnittsalter lag bei 22,1 Jahren. Der jüngste Patient war zwei Jahre und der älteste 60 Jahre alt.

Bei 239 der insgesamt 285 Alport-Patienten war der Erbgang bekannt. Es wiesen 199 einen X-chromosomalen (83,3\%) und 40 Patienten einen autosomalen (16,7\%) Erbgang auf. Bei 46 AS-Patienten lagen bezüglich des Erbgangs keine Daten vor. Diese Verteilung der Erbgänge entspricht dem schon bekannten Muster aus der Literatur. Dabei erfolgt die Vererbung des AS in über $80 \%$ X-chromosomal (Antignac 1995) und in $10-15 \%$ autosomal (Flinter et al. 1988). Von den 199 Patienten mit Xchromosomalem Erbgang, waren 194 (97,5\%) hemizygote männliche Träger und fünf $(2,5 \%)$ heterozygote weibliche Überträgerinnen des AS. Diese fünf weiblichen Überträgerinnen des X-chromosomalen AS wurden in die Auswertung mit einbezogen, da auch sie die in dieser Arbeit untersuchten Therapieformen des AS erhielten. Vier bekamen ACE-Hemmer, zwei eine Dialyse und eine Überträgerin wurde nierentransplantiert.

Einen autosomalen Erbgang wiesen 18 (45\%) weibliche und 22 (55\%) männliche Patienten auf. Auch diese Verteilung hinsichtlich des Geschlechts unterscheidet sich nicht von den schon bekannten Ergebnissen älterer Studien (Pirson 1999). 


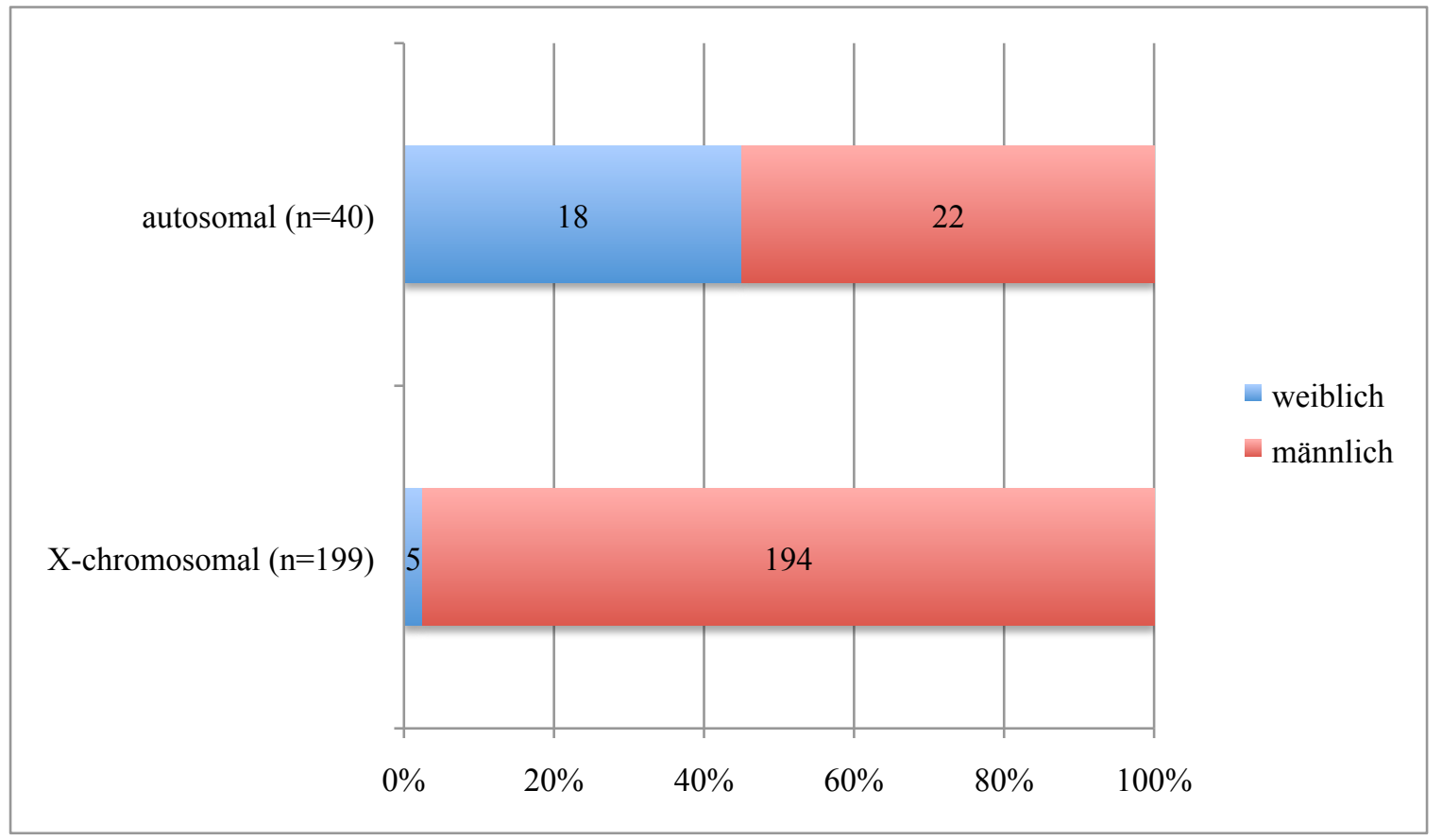

Abbildung 5: Verteilung der Geschlechter in den Erbgängen ( $n=$ Anzahl)

Eine Dialysetherapie erhielten 111/285 Alport-Patienten (38,9\%), 53/111 wurden nach durchschnittlich 2,8 Jahren an der Dialyse nierentransplantiert $(47,7 \%)$. Von den 111 dialysierten Patienten war bei 18 Patienten der Erbgang unbekannt. Von den übrigen 93 wiesen 86 (92,5\%) eine X-chromosomale und 7 (7,5\%) eine autosomale Vererbung auf.

Von den Patienten, die dialysiert, aber nicht transplantiert wurden $(58 / 111 ; 52,3 \%)$, waren 43/58 (74,1\%) vor Dialysebeginn unbehandelt und 15/58 $(25,9 \%)$ haben vor der Dialyse eine ACE-Hemmer-Therapie bekommen. Darüber, ob die Patienten mit Beginn der Nierenersatztherapie weiter mit ACE-Hemmern behandelt wurden, liegen keine Informationen vor. Aus dieser Gruppe der Dialysierten verstarben drei Patienten im Alter von 32, 40 und 55 Jahren. Diese drei verstorbenen Patienten hatten vor Dialysebeginn alle keine ACE-Hemmer-Therapie bekommen.

Bei den transplantierten Patienten waren 34/53 unbehandelt $(64,2 \%)$ während 19/53 vor Dialysebeginn eine ACE-Hemmer-Therapie erhalten hatten (35,8\%). Das AS wurde in dieser Gruppe bei 36/41 (87,8\%) durch den X-chromosomalen und bei den übrigen 5/41 (12,2\%) durch den autosomalen Erbgang vererbt. Bei zwölf Patienten war der Erbgang nicht bekannt. Aus der Transplantationsgruppe waren drei Patienten im Alter von 35, 39 und 45 Jahren verstorben. Auch diese verstorbenen Patienten stammten - wie die bei den Dialysierten - aus der Gruppe der NichtTherapierten. 


\subsection{Lebenserwartung beim Alport-Syndrom}

Die Lebenserwartung beim AS wird zunächst unabhängig von einer Aufteilung in unterschiedliche Gruppen (Therapierte vs. Nicht-Therapierte oder X-chromosomaler vs. autosomaler Erbgang) erfasst. Diese Aufteilung findet in nachfolgenden Abschnitten statt.

Die Auswertung fußt auf 276/285 Patientendaten. Von neun Patienten lag die Angabe des Alters nicht vor.

Die mediane Lebenserwartung beim AS ist aus dem für diese Arbeit verwendeten Patientenkollektiv nicht zu ermitteln, da $>50 \%$ der Patienten zum Abfragezeitpunkt noch lebten. Lediglich sechs Patienten im Alter von 32, 35, 39, 40, 45 und 55 Jahren waren verstorben. Dies ergibt ein durchschnittliches Sterbealter von 41 Jahren. Der Zeitpunkt, an dem 25\% der Patienten verstorben waren, lag bei 55 Jahren $(95 \% \mathrm{KI}$ 40 Jahre - .) (Abb. 6).

Die Wahrscheinlichkeit, mit AS das 40. Lebensjahr zu erreichen, lag bei 89,9\% (95\% $\mathrm{KI} 74,6 \%-96,2 \%)$. 


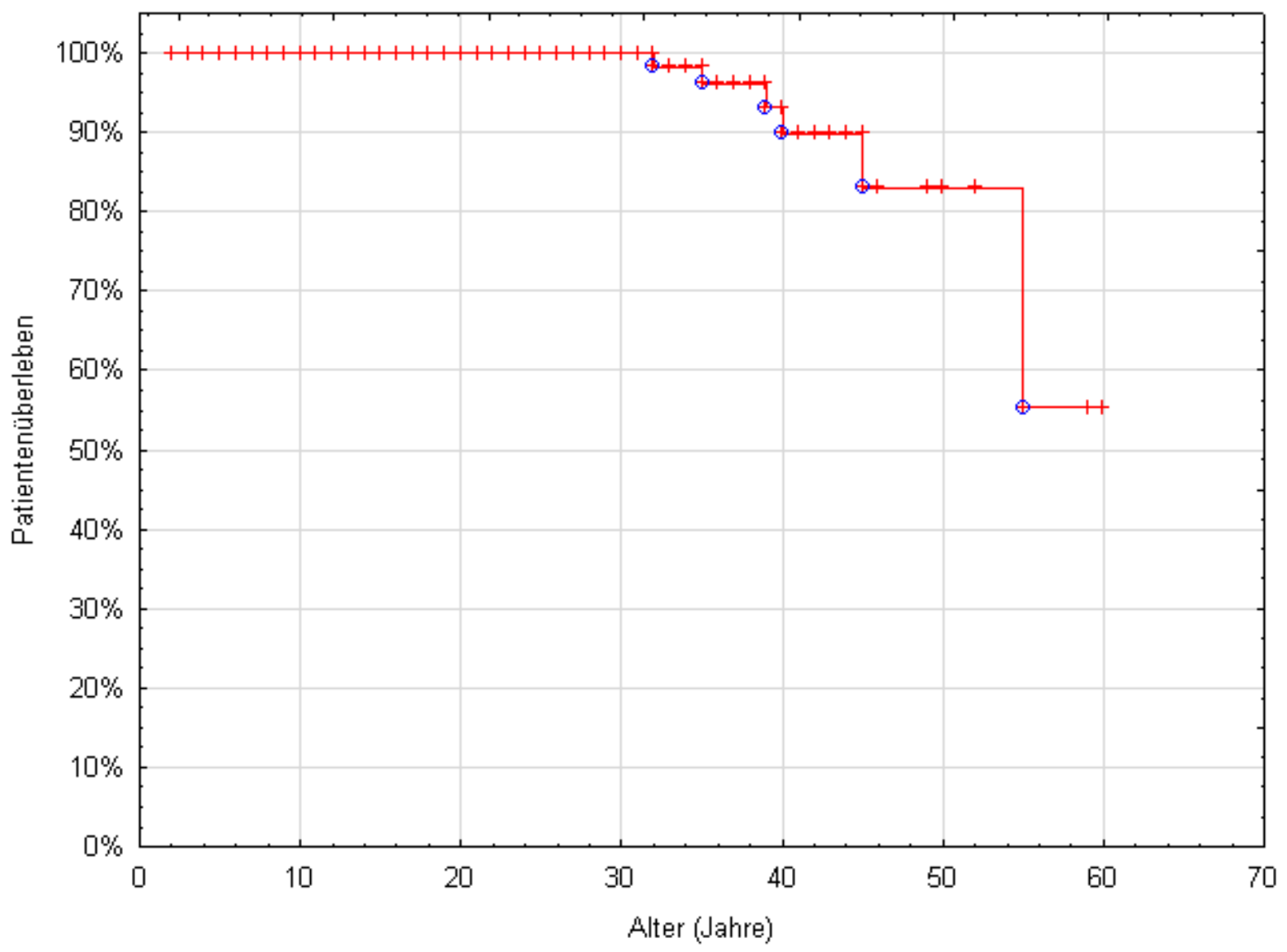

Abbildung 6: Lebenserwartung beim Alport-Syndrom. Darstellung der Lebenserwartung, bezogen auf das jeweilige Patientenalter. Keine Aufteilung der Patienten hinsichtlich einer ACE-Hemmer-Therapie (hierfür siehe Abb. 8). Die Skalenstriche zeigen die zensierten Daten an. Kaplan-Meier-Kurve.

\subsection{Auswirkungen von ACE-Hemmern auf die Lebenserwartung von Patienten mit Alport-Syndrom}

Es stellte sich die Frage, ob und inwiefern eine ACE-Hemmer-Therapie die Lebenserwartung der Alport-Patienten beeinflusst. Im Rahmen dieser Therapie wurde den Patienten vor Dialysebeginn ACE-Hemmer verabreicht, um eine Niereninsuffizienz zu verzögern. Es lagen keine Daten vor, ob die Patienten mit Erreichen der Notwendigkeit einer Nierenersatztherapie weiter mit ACE-Hemmern behandelt wurden.

Es wurden erneut die Daten von 276/285 Patienten ausgewertet. Von innen erhielten 98/276 (35,5\%) keine Behandlung, während 178/276 (64,5\%) vor Dialysebeginn ACE-Hemmer bekamen. Bei 9 Patienten waren die Daten unvollständig. Sie erscheinen deshalb nicht in der Auswertung. 


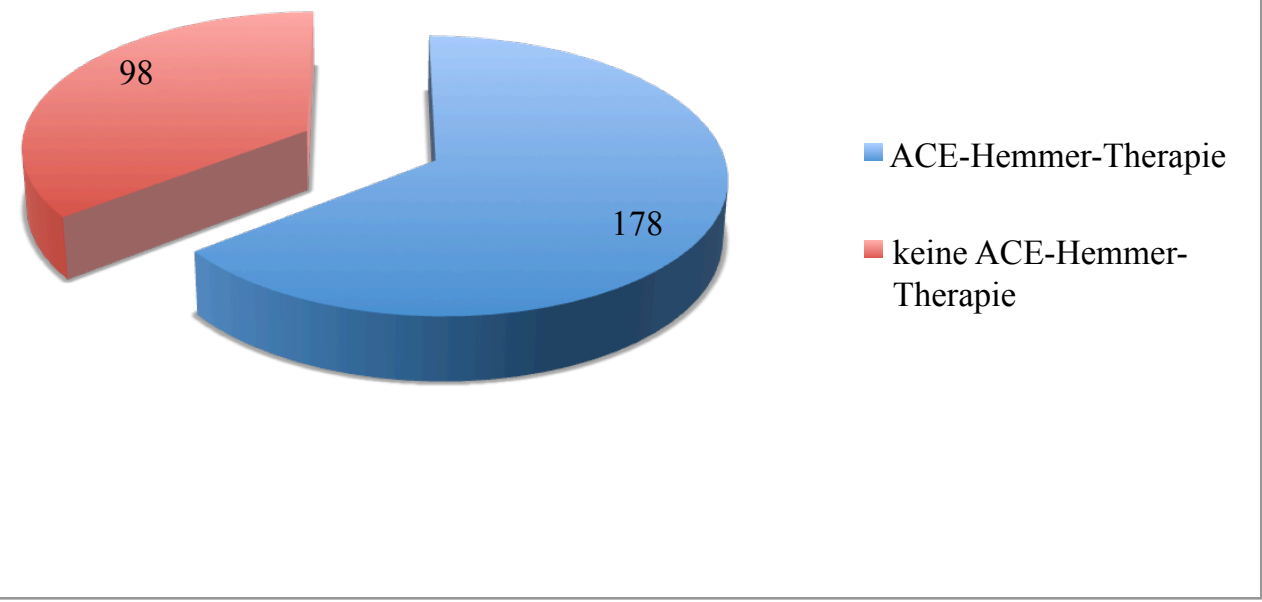

Abbildung 7: Verteilung einer ACE-Hemmer-Therapie im untersuchten Patientenkollektiv

Von den Therapierten $(n=178)$ waren $151(84,8 \%)$ männlich und $27(15,2 \%)$ weiblich. Der Erbgang in der Gruppe der Therapierten teilte sich so auf, dass bei 114/149 (76,5\%) ein X-chromosomaler und bei 35 (23,5\%) ein autosomaler Erbgang vorlag. Von den Übrigen lagen keine Informationen bezüglich des Erbgangs vor. Das durchschnittliche Alter bei Therapiebeginn lag bei 14,7 Jahren. Der jüngste Patient war 1 Jahr und der älteste 56 Jahre alt.

Die mediane Überlebenszeit in der Gruppe, in der die Patienten keine ACE-Hemmer erhielten (rote Kurve, Abb. 8), betrug 55 Jahre (95\% KI 45 Jahre - .). Die Wahrscheinlichkeit, das 40. Lebensjahr zu erreichen, lag bei 83,0\% (95\% KI 59,9\% 93,5\%). In dieser Gruppe waren sechs Patienten im Alter von 32, 35, 39, 40, 45 und 55 Jahren verstorben. Somit ergibt sich ebenfalls ein durchschnittliches Sterbealter von 41 Jahren. Das entspricht dem bereits oben genannten Ergebnis (Abschnitt 3.2.). Dies ist auf die Tatsache zurückzuführen, dass alle verstorbenen Patienten aus der Gruppe stammen, die vor Dialysebeginn keine ACE-Hemmer erhalten haben. In der Kurve in Abbildung 8 ist das jeweilige Patientenalter in Bezug auf die Lebenserwartung dargestellt. Im Falle des Eintritts des Events „Tod“ zeigt diese Kurve jeweils einen stufenförmigen Abfall (rote Kurve).

In der Gruppe, in der die Patienten vor Dialysebeginn mit ACE-Hemmern behandelt worden waren, lebten zum Abfragezeitpunkt noch alle Patienten, so dass sich hier keine mediane Überlebenszeit angeben ließ.

Der Unterschied der beiden Gruppen, bezogen auf die mediane Überlebenszeit, ist bei einem $p$-Wert $<0.05(p=0,0393)$ signifikant (Abb. 8). 
So ergibt sich, auch unter der Einschränkung, dass die Todesrate im unbehandelten Kollektiv sehr gering war $(n=6)$, eine signifikant höhere Lebenserwartung derjenigen Patienten, die vor Dialysebeginn mit ACE-Hemmern therapiert wurden.

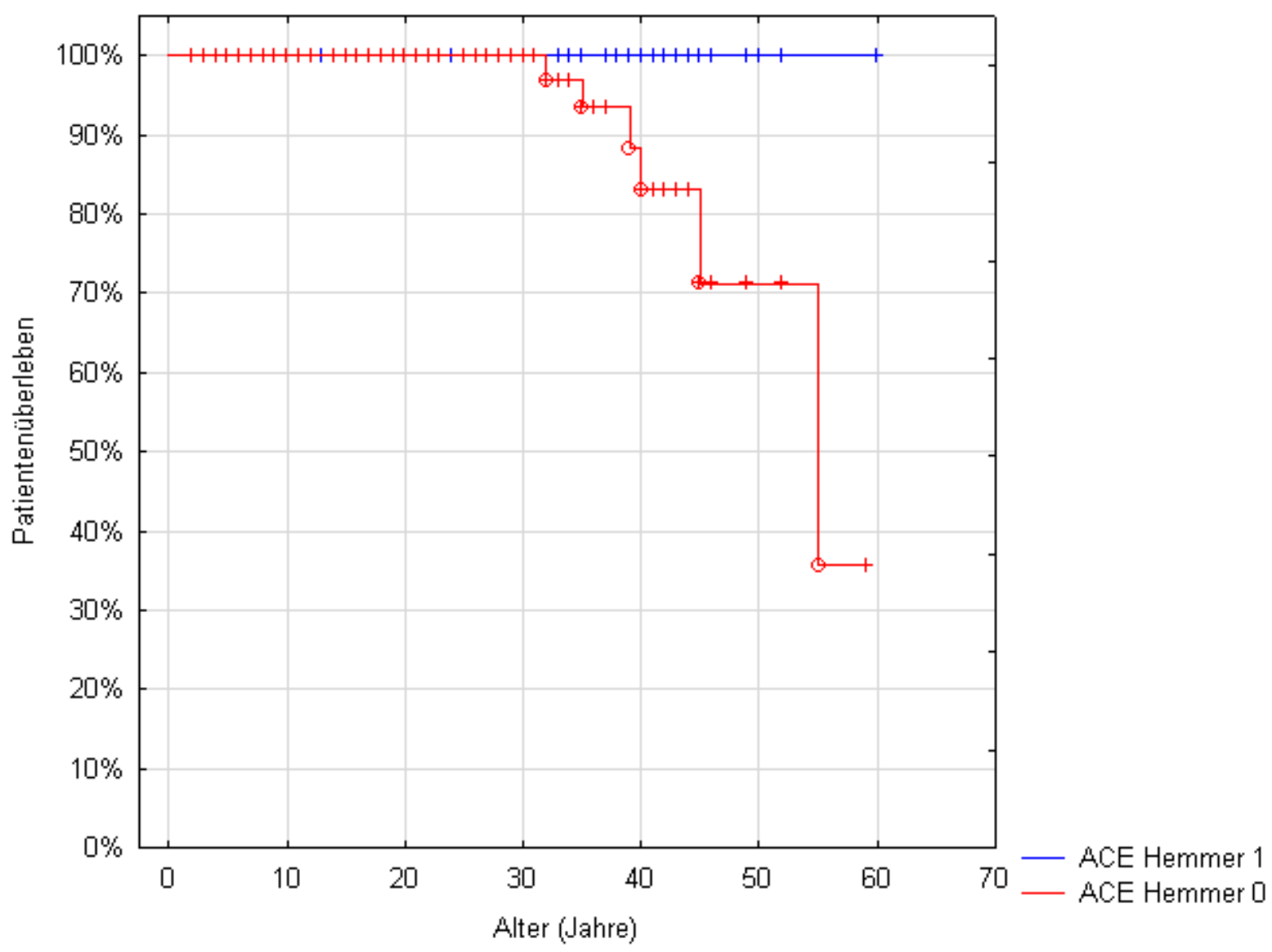

Abbildung 8: Auswirkungen von ACE-Hemmern auf die Lebenserwartung von Patienten mit Alport-Syndrom. Unbehandelte Patienten (rote Kurve) werden mit behandelten $\mathrm{Pa}-$ tienten (blaue Kurve) verglichen. ACE-Hemmer beeinflussen die Lebenserwartung positiv ( $p$ $=0,0393$ vs. keine Therapie). Die Skalenstriche zeigen die zensierten Daten an. KaplanMeier-Kurve.

\subsection{Alter bei Dialysebeginn}

Die Auswertung des Einflusses der Faktoren: „ACE-Hemmer-Therapie“ sowie „Erbgang“ auf die Größe „Alter bei Dialysebeginn“ wird im Folgenden dargestellt. Abbildung 9 zeigt das Alter nicht-dialysepflichtiger Alport-Patienten zum Zeitpunkt ihrer Erfassung. Es wurden die Daten von 283 Patienten in der Auswertung berücksichtigt. Das mediane Alter bei Dialysebeginn lag bei 26 Jahren $(95 \% \mathrm{KI} 25$ Jahre - 28 Jahre). Die Altersspanne reichte von 7 Jahren bis 48 Jahren. Es wird 
deutlich, dass vor allem zwischen dem 10. und 40. Lebensjahr die meisten der Patienten dialysepflichtig wurden. Während mit 10 Jahren noch $100 \%$ der Patienten keine Dialyse benötigten, waren es mit 40 Jahren nur noch weniger als $20 \%$.

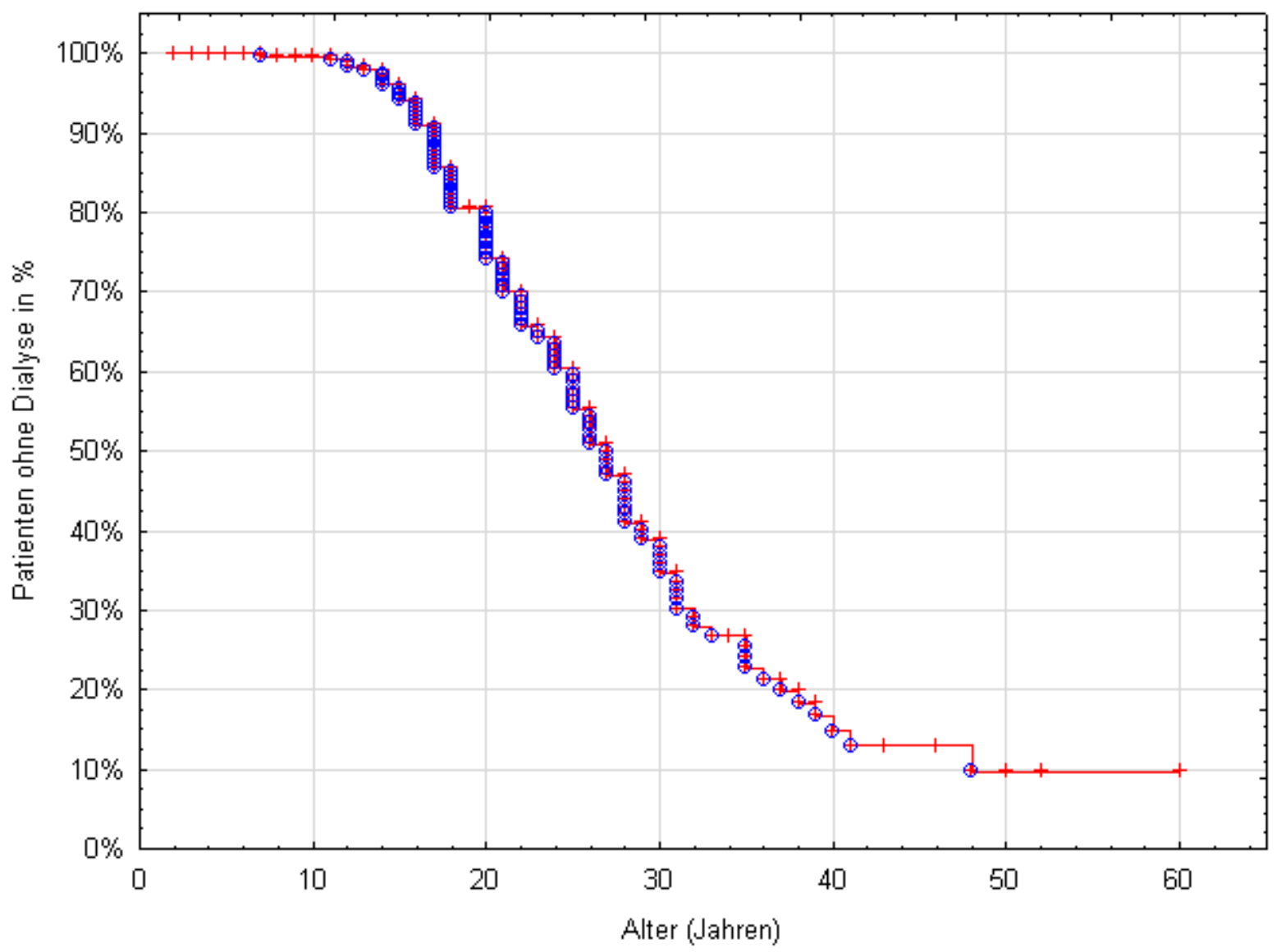

Abbildung 9: Anzahl an nicht-dialysepflichtigen Alport-Patienten zum Zeitpunkt der Datenerhebung. Es werden alle Alport-Patienten untersucht. Bezugspunkt ist die Wahrscheinlichkeit, in einem bestimmten Alter dialysepflichtig zu sein. Die Skalenstriche zeigen die zensierten Daten an (rot). Bei jedem Event (Dialysebeginn) zeigt die Kurve einen stufenförmigen Abfall (blau). Kaplan-Meier-Kurve.

\subsubsection{Einfluss einer ACE-Hemmer-Therapie auf das Alter bei Dialysebeginn}

Der Fokus dieser Untersuchung lag darin, festzustellen, ob ACE-Hemmer die Zeit bis zum Erreichen der terminalen Niereninsuffizienz und damit der Dialysepflichtigkeit verlängern können. Dafür wurden die Alport-Patienten hinsichtlich einer stattgefundenen oder nicht stattgefundenen ACE-Hemmer-Therapie in zwei Gruppen unterteilt. Analog zu 1.3 bezieht sich diese Auswertung ebenfalls auf die ACEHemmer-Therapie vor Dialysebeginn.

Die Auswertung der Daten macht deutlich, dass eine ACE-Hemmer-Therapie bei Alport-Patienten zu einer Verzögerung der Niereninsuffizienz führte (Abb. 10). Das mediane Alter bei Dialysebeginn in der Gruppe der Nicht-Therapierten lag bei 22 
Jahren (95\% KI 20 Jahre - 24 Jahre). Der jüngste Patient wurde mit 7, der älteste Patient mit 39 Jahren dialysepflichtig. Im Gegensatz dazu betrug bei den therapierten Patienten das mediane Alter 35 Jahre (95\% KI 31 Jahre - 48 Jahre). Die Altersspanne reichte von 13 bis 48 Jahren.

Bei einem $\mathrm{p}$-Wert von $<0,0001$ ist der Unterschied zwischen den Patienten mit und ohne ACE-Hemmer-Therapie hinsichtlich des Durchschnittsalters bei Erreichen der Diaysepflichtigkeit signifikant. In der vorliegenden Untersuchung hat eine ACEHemmer-Therapie die Notwendigkeit einer Dialysetherapie im Median um 13 Jahre verzögert.

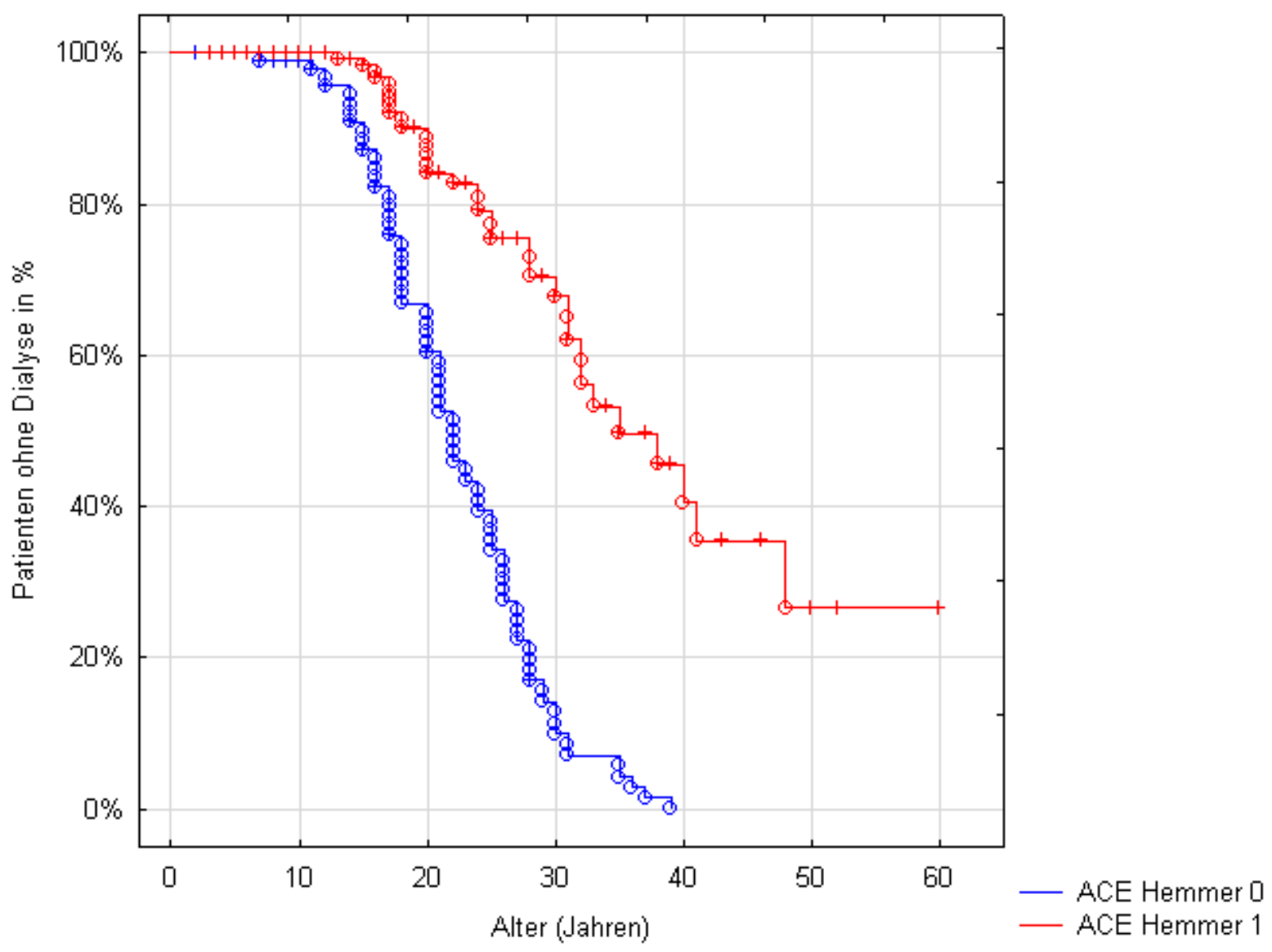

Abbildung 10: Anzahl an nicht-dialysepflichtigen Alport-Patienten zum Zeitpunkt der Datenerhebung unter Berücksichtigung einer stattgefundenen oder unterbliebenen ACE-Hemmer-Therapie. Der Vergleich von Unbehandelten (blaue Kurve) und Behandelten (rote Kurve) zeigt einen signifikanten Unterschied in der Zeitspanne bis zum Erreichen einer Dialysepflicht. Die Skalenstriche zeigen die zensierten Daten an. Kaplan-Meier-Kurve. 


\subsubsection{Einfluss des Erbgangs beim Alport-Syndrom auf das Alter bei Dialysebeginn}

Die Analyse über den Einfluss des Erbgangs des AS auf die Zeit bis zum Erreichen der terminalen Niereninsuffizienz erfolgte ohne Berücksichtigung einer stattgefundenen oder nicht stattgefundenen ACE-Hemmer-Therapie. Es wurde allein untersucht, ob der Erbgang Einfluss auf die Zeit bis zum Erreichen der terminalen Niereninsuffizienz hat. Dazu konnten die Daten von 236/239 Patienten, bei denen der Erbgang bekannt war, herangezogen werden. Von diesen 236 Alport-Patienten wiesen 196 einen X-chromosomalen Erbgang und 40 einen autosomalen Erbgang auf.

Das mediane Alter bei Erreichen des Dialysebeginns in der Gruppe der Patienten mit X-chromosomalem Erbgang lag bei 26 Jahren (95\% KI 24 Jahre - 28 Jahre).

In der Gruppe der Patienten mit autosomalem Erbgang hingegen lag es bei 32 Jahren (95\% KI 30 Jahre - .). Bei einem p-Wert von 0.0525 ist dieser Unterschied jedoch nicht signifikant. Trotz der nicht vorliegenden Signifikanz ist als Tendenz zu erkennen, dass Patienten mit autosomalem Erbgang des AS später dialysepflichtig zu werden scheinen als Patienten mit einem X-chromosomalen Erbgang (Abb. 11). Das Alter bei Dialysebeginn korreliert bei den männlichen Trägern des $X$ chromosomal vererbten AS mit dem vorliegenden Genotyp. Wie bereits erwähnt, entwickeln z.B. Patienten mit einer Nonsense-Mutation früher eine terminale Niereninsuffizienz als Patienten mit einer Missense-Mutation (Gross et al. 2002). Im untersuchten Patientenkollektiv lag bei 59/236 Patienten der Befund einer Mutationsanalyse vor. Eine Missense-Mutation wurde bei 31/196 (15,8\%) Xchromosomalen und bei $5 / 40$ (12,5\%) autosomalen Trägern nachgewiesen. Eine Nonsense-Mutation wiesen 19/196 (9,7\%) der X-chromosomalen und 4/40 (10\%) der autosomalen Trägern auf. Demnach ist die Verteilung der Nonsense-Mutationen und damit der Mutationen mit einem schlimmeren Krankheitsverlauf in beiden Erbgängen ungefähr gleich und stellt keine Erklärung für den früheren Dialysebeginn in der Gruppe der Patienten mit X-chromosomalem Erbgang, dar. Eine mögliche Erklärung wäre allerdings die stattgefundene bzw. nicht-stattgefundene ACE-HemmerTherapie. Der Anteil der Patienten, die eine ACE-Hemmer-Therapie erhalten haben, liegt in der Gruppe der Patienten mit X-chromosomalem Erbgang und bekannter Mutation bei $56 \%$ (28/50), in der Gruppe mit autosomalem Erbgang und bekannter Mutation bei $66,6 \%(6 / 9)$. 


\begin{tabular}{|l|l|l|l|}
\hline Erbgang & Nonsense-Mutation & Missense-Muation & $\begin{array}{l}\text { ACE-Hemmer- } \\
\text { Therapie }\end{array}$ \\
\hline X-chromosomal & 19 & 31 & 28 \\
\hline Autosomal & 4 & 5 & 6 \\
\hline
\end{tabular}

Tabelle 5: Aufteilung der Mutationen in den Erbgängen von Dialyse-Patienten $(n=59)$.

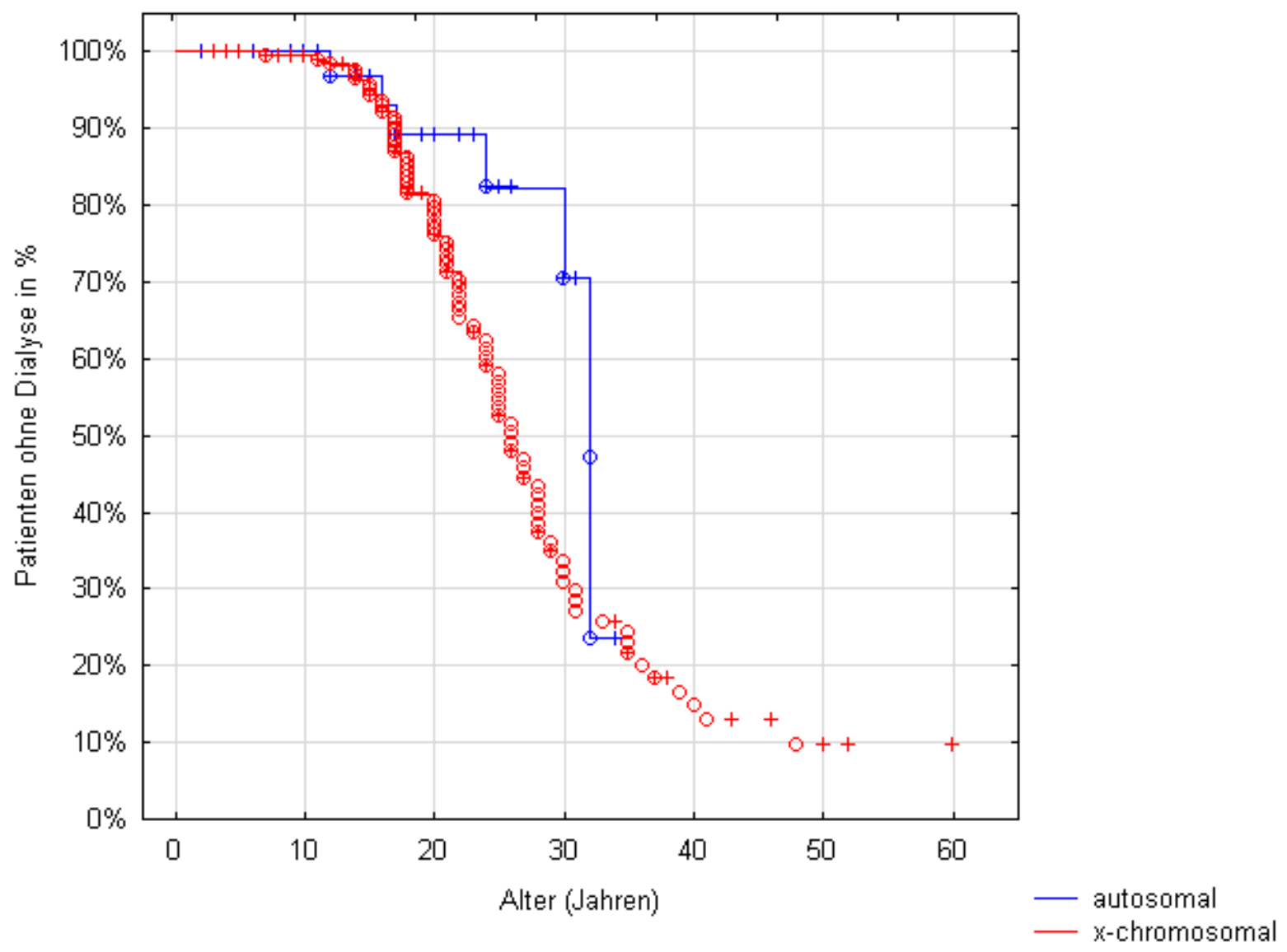

Abbildung 11: Einfluss des Erbgangs auf das Alter bei Dialysebeginn. Der Unterschied hinsichtlich der Zeit bis zum Erreichen der terminalen Niereninsuffizienz von autosomalen (blaue Kurve) und X-chromosomalen Trägern (rote Kurve) ist nicht signifikant. Die Skalenstriche zeigen die zensierten Daten an. Kaplan-Meier-Kurve. 


\subsection{Dauer der Transplantatfunktion}

Die Dauer der Transplantatfunktion konnte bei 44 von 53 transplantierten Patienten erfasst werden. Bei den Übrigen waren die Daten unvollständig.

Das Durchschnittsalter der Alport-Patienten bei der Transplantation lag bei 25,4 Jahren und reichte von 10 bis 48 Jahren.

Die mediane Transplantatfunktionsdauer betrug 19 Jahre (95\% KI 10 Jahre - .). Das 1-, 3- und 5-Jahres-Überleben des Transplantats lag bei 98\%, 92\% und 89\%.

Bei den 44 untersuchten transplantierten Patienten wurde acht Mal ein Transplantatversagen festgestellt. Die transplantierte Niere wurde in diesen Fällen nach durchschnittlich 8,3 Jahren abgestoßen (Abb. 12). Die Zeitspanne bis zur Abstoßung reichte von einem Jahr bis zu maximal 19 Jahren.

Die längste Funktionsdauer eines Transplantats bis zum Zeitpunkt der Datenerhebung betrug 28 Jahre.

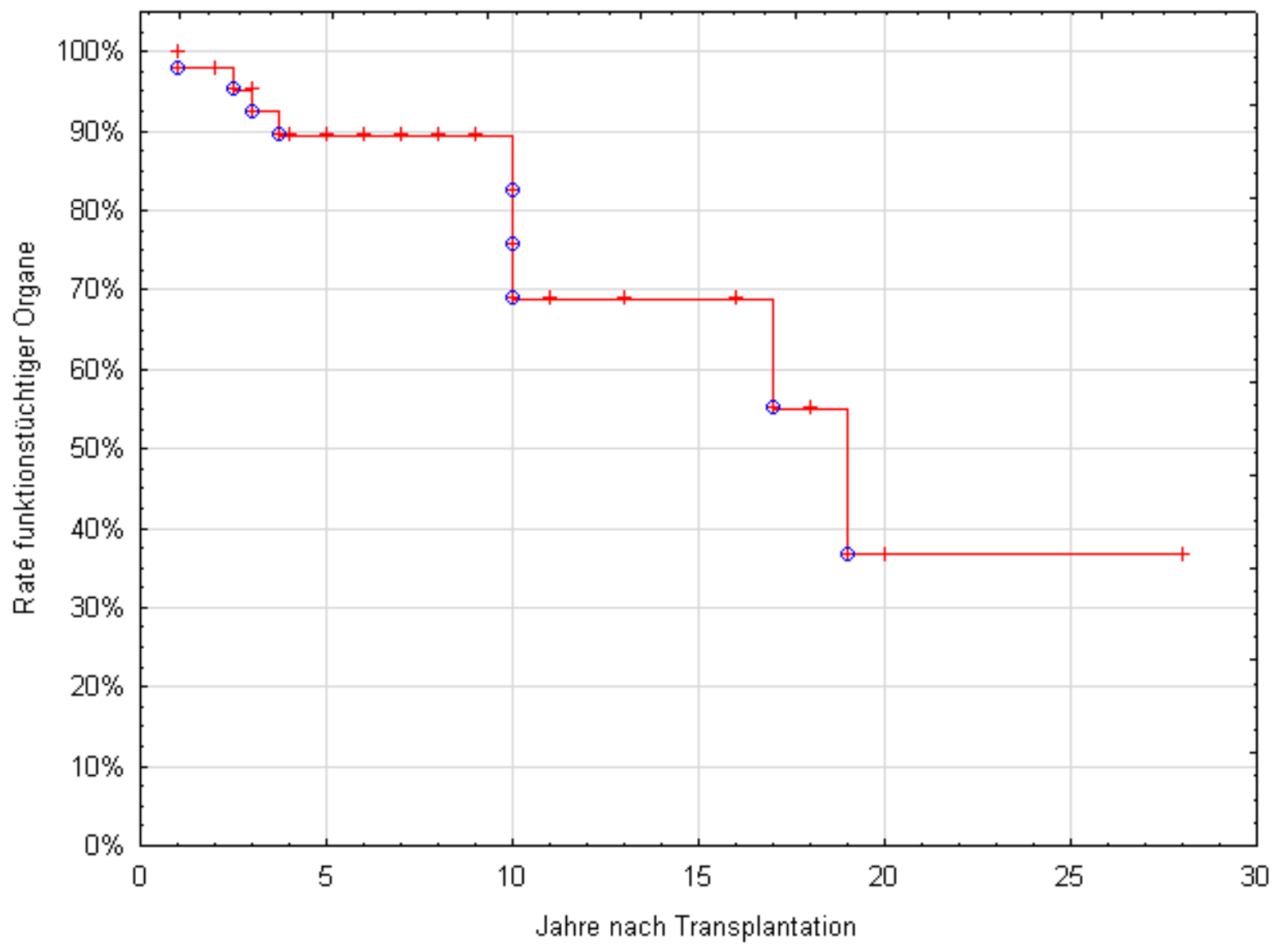

Abbildung 12: Transplantatfunktionsdauer in Jahren. Darstellung des Anteils an noch funktionstüchtigen Transplantaten nach einer bestimmten Anzahl an Jahren nach Transplantation. Events (Transplantatverluste) zeigen sich in einem stufenförmigen Abfall der Kurve (blau). Die Skalenstriche zeigen die zensierten Daten an. Kaplan-Meier-Kurve. 


\subsubsection{Dauer der Transplantatfunktion unter Berücksichtigung einer ACE-}

\section{Hemmer-Therapie}

Es stellt sich die Frage, ob eine ACE-Hemmer-Therapie in der Lage ist, die Dauer der Transplantatfunktion beim AS positiv zu beeinflussen. Wie bereits beschrieben, erhielten ein Teil der Patienten vor Dialysebeginn ACE-Hemmer, um eine Niereninsuffizienz zu verzögern. Es lagen keine Daten vor, ob diese Patienten mit Erreichen der Notwendigkeit einer Dialyse weiter mit ACE-Hemmern behandelt wurden.

Von den 44 für diese Auswertung analysierten Patienten hatten 16 vor Dialysebeginn eine ACE-Hemmer-Therapie erhalten, 28 erhielten diese nicht.

In der Gruppe der Nicht-Therapierten lag die mediane Transplantatfunktionsdauer bei 19 Jahren (95\% KI 10 Jahre - .). Unter diesen Patienten gab es sieben Transplantatversagen. Die Transplantatfunktionsdauer bis zum Versagen reichte von 2,5 bis 19 Jahren.

In der Gruppe der Therapierten hingegen konnte nur ein einziges Transplantatversagen festgestellt werden. Daher waren zum Abfragezeitpunkt noch 93,75\% (15/16) der Nierentransplantate funktionstüchtig und die mediane Funktionsdauer der Nieren ließ sich nicht berechnen. Die eine stattgefundene Transplantatabstoßung fand nach einer Funktionsdauer von einem Jahr statt.

Da nur ein Transplantatverlust in der Gruppe der Therapierten vorlag, ergab sich bei einem p-Wert von 0,7402 kein signifikanter Unterschied zwischen den beiden Gruppen (Abb. 13). Dennoch kann der Graphik eine Tendenz entnommen werden: Patienten, die zur Verzögerung des terminalen Nierenversagens mit ACE-Hemmern behandelt wurden, haben eine längere Transplantatfunktionsdauer als Patienten ohne ACE-Hemmer-Therapie. 


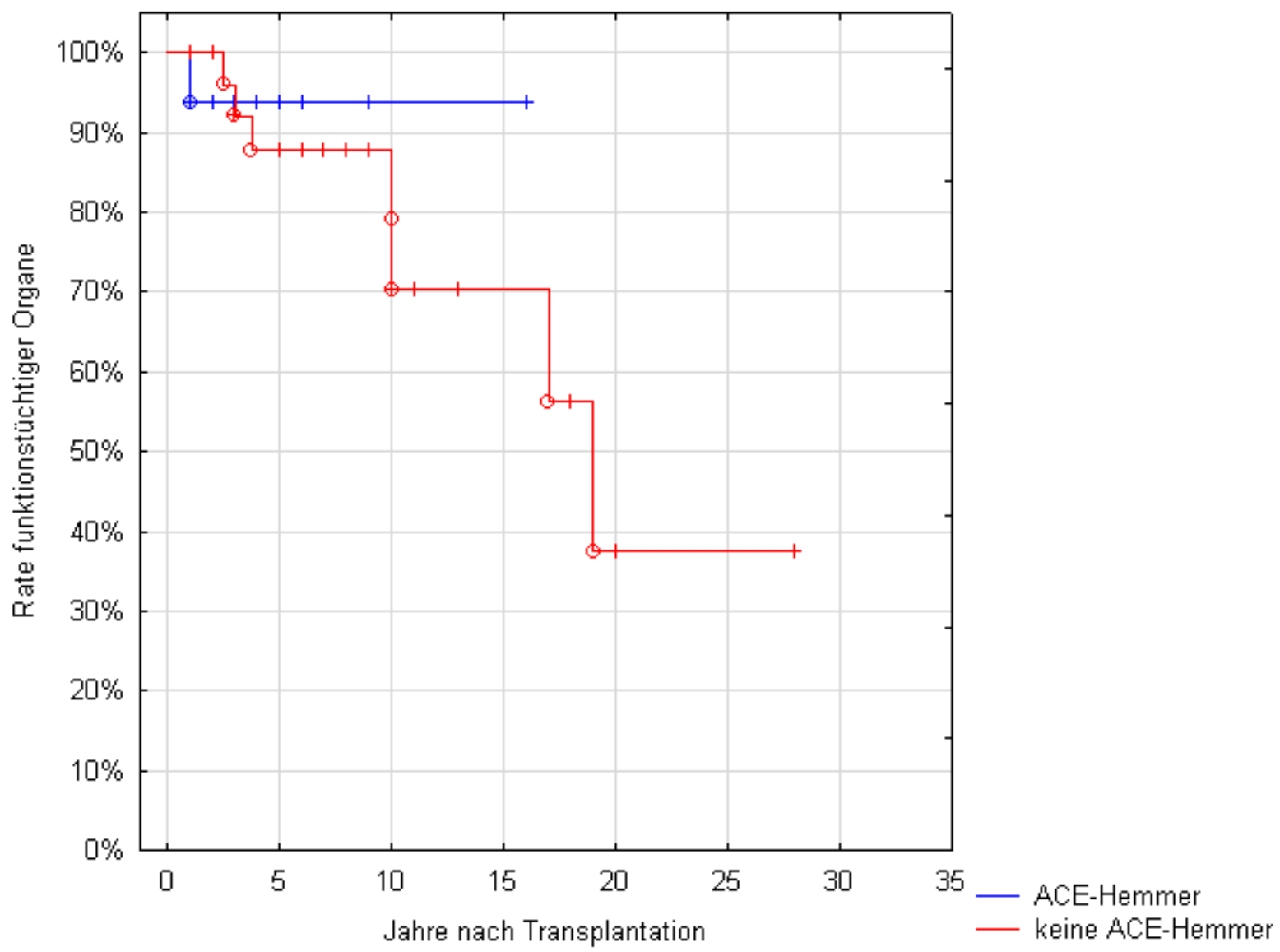

Abbildung 13: Auswirkung einer ACE-Hemmer-Therapie auf die Dauer der Transplantatfunktion. Patienten ohne ACE-Hemmer-Therapie (rote Kurve) werden mit Patienten mit ACE-Hemmer-Therapie (blaue Kurve) hinsichtlich des Unterschieds in der Dauer der Transplantatfunktion verglichen. Der Unterschied ist nicht signifikant, ein Trend ist jedoch zu erkennen. Die Skalenstriche zeigen die zensierten Daten an. Kaplan-Meier-Kurve.

\subsubsection{Dauer der Transplantatfunktion unter Berücksichtigung des Erbgangs}

Abschließend wurde untersucht, ob der dem AS zugrundeliegende Erbgang (Xchromosomal oder autosomal) einen Einfluss auf die Transplantatfunktionsdauer hat. Bei dieser Analyse wurde die Aufteilung der Patienten hinsichtlich einer stattgefundenen oder unterbliebenen ACE-Hemmer-Therapie nicht berücksichtigt. Die Daten von 33 AS-Patienten wurden ausgewertet. Von diesen 33 hatten 29 einen X-chromosomalen und 4 einen autosomalen Erbgang. In der Gruppe der Xchromosomalen Träger gab es fünf Transplantatabstoßungen. In der Gruppe der autosomalen Träger hat kein Transplantatversagen stattgefunden.

Die Dauer der Transplantatfunktion bei Patienten mit AS, denen entweder der Xchromosomale oder der autosomale Erbgang zugrunde liegt, unterscheidet sich nicht signifikant. Dies lässt sich allerdings auch auf die sehr kleine Fallzahl der Transplantatträger mit autosomalem Erbgang (4 Patienten) im untersuchten Kollektiv (Abb. 14) zurückführen. Die Betrachtung der Graphik und die Anzahl an 
Transplantatabstoßungen in den beiden unterschiedlichen Erbgängen erhärtet folgenden Anschein: Wie bereits in Kapitel 3.4.3 beschrieben, ist der autosomale Erbgang mit einer besseren Prognose assoziiert.

Von den AS-Patienten mit einer Nierentransplantation und bekanntem Erbgang ( $\mathrm{n}=$ 33) lag bei elf Patienten der Befund einer Mutationsanalyse vor. Eine MissenseMutation konnte bei sechs $(20,7 \%)$ der X-chromosomalen und bei einem (25\%) der autosomalen Träger nachgewiesen werden.

Vier der 29 (13,8\%) X-chromosomalen und keiner der vier (0\%) autosomalen Träger wiesen eine Nonsense-Mutation auf. Hierbei muss die kleine Fallzahl und der geringfügige Unterschied des Anteils an Nonsense-Mutationen in den beiden Erbgängen beachtet werden. Dies stellt, wie in Abschnitt 3.4.3, keine Erklärung für die vermeintlich längere Transplantatfunktionsdauer beim autosomalen Erbgang dar. In dieser Untersuchung ist, anders als in Abschnitt 3.4.3, der Anteil an Patienten, die mit ACE-Hemmern behandelt wurden, in der Gruppe der X-chromosomalen Träger höher (40\%). Bei den autosomalen Trägern liegt er bei $0 \%$. Aufgrund der Tatsache, dass es in der Untersuchung nur einen Patienten mit autosomal vererbten AS und bekannter Mutation gegeben hat, lassen sich aus diesem Ergebnis allerdings keine Rückschlüsse ziehen.

\begin{tabular}{|l|l|l|l|}
\hline Erbgang & Nonsense-Mutation & Missense-Muation & $\begin{array}{l}\text { ACE-Hemmer- } \\
\text { Therapie }\end{array}$ \\
\hline X-chromosomal & 4 & 6 & 4 \\
\hline Autosomal & - & 1 & - \\
\hline
\end{tabular}

Tabelle 6: Aufteilung der Mutationen in den Erbgängen von Patienten mit Nierentransplantation $(n=11)$. 


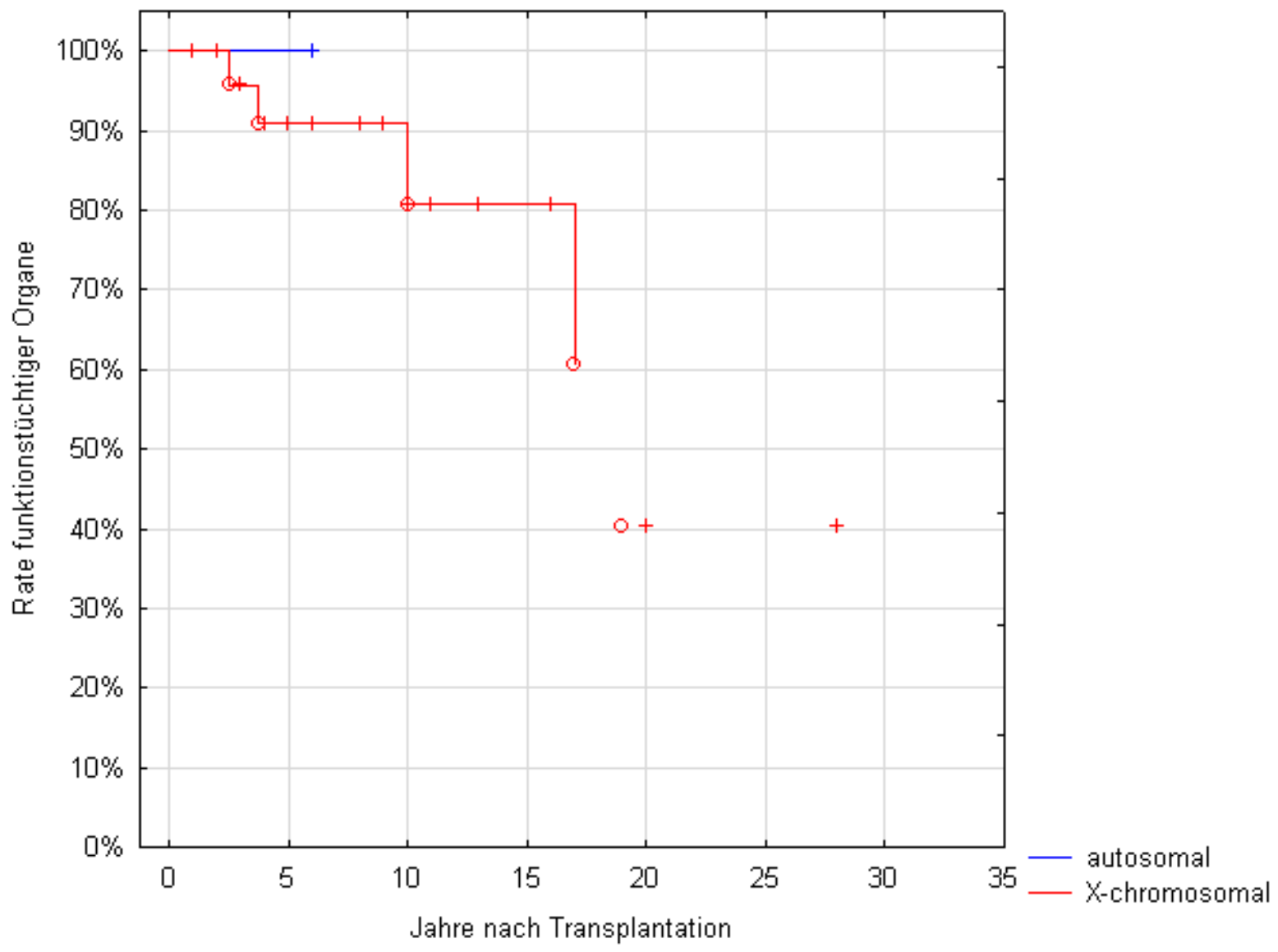

Abbildung 14: Dauer der Transplantatfunktion unter Berücksichtigung des Erbgangs. Vergleich zwischen Patienten mit X-chromosomalem (rote Kurve) und autosomalem Erbgang (blaue Kurve) bezüglich des Unterschieds in der Dauer der Transplantatfunktion. Der Unterschied ist nicht signifikant. Die Skalenstriche zeigen die zensierten Daten an. Kaplan-MeierKurve. 


\section{Diskussion}

In der hier vorliegenden Dissertation wird die Prognose von Patienten mit AS unter Berücksichtigung einer medikamentösen Intervention und verschiedener Nierenersatzverfahren analysiert. Zunächst wurde der Nutzen einer ACE-HemmerTherapie bei AS-Patienten untersucht. Dabei wurde der Effekt dieser Therapie sowohl auf die Lebenserwartung als auch hinsichtlich der Verzögerung des Erreichens der terminalen Niereninsuffizienz erfasst. Weiterhin wurde die Dauer der Transplantatfunktion mit oder ohne vorangegangene ACE-Hemmer-Therapie bestimmt. Außerdem war es Gegenstand dieser Arbeit, die Auswirkungen der beiden Erbgänge des AS auf den Dialysebeginn und die Transplantatfunktionsdauer zu untersuchen.

Zusammenfassend ergab sich ein signifikanter Unterschied in Bezug auf die Lebenserwartung und die Verzögerung der terminalen Niereninsuffizienz zwischen den therapierten und unbehandelten AS-Patienten. Bei der Dauer der Transplantatfunktion konnte ebenfalls ein positiver Einfluss der ACE-Hemmer ermittelt werden. Patienten, die vor Dialysebeginn mit ACE-Hemmern behandelt worden waren, wiesen eine längere Transplantatfunktionsdauer auf als die unbehandelten Patienten.

\subsection{Datenerhebung}

Die Datenerhebung für diese Arbeit fand mit Hilfe von Fragebögen statt, deren Aufbau im Abschnitt Material und Methoden im Detail beschrieben wird.

Eine Besonderheit bei der Datenerhebung stellen die X-chromosomalen Überträgerinnen dar. Der klinische Verlauf weist bei diesen Patientinnen eine große Variabilität auf. Hinzu kommt, dass bei innen die terminale Niereninsuffizienz meist erst sehr spät im Leben eintritt (Jais et al. 2003). Deshalb führte die Einbeziehung dieser Gruppe in die Untersuchung zu einem besseren Outcome des Gesamtkollektivs hinsichtlich der Lebenserwartung beim AS, der Auswirkungen von ACE-Hemmern, des Durchschnittsalters bei Erreichen der terminalen Niereninsuffizienz und der Dauer der Transplantatfunktion. Diese Gruppe von Patientinnen macht allerdings nur einen sehr kleinen Anteil am Gesamtkollektiv aus. Fünf der insgesamt 285 Patienten, die in die Auswertung mit einbezogen wurden, waren weibliche Überträgerinnen des X-chromosomalen Erbgangs. Des Weiteren 
war es sinnvoll, diese Patientinnen in die Auswertung mit einzubeziehen, da auch sie die in dieser Arbeit untersuchten Therapieformen des AS (ACE-Hemmer, Dialyse und Transplantation) erhielten.

Ein weiteres Merkmal dieser Beobachtungsstudie ist die Gefahr der Selektionsverzerrung. Diese kommt dadurch zustande, dass die Zuordnung der Patienten zur Therapiegruppe im Allgemeinen nicht zufällig geschieht. So ist es möglich, dass z. B. nur die Patienten mit einer milderen Verlaufsform des AS aus jedem Land für die Therapiegruppe ausgewählt werden, was zu einem besseren Outcome führt. Um dieses Risiko der Selektionsverzerrung zu minimieren, fand unter anderem im Rahmen dieser Dissertation eine Aktualisierung der primären Daten statt. Das dieser Arbeit zugrunde liegende Alport-Register von 2006 wurde für die vorliegende Analyse 2010 durch die erwähnten Fragebögen aktualisiert. Außerdem fand eine umfangreiche internationale Datenerhebung durch die Einbeziehung von Daten aus 310 Zentren statt.

Bei der durchgeführten Datenerhebung hat es sich als positiv herausgestellt, dass die Endpunkte klar definiert und leicht nachprüfbar waren. Obwohl der Dialysebeginn nicht klar durch einen bestimmten Blutwert definiert war, konnte sich jeder befragte Patient an den Beginn seiner Dialysetherapie erinnern, der somit durch den verwendeten Fragebogen exakt zu ermitteln war.

Für die Arbeit war es weiterhin nützlich, dass es im Interesse aller Beteiligten (z. B. Eltern betroffener Kinder oder Nephrologen) lag, mehr über die Therapiemöglichkeiten des AS zu erfahren. Dieses Interesse spiegelt sich in der hohen Anzahl an internationalen Teilnehmern der Fragebogen-Aktion und dem geringen Verlust von Follow-up Daten wider.

\subsection{Lebenserwartung beim Alport-Syndrom im Vergleich zu anderen Nierenerkrankungen}

Im Allgemeinen erreicht die Lebenserwartung eines Patienten mit terminaler Niereninsuffizienz laut dem United States Renal Data System nur 18\% - 47\% der Lebenserwartung der Allgemeinbevölkerung.

Die mediane Lebenserwartung beim AS konnte in dieser Dissertation nicht ermittelt werden, da zum Abfragezeitpunkt noch über $50 \%$ der Patienten lebten. Stattdessen wurde die Wahrscheinlichkeit angegeben, mit der Diagnose AS das 40. Lebensjahr zu erreichen. Diese lag bei $89,9 \%$. 
Ähnliche Daten zu vergleichbaren Nierenerkrankungen konnten in der Fachliteratur nicht ermittelt werden. Die Studie von Hateboer et al. aus dem Jahr 1999 untersuchte jedoch das mediane Überleben bzw. den Beginn der terminalen Niereninsuffizienz bei Patienten mit polyzystischer Nierenerkrankung. Hierzu wurden 333 Patienten mit polyzystischer Nierenerkrankung Typ I (PKD1) und 291 Patienten mit Typ 2 (PKD2) untersucht. Dabei konnte gezeigt werden, dass das mediane Alter zum Zeitpunkt des Todes bzw. bei Beginn der terminalen Niereninsuffizienz bei 53,0 (PKD1) bzw. 69,1 (PKD2) Jahren lag. Die Wahl des Endpunktes hing dabei von der Möglichkeit zum Zugang einer Dialyse ab. Interessanterweise konnte in dieser Studie bei der PKD2 ein Geschlechtsunterschied hinsichtlich des medianen Überlebens nachgewiesen werden. Das mediane Alter zum Todeszeitpunkt oder bei Beginn der terminalen Niereninsuffizienz lag bei den untersuchten Frauen bei 71,0 und bei den Männern bei 67,3 Jahren. Bei dieser Erkrankung handelt es sich ebenfalls um eine hereditäre Nephropathie, bei der sich in der Niere eine Vielzahl von Zysten bilden, welche die Funktion dieses Organs erheblich einschränken.

In einer Studie von Temme et al. (2012a) wurde nachgewiesen, dass Patienten mit AS, die bereits auf eine Nierenersatztherapie angewiesen waren, eine höhere Lebenserwartung hatten als Patienten mit Nierenersatztherapie, bei denen die Ursache der terminalen Niereninsuffizienz eine andere war (Hazard Ratio 0,42). Als Datengrundlage diente dieser Studie das European Renal Association - European Dialysis and Transplant Association (ERA-EDTA) Register. Dieses Register sammelt jährlich Daten von Patienten, die mit einer Nierenersatztherapie beginnen und in Europa in nationalen oder regionalen Nierenregistern aufgelistet sind. Dies ergibt ein umfassendes Bild über die Nierenersatztherapie in Europa (Temme et al. 2012a). Alport-Patienten sind im Vergleich zu anderen nierenkranken Patienten bei Erreichen der terminalen Niereninsuffizienz besonders jung. Nach Datenlage dieser Arbeit lag das Alter im Median bei 26 Jahren. Vergleicht man dies mit allen Patienten, die 2006 mit einer Nierenersatztherapie begonnen haben, so lag das Alter hier im Median bei 70 Jahren (Frei und Schober-Halstenberg 2008). Dieser Altersunterschied resultiert aus den hauptsächlichen Ursachen der terminalen Niereninsuffizienz. So ist die häufigste Erkrankung der terminalen Niereninsuffizienz, der Diabetes mellitus Typ II (32\% aller Fälle), nicht wie beim AS auf eine hereditäre Ursache zurückzuführen. $\mathrm{Er}$ entwickelt sich erst aufgrund von Risikofaktoren wie Adipositas im Laufe des Lebens und führt daher in der Regel erst später zur terminalen Niereninsuffizienz. 


\subsection{Auswirkungen von ACE-Hemmern auf die Lebenserwartung von Patienten mit Alport-Syndrom}

Die vorliegende Arbeit erhärtet die Aussage, dass im Gegensatz zu Patienten, die nicht mit ACE-Hemmern therapiert worden waren, die Lebenserwartung von ASPatienten durch den Einsatz von ACE-Hemmern signifikant verbessert werden kann ( $p$-Wert $<0,05$ ). Die mediane Lebenserwartung der unbehandelten Patienten betrug 55 Jahre. Eine mediane Zeitangabe der Lebenserwartung für die therapierten Patienten war nicht möglich. Obwohl diese Gruppe nahezu doppelt so groß war wie die der Nicht-Therapierten, war in ihr während des Untersuchungszeitraums kein Patient verstorben. Im Gegensatz dazu traten in der unbehandelten Gruppe sechs Todesfälle auf.

Das AS ist eine Erkrankung, die in der Regel in der zweiten oder dritten Lebensdekade unvermeidlich zum terminalen Nierenversagen führt (Jais et al. 2000). ACE-Hemmer sind in der Lage, das Eintreten der terminalen Niereninsuffizienz hinauszuzögern und so auch die Lebenserwartung von AS-Patienten zu verbessern (Gross et al. 2012). In welcher Weise genau ACE-Hemmer beim AS wirken, ist nur teilweise geklärt und wird in Zukunft Thema weiterer Forschung sein. Bewiesen ist inre antiproteinurische und antihypertensive Wirkung (Proesmans und Van Dyck 2004). Die bereits in der Einleitung erwähnte antifibrotische Wirkung ist bisher nur am Mausmodell nachgewiesen worden (Gross et al. 2003) und wird beim Menschen lediglich vermutet. Der in dieser Arbeit dargestellte Nutzen einer ACE-HemmerTherapie auf die Verzögerung der terminalen Niereninsuffizienz und die dadurch erhöhte Lebenserwartung beim AS macht zwei Dinge deutlich: Erstens die Wichtigkeit einer frühzeitigen Diagnose. Zweitens die rechtzeitige nephroprotektive Therapie schon bei oligosymptomatischen AS-Patienten. Der Nutzen solch einer Therapie konnte bereits in früheren Studien bei häufigen Nierenerkrankungen (z.B. Diabetes mellitus oder Bluthochdruck) nachgewiesen werden (Ruggenenti et al. 2004). 


\subsection{Auswirkungen einer ACE-Hemmer-Therapie auf das Alter bei Dialysebeginn}

Wie bereits ausgeführt, konnte in dieser Arbeit der positive Nutzen einer ACEHemmer-Therapie bezüglich der Verzögerung der terminalen Niereninsuffizienz bei AS-Patienten gezeigt werden. Es ergab sich ein signifikanter Unterschied hinsichtlich des Alters bei Erreichen der terminalen Niereninsuffizienz zwischen den Patienten mit und ohne ACE-Hemmer-Therapie von im Median 13 Jahren.

Unterstützt wird dieses Ergebnis hinsichtlich der Nephroprotektion durch ACEHemmer unter anderem durch die ESCAPE-Studie (Effect of Strict Blood Pressure Control and ACE Inhibition on the Progression of Chronic Renal Failure in Pediatric Patients) (Wühl et al. 2004). In dieser Studie wurden 397 Kinder mit chronischen Nierenerkrankungen und Bluthochdruck über sechs Monate mit dem ACE-Hemmer Ramipril behandelt, was eine Senkung des Risikos im Hinblick auf ein terminales Nierenversagen um 35\% bewirkte (Wühl et al. 2004).

Eine Studie von Temme et al. (2012a) hat gezeigt, dass das Durchschnittsalter von AS-Patienten bei Erreichen der terminalen Niereninsuffizenz mit Notwendigkeit einer Nierenersatztherapie in den letzten Jahren deutlich angestiegen ist. So lag es in der Zeitspanne von 1990 - 1994 noch bei 26,6 Jahren, während es in der Zeitspanne von 2005 - 2009 auf 33,7 Jahre anstieg. Auch diese Tatsache könnte auf den positiven Effekt von ACE-Hemmern zurückzuführen sein. Hinzu kommt, dass im Laufe der Jahre eine immer frühere Diagnosestellung möglich wurde und der Einsatz von ACEHemmern beim AS zunahm. All dies könnte die verzögerte Einsetzung des Nierenversagens erklären.

\subsection{Auswirkungen des Erbgangs auf den Dialysebeginn bzw. die Transplantatfunktionsdauer}

Die Vererbung des AS erfolgt X-chromosomal oder autosomal-rezessiv (Atkin 1988). In beiden Untersuchungen hinsichtlich der Auswirkungen des Erbgangs auf das Alter bei Dialysebeginn bzw. die Dauer der Transplantatfunktion ließ sich eine Tendenz dahingehend erkennen, dass der autosomal-rezessive Erbgang mit einer generell besseren Prognose assoziiert ist (siehe Abschnitt 3.4.2 und 3.5.2). Es ergab sich ein Unterschied von 6 Jahren bezüglich des Alters bei Erreichen des Dialysebeginns zwischen den beiden Erbgängen (Abschnitt 3.4.2). Ferner zeigen die in dieser Studie 
gewonnen Daten, dass der autosomale Erbgang mit einer längeren Transplantatfunktionsdauer assoziiert ist (Abschnitt 3.5.2). Hier muss man allerdings auch die kleine Fallzahl von autosomalen Trägern berücksichtigen (4 Patienten).

Diese Entwicklung deckt sich jedoch nicht mit den Ergebnissen anderer Studien. Danach unterscheiden sich die beiden Erbgänge hinsichtlich ihrer Schwere des Krankheitsverlaufs nicht (Savige et al. 2013).

Ein möglicher Grund für die scheinbar bessere Prognose beim autosomalen Erbgang in der vorliegenden Dissertation könnte sein, dass der Anteil an Patienten, die eine ACE-Hemmer-Therapie erhalten haben, in der Gruppe der autosomalen Träger größer ist als in der X-chromosomaler Träger (66,6\% zu 56\%).

Sinnvoll wäre es, diesbezüglich weitere Studien mit größeren Patientenkollektiven durchzuführen, um zu überprüfen, ob die ACE-Hemmer-Therapie tatsächlich für die bessere Prognose verantwortlich ist.

\subsection{Auswirkungen von ACE-Hemmern auf die Dauer der Transplantatfunktion}

Von besonderer Bedeutung der in dieser Arbeit erzielten Ergebnisse war die Erkenntnis über die möglichen positiven Auswirkungen von ACE-Hemmern auf die Dauer der Transplantatfunktion. Aufgrund des Datenmaterials ließ sich zumindest ein Trend dahingehend erkennen, dass Patienten, die vor Diaylsebeginn bzw. Transplantation mit ACE-Hemmern behandelt worden waren, eine längere Transplantatfunktionsdauer aufwiesen als die unbehandelten Patienten. Leider konnten keine Informationen darüber erhoben werden, ob die AS-Patienten nach der Transplantation weiter mit ACE-Hemmern behandelt wurden. Es kann aber davon ausgegangen werden, dass eine vor Erreichen der terminalen Niereninsuffizienz erhaltene ACE-Hemmer-Therapie auch Auswirkungen auf die Zeit danach hat.

Eine mögliche Erklärung dafür, wie ACE-Hemmer die Funktionsdauer der Nierentransplantate positiv beeinflussen könnten, wäre deren Wirkung auf das kardiovaskuläre Risiko von Transplantatpatienten. Über $50 \%$ ihrer Mortalität ist auf kardiovaskuläre Erkrankungen zurückzuführen (Budde und Budde 2009). ACEHemmer reduzieren dieses Risiko (Yusuf et al. 2000).

Zukünftige Untersuchungen müssten gezielt Daten darüber erheben, ob ASPatienten nach einer Transplantation weiter mit ACE-Hemmern behandelt wurden. In diesem Zusammenhang müsste berücksichtigt werden, ob dies die Dauer der 
Transplantatfunktion positiv beeinflusst hat oder ob die Therapie beendet wurde. Nur so wäre ein Vergleich beider Gruppen auch im Hinblick auf eine vor der Transplantation verabreichten oder nicht verabreichten ACE-Hemmer Therapie möglich.

\subsection{Dauer der Transplantatfunktion beim Alport-Syndrom im Vergleich zu anderen Patienten mit Nierentransplantation}

Die Nieren sind das am häufigsten transplantierte Organ. Wenn man den Jahresbericht 2012 der DSO (Deutsche Stiftung Organtransplantation), einer gemeinnützigen Stiftung bürgerlichen Rechts, die nach dem Transplantationsgesetz mit der Koordinierung der Organspende in Deutschland beauftragt ist, betrachtet, haben 2012 in Deutschland 2586 Personen eine Nierentransplantation erhalten. Im Gegensatz dazu erhielten nur 346 Patienten eine Herztransplantation.

Das 5-Jahres-Überleben der transplantierten Niere betrug bei postmortaler Spende $71,1 \%$ und bei Lebendspende $87,2 \%$. Ein Grund für die bessere Funktionsrate bei Lebendspende ist unter anderem die kürzere Ischämiezeit, da Organentnahme und Übertragung an einem Ort stattfinden (DSO 2013). Außerdem konnte bei der Lebendspende eine Downregulation inflammatorischer Zytokine beobachtet werden (Sadeghi et al. 2003).

Insgesamt liegt die Fünf-Jahres-Transplantatfunktionsrate nach Nierentransplantation in Deutschland bei 73,4 Prozent, international bei 78,9 Prozent (Abb. 15) (CTS 2010). 


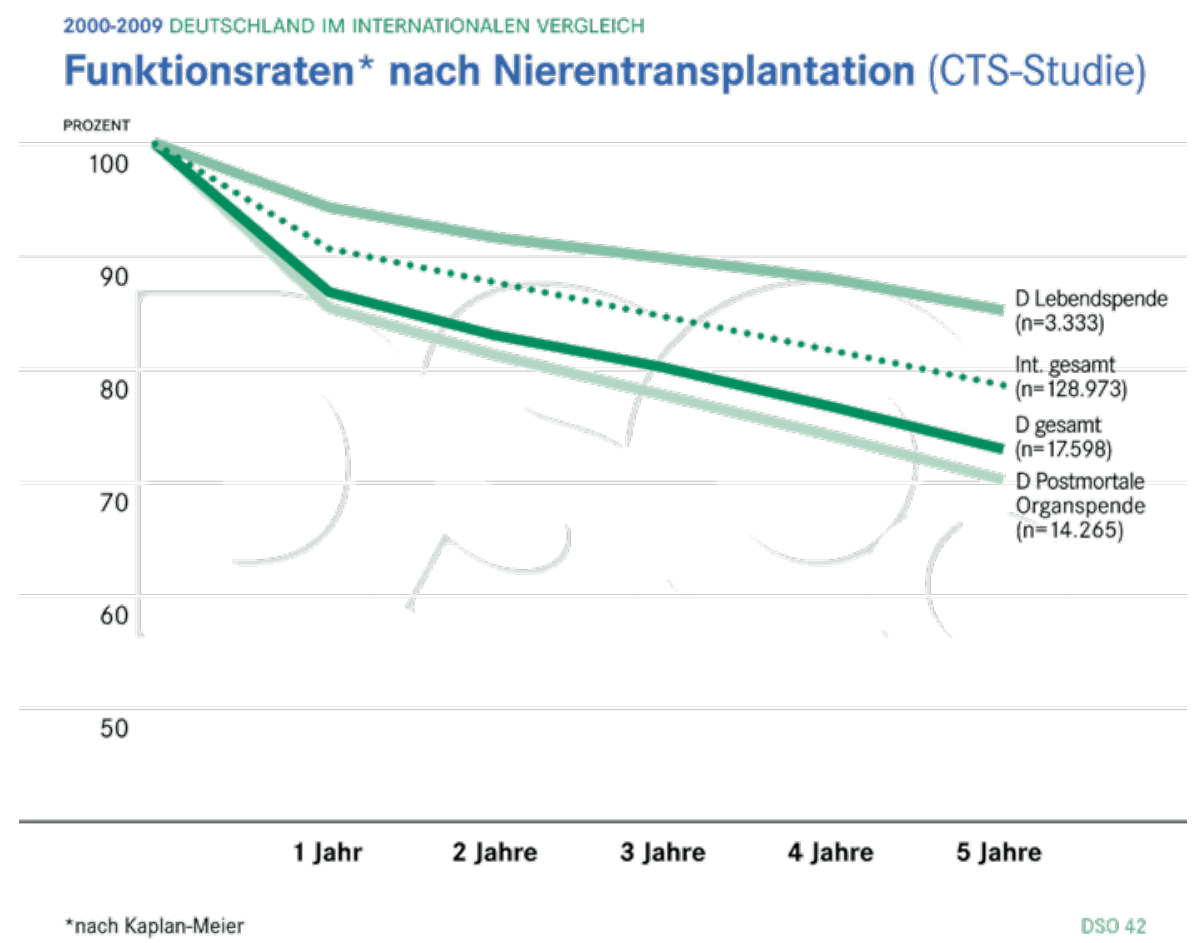

Abbildung 15: Funktionsdauer der Nierentransplantate in Deutschland im internationalen Vergleich. Es wird zwischen Lebendspende und Todspende unterschieden (CTS 2010).

Im Vergleich zu den oben genannten Daten gibt es beim AS eine bessere Transplantatfunktionsrate. Diese liegt mit $89 \%$ nach fünf Jahren um zehn Prozent über dem internationalen Durchschnitt aller Nierentransplantationen. Ergänzende Daten gibt die Arbeit von Kashtan et al. (1995). In dieser Untersuchung wurde das Transplantatüberleben bei unterschiedlich zugrundeliegenden Nierenerkrankungen verglichen. Das AS war die Erkrankung mit dem zweitbesten Transplantatüberleben $(88,9 \%)$ bei Lebendspende. Das beste Transplantatüberleben bei Lebendspende zeigte die Cystinose $(92,9 \%)$, eine Cystinspeicherkrankheit, die auf einer Transportstörung des Cystins aus den Lysosomen basiert. Im Vergleich dazu gab es, zum Beispiel bei der fokal segmentalen Glomerulosklerose (FSGS), eine verhältnismäßig schlechte Transplantatüberlebensrate von nur 74,3\%, die unabhängig von der Art der Spende (Lebendspende vs. Todspende) war (Kashtan et al. 1995).

Der Unterschied hinsichtlich der Dauer der Transplantatfunktion zwischen dem AS und anderen Nierenerkrankungen ist unter anderem durch das geringe Alter bei Transplantation bedingt. Dieses ist beim AS mit durchschnittlich 25,4 Jahren im Vergleich zu 49,5 Jahren bei anderen Nierenerkrankungen sehr niedrig (Frei und Schober-Halstenberg 2008). Hinzu kommen die unterschiedlichen Ursachen, die zur 
terminalen Niereninsuffizienz und damit zur Notwendigkeit einer Nierenersatztherapie führen. Diese unterscheiden sich beim $A S$ von anderen Nierenerkrankungen. Beim AS handelt es sich um eine genetisch bedingte, angeborene Nephropathie mit Innenohrschwerhörigkeit und für das AS typischen Augenveränderungen. Davon abgesehen sind die anderen Organsysteme gesund. Hierin ist der Unterschied zu den übrigen Nierenerkrankungen zu sehen. Beispielhaft seien hier die entzündlichen Autoimmunerkrankungen wie der systemische Lupus erythematodes oder systemische Vaskulitiden aufgeführt, die immer mehrere Organsysteme betreffen, zu einer höheren Morbidität nach Transplantation führen und mitverantwortlich für die schlechtere Transplantatfunktionsdauer sind (Bleyer et al. 2001). Hinzu kommt, dass derartige Krankheiten eine aggressivere Arzneimitteltherapie verlangen und daher auch mit schwereren Nebenwirkungen zu rechnen ist. Weiterhin kommen bei zum Beispiel angeborenen Harntraktanomalien die typischen Operationsrisiken (Infektionen etc.) hinzu. Wie schon erwähnt, haben Alport-Patienten zudem den großen Vorteil, dass bei ihnen keine Gefahr der Rekurrenz der Erkrankung in der transplantierten Niere besteht (Temme et al. 2012a).

Eine Untersuchung von Goldfarb-Rumyantzev et al. (2005) hat gezeigt, dass es einen Zusammenhang zwischen der Zeitdauer einer Dialyse vor einer Transplantation und der Überlebenszeit eines Transplantats gibt. Je kürzer die Zeit an der Dialyse vor der Transplantation ist, desto besser ist das Transplantatüberleben. Dieser Aspekt wurde in der vorliegenden Arbeit nicht erfasst, sollte aber in weiterführenden Analysen evaluiert werden. Es müsste die Hypothese überprüft werden, ob eine kurze Dialysezeit gesündere Patienten der Transplantation zuführt im Gegensatz zu einer langen Behandlungszeit. Dies wäre dann eine weitere Erklärung für die gute Transplantatfunktionsdauer beim AS.

Faktoren, die das Transplantatüberleben beeinflussen, wurden in der Vergangenheit intensiv untersucht (Goldfarb-Rumyantzev et al. 2003, Gjertson 1999). So spielen das Alter von Patient und Spender (Alexander et al. 1994) sowie Vorerkrankungen des Spenders wie z.B. Bluthochdruck und Diabetes (Ojo et al. 2000) eine Rolle. Eine Ursache des Transplantatverlusts, die so gut wie einzigartig für das AS ist, ist die schon erwähnte Anti-GBM-Nephritis. Diese tritt gewöhnlich im ersten Jahr nach der Transplantation auf und führt bei ca. $90 \%$ der betroffenen Patienten innerhalb weniger Wochen bis Monate zum Transplantatversagen. Ursächlich dafür sind 
Autoimmunreaktionen gegen Antigene der GBM des Transplantats. Diese Komplikation tritt jedoch nur selten (bei $2-5 \%$ der Transplantierten) auf und mindert die hervorragenden Transplantatergebnisse beim AS nur in geringem Maße (Hudson et al. 1992).

$\mathrm{Zu}$ all den bereits aufgeführten möglichen Folgeuntersuchungen bei AS-Patienten gehört auch die Analyse des Transplantaterfolges in Bezug auf die Art der Spende (Lebendspende vs. Todspende). In der Regel liefert die Lebendspende bessere Ergebnisse, ist aber aufgrund der Vererbung bei weiteren betroffenen Familienmitgliedern beim AS nicht immer möglich (Kashtan 2006). Da beim Xchromosomal vererbten AS die Mütter meist als heterozygote Konduktorinnen die Erkrankung an ihre Söhne vererben, stellt dies oft eine Kontraindikation zur Lebendspende der Mütter dar.

Vergleicht man die Daten dieser Dissertation mit denen älterer Studien hinsichtlich der Dauer der Transplantatfunktion beim AS, so sind die Ergebnisse ähnlich. In einer Studie von Mojahedi et al. (2007) lag das 1-, 3- und 5-Jahres-Überleben des Transplantates bei $100 \%, 92 \%$ und $84 \%$. Im Vergleich hierzu betrug es in der vorliegenden Auswertung 98\%, 92\% und $89 \%$. Ein besseres Transplantatüberleben bei AS-Patienten im Gegensatz zu Transplantationen bei anderen Nierenerkrankungen, konnte in der Untersuchung von Mojahedi et al. (2007) nicht nachgewiesen werden. Hier waren das 1-, 3- und 5-Jahres-Überleben annähernd gleich (Mojahedi et al. 2007). Dieses Ergebnis konnte jedoch mittlerweile widerlegt und ein besseres Transplantatüberleben bei AS-Patienten nachgewiesen werden (Temme et al. 2012a). 


\subsection{Ausblick}

ACE-Hemmer sind zur Behandlung des AS nicht offiziell zugelassen und werden daher nur im Rahmen einer Off-label-Therapie eingesetzt. Da aber sowohl diese Arbeit als auch weitere Studien (Gross et al. 2012, Temme et al. 2012b) signifikante positive Effekte hinsichtlich des Nutzens von ACE-Hemmern verdeutlicht haben, sollten weitere Bemühungen mit dem Ziel angestellt werden, eine offizielle Zulassung von ACE-Hemmern beim AS zu erreichen. Um den günstigsten Zeitpunkt herauszufinden, wann mit einer ACE-Hemmer-Therapie begonnen werden sollte, läuft seit Frühjahr 2012 die erste randomisierte, prospektive, Placebo-kontrollierte Phase-III-Therapiestudie EARLY PRO-TECT Alport. Mit Hilfe dieser Studie soll die Risiko-Nutzen-Abwägung einer frühen Therapie bei oligosymptomatischen Kindern mit AS stattfinden. Außerdem sollen Prognosefaktoren ermittelt werden, um den Fortschritt der Erkrankung besser beurteilen zu können (Gross et al. 2012).

Die Lebenserwartung beim AS wurde in der vorliegenden Arbeit untersucht und es konnte eine Vierzigjahresüberlebensrate von ca. 90\% ermittelt werden. Was fehlt, ist eine Folgeuntersuchung über die Lebenserwartung solcher AS-Patienten, die bereits dialysepflichtig oder transplantiert worden sind. Dies konnte aufgrund von zu wenigen Todesfällen in der Gruppe der dialysierten bzw. transplantierten ASPatienten im beobachteten Zeitraum nicht ermittelt werden. 


\section{$5 \quad$ Zusammenfassung}

Das Alport-Syndrom (AS) ist eine hereditäre, progredient verlaufende Nierenerkrankung (Alport 1927). Zu den extrarenalen Symptomem zählen eine Innenohrschwerhörigkeit und typische Augenveränderungen wie der Lenticonus anterior (Flinter et al. 1988). Das AS wird durch Mutationen in den $\alpha 3-, \alpha 4-$ oder $\alpha 5-$ Ketten des Kollagen Typ IV verursacht. Diese Mutationen führen zu einem gestörten Aufbau der glomerulären Basalmembran, der sich klinisch zunächst mit einer Hämaturie und Proteinurie bemerkbar macht. Im weiteren Verlauf der Erkrankung kommt es zur Nierenfibrose, was schließlich in der Regel in der 2. - 3. Lebensdekade unweigerlich zum terminalen Nierenversagen führt (Gunwar et al. 1998). Um die terminale Niereninsuffizienz zu verzögern, werden ACE-Hemmer eingesetzt, die aber zur Zeit nur als Therapieempfehlung beim AS gelten und noch nicht offiziell zugelassen sind.

Das Ziel der vorliegenden Arbeit war, im Rahmen einer nicht-interventionellen Verlaufsbeobachtung Daten von AS-Patienten $(n=285)$ zu erheben und diese hinsichtlich unterschiedlicher Prognosefaktoren auszuwerten. Die Zusammensetzung des Patientenkolletivs aus $83 \%$ X-chromosomal und $17 \%$ autosomal betroffenen Patienten war repräsentativ. 178 der 285 AS-Patienten erhielten vor Dialysebeginn eine ACE-Hemmer-Therapie. 111 AS-Patienten waren zum Zeitpunkt der Datenerhebung bereits niereninsuffizient und 53 von diesen hatten eine Nierentransplantation erhalten.

Eine mediane Lebenserwartung aller AS-Patienten ließ sich nicht ermitteln, da noch über $50 \%$ der Patienten lebten. Hinsichtlich der Lebenserwartung unter Berücksichtigung einer ACE-Hemmer-Therapie zeigte sich jedoch, dass die therapierten Patienten eine signifikant höhere Lebenserwartung hatten als die nichttherapierten AS-Patienten ( $p$-Wert < 0,05). So lag die Lebenserwartung bei den wenigen verstorbenen AS-Patienten $(n=6)$ bei durchschnittlich 41 Jahren. Sie hatten alle keine ACE-Hemmer-Therapie erhalten. Die mediane Lebenserwartung betrug in dieser Gruppe 55 Jahre. Für die therapierten Patienten konnte eine mediane Zeitangabe nicht gegeben werden, da in dieser Gruppe noch kein Patient verstorben war.

Das mediane Alter bei Dialysebeginn konnte durch den Einsatz von ACE-Hemmern signifikant hinausgezögert werden ( $p$-Wert < 0,0001). Während es bei den therapierten Patienten bei 35 Jahren lag, betrug es in der Gruppe der Nicht- 
Therapierten 22 Jahre. So konnte eine ACE-Hemmer-Therapie die Zeit bis zur Dialysepflichtigkeit um 13 Jahre verlängern.

Außerdem konnte in dieser Arbeit nachgewiesen werden, dass AS-Patienten, die vor Dialysebeginn eine ACE-Hemmer-Therapie erhalten hatten, ein längeres Überleben des Nierentransplantates aufwiesen als Patienten ohne Therapie. Das Durchschnittsalter der AS-Patienten lag zum Zeitpunkt der Transplantation bei 25 Jahren. Das mediane Transplantatüberleben betrug bei den Patienten, die vor Dialysebeginn keine ACE-Hemmer-Therapie erhalten hatten, 19 Jahre. In dieser Gruppe traten sieben Transplantatverluste auf. Das Transplantatüberleben bis zum Transplantatversagen reichte von 2,5 bis 19 Jahren. In der Gruppe der therapierten Transplantatträger ließ sich keine mediane Zeitangabe machen. In dieser Gruppe waren noch über $50 \%$ der Nierentransplantate funktionstüchtig. In der Gruppe der Therapierten gab es nur ein einziges Transplantatversagen. Es ließ sich kein signifikanter Unterschied für das Transplantatüberleben zwischen diesen beiden Gruppen nachweisen. Jedoch zeichnete sich eine Tendenz zugunsten der therapierten Patienten ab.

Die Ergebnisse dieser Studie basieren auf der Auswertung des Europäischen Alportregisters und sollten daher im Kontext mit diesem gesehen werden. Wie es bereits in früheren Studien deutlich wurde, ergab diese Dissertation signifikante Daten zugunsten einer ACE-Hemmer-Therapie beim AS. Daher sollte die Off-labelTherapie verlassen und ACE-Hemmer offiziell für die Therapie des AS zugelassen werden. 


\section{$6 \quad$ Literaturverzeichnis}

Alexander JW, Bennett LE, Breen, TJ (1994): Effect of donor age on outcome of kidney transplantation. A two-year analysis of transplants reported to the United Network for Organ Sharing Registry. Transplantation 57, 871-6

Alport AC (1927): Hereditary Familial Congenital Haemorrhagic Nephritis. Br Med J $1,504-506$

Antignac C (1995): Molecular genetics of basement membranes: the paradigm of Alport-syndrome. Kidney Int Suppl 49, 29-33

Antignac C, Knebelmann B, Drouot L, Gros F, Deschenes G, Hors-Cayla MC, Zhou J, Tryggvason K, Grunfeld JP, Broyer M et al. (1994): Deletions in the COL4A5 collagen gene in X-linked Alport-syndrome. Characterization of the pathological transcripts in nonrenal cells and correlation with disease expression. J Clin Invest 93, 1195-207

Atkin CL, Gregory MC, Border WA: Alport-syndrome. 4.Auflage; Little, Brown \& Company, Boston 1988

Bland JM, Altman DG (2004): The logrank test. BMJ 328, 1073

Bleyer AJ, Donaldson LA, Mclntosh M, Adams PL (2001): Relationship between underlying renal disease and renal transplantation outcome. Am J Kidney Dis $37,1152-61$

Böhler J: Hämodialyse; Nephrologie Pathophysiologie-Klinik-Nierenersatzverfahren, 5. Auflage, hrsg. v. Kuhlmann U, Walb D, Böhler J, Luft FC; Georg Thieme Verlag, Stuttgart 2008a, 547-581

Böhler J: Nierentransplantation; in: Nephrologie Pathophysiologie-KlinikNierenersatzverfahren, 5. Auflage, hrsg. v. Kuhlmann U, Walb D, Böhler J, Luft FC; Georg Thieme Verlag, Stuttgart 2008b, 619-662

Budde D, Budde K: Transplantation in der Therapie des Nierenversagens; in: Harrisons Innere Medizin, Band 2, 17. Auflage, hrsg. v. Dietel M, Suttorp N, Zeitz M; ABW-Wissenschaftsverlag, Berlin 2009, 2189-2198

Chiurchiu C, Remuzzi G, Ruggenenti P (2005): Angiotensin-Converting Enzyme Inhibition and Renal Protection in Nondiabetic Patients: The Data of the MetaAnalyses. J Am Soc Nephrol 16, 58-63

Cohen D, Galbraith C (2001): General health management and long-term care of the renal transplant recipient. Am J Kidney Dis $\underline{38}, 10-24$

Collins AJ, Kasiske B, Herzog C, Chavers B, Foley R, Gilbertson D, Grimm R, Liu J, Louis T, Manning W et al. (2007): Excerpts from the United States Renal Data System 2006 Annual Data Report. Am J Kidney Dis 49, 1-296

Cosgrove D, Meehan DT, Grunkemeyer JA, Kornak JM, Sayers R, Hunter WJ, Samuelson GC (1996): Collagen COL4A3 knockout: a mouse model for autosomal Alport-syndrome. Genes Dev 10, 2981-92

CTS $(2010)=$ Collaborative Transplant Study, University of Heidelberg, Department of Transplantation Immunology, Funktionsraten nach Nierentransplantation (CTS Studie)

verfügbar: http://www.dso.de/dso/qualitaet-und-sicherheit/collaborative-transplant-study.html (abgerufen: 12.09.2012)

DSO $(2013)=$ Deutsche Stiftung Organtransplantation

verfügbar: http://www.dso.de/organspende-und-transplantation/warteliste-undvermittlung/niere.html (abgerufen 11.10.2013) 
Davies DF, Shock NW (1950): Age changes in glomerular filtration rate, effective renal plasma flow, and tubular excretory capacity in adult males. J Clin Invest $\underline{29}, 496-507$

Fischler MP, Follath F (1999): Comparative evaluation of ACE inhibitors: which differences are relevant?. Schweiz Med Wochenschr 129, 1053-60

Flinter FA: Disorders of the basement membrane: Hereditary nephritis; in: Inherited Disorders of the Kidney; hrsg. v. Morgan SH und Grünfeld JP; Oxford University Press, Oxford 1998, 192 - 214

Flinter FA, Cameron JS, Chantler C, Houston I, Bobrow M (1988): Genetics of classic Alport's syndrome. Lancet $\underline{2}, 1005-7$

Foley RN, Parfrey PS, Sarnak MJ (1998): Epidemiology of cardiovascular disease in chronic renal disease. J Am Soc Nephrol $\underline{9}, 16-23$

Foley RN, Murray AM, Li S, Herzog CA, McBean AM, Eggers PW, Collins AJ (2005): Chronic kidney disease and the risk for cardiovascular disease, renal replacement, and death in the United States Medicare population, 1998 to 1999. J Am Soc Nephrol 16, 489-95

Frei U, Schober-Halstenberg $\mathrm{HJ}$ : Nierenersatztherapie in Deutschland-Bericht über Dialysebehandlung und Transplantation in Deutschland 2006/2007, QuaSi Niere gGmbH, Berlin 2008

Geiger H, Jonas D, Lenz T, Kramer W: Nierenerkrankungen. Pathophysiologie, Diagnostik und Therapie. Schattauer GmbH, Stuttgart 2003

Gjertson DW (1999): Determinants of long-term survival of adult kidney transplants: a 1999 UNOS update. Clin Transpl, 341-52

Goldfarb-Rumyantzev AS, Scandling JD, Pappas L, Smout RJ, Horn S (2003): Prediction of 3-yr cadaveric graft survival based on pre-transplant variables in a large national dataset. Clin Transplant 17, 485-97

Goldfarb-Rumyantzev AS, Hurdle JF, Scandling J, Wang Z, Baird B, Barenbaum L, Cheung AK (2005): Duration of end-stage renal disease and kidney transplant outcome. Nephrol Dial Transplant 20, 167-75

Gross O, Kashtan CE (2009): Treatment of Alport-syndrome: beyond animal models. Kidney Int 76, 599-603

Gross O, Netzer KO, Lambrecht R, Seibold S, Weber M (2002): Meta-analysis of genotype-phenotype correlation in X-linked Alport-syndrome: impact on clinical counselling. Nephrol Dial Transplant 17, 1218-27

Gross O, Beirowski B, Koepke ML, Kuck J, Reiner M, Addicks K, Smyth N, SchulzeLohoff E, Weber M (2003): Preemptive ramipril therapy delays renal failure and reduces renal fibrosis in COL4A3-knockout mice with Alport-syndrome. Kidney Int $\underline{63}, 438-46$

Gross O, Licht C, Anders HJ, Hoppe B, Beck B, Tonshoff B, Hocker B, Wygoda S, Ehrich JH, Pape L et al. (2012): Early angiotensin-converting enzyme inhibition in Alport-syndrome delays renal failure and improves life expectancy. Kidney Int 81, 494-501

Grunfeld JP (1985): The clinical spectrum of hereditary nephritis. Kidney Int 27, 8392

Grunfeld JP, Noel LH, Hafez S, Droz D (1985): Renal prognosis in women with hereditary nephritis. Clin Nephrol $\underline{23}, 267-71$

Gubler MC (2008): Inherited diseases of the glomerular basement membrane. Nat Clin Pract Nephrol 4, 24-37

Gubler M, Levy M, Broyer M, Naizot C, Gonzales G, Perrin D, Habib R (1981): Alport's syndrome. A report of 58 cases and a review of the literature. Am J Med $\underline{70}$, 493-505 
Gunwar S, Ballester F, Noelken ME, Sado Y, Ninomiya Y, Hudson BG (1998): Glomerular basement membrane. Identification of a novel disulfide-crosslinked network of alpha3, alpha4, and alpha5 chains of type IV collagen and its implications for the pathogenesis of Alport-syndrome. J Biol Chem $\underline{273}$, 876775

Gupta R, Birnbaum Y, Uretsky BF (2004): The renal patient with coronary artery disease: current concepts and dilemmas. J Am Coll Cardiol 44, 1343-53

Hakim RM, Lazarus JM (1995): Initiation of dialysis. J Am Soc Nephrol $\underline{6}$, 1319-28

Hateboer N, v Dijk MA, Bogdanova N, Coto E, Saggar-Malik AK, San Millan JL, Torra R, Breuning M, Ravine D (1999): Comparison of phenotypes of polycystic kidney disease types 1 and 2. European PKD1-PKD2 Study Group. Lancet 353, 103-7

Herbst H, Hübner JH (2000): Pathologie-Online = Online-Skript der Pathologie. (letzte Aktualisierung: 05.09.2012) verfügbar: http://www.pathologieonline.de/?page_id=101 (abgerufen 13.08.2012)

Hudson BG, Kalluri R, Gunwar S, Weber M, Ballester F, Hudson JK, Noelken ME, Sarras M, Richardson WR, Saus J et al. (1992): The pathogenesis of Alportsyndrome involves type IV collagen molecules containing the alpha 3(IV) chain: evidence from anti-GBM nephritis after renal transplantation. Kidney Int 42, $179-87$

Hudson BG, Reeders ST, Tryggvason K (1993): Type IV collagen: structure, gene organization, and role in human diseases. Molecular basis of Goodpasture and Alport-syndromes and diffuse leiomyomatosis. J Biol Chem 268, 26033-6

Hudson BG, Tryggvason K, Sundaramoorthy M, Neilson EG (2003): Alport's syndrome, Goodpasture's syndrome, and type IV collagen. N Engl J Med $\underline{348}$, 2543-56

Jais JP, Knebelmann B, Giatras I, De Marchi M, Rizzoni G, Renieri A, Weber M, Gross O, Netzer KO, Flinter F et al. (2000): X-linked Alport-syndrome: natural history in 195 families and genotype- phenotype correlations in males. J Am Soc Nephrol 11, 649-57

Jais JP, Knebelmann B, Giatras I, De Marchi M, Rizzoni G, Renieri A, Weber M, Gross O, Netzer KO, Flinter F et al. (2003): X-linked Alport-syndrome: natural history and genotype-phenotype correlations in girls and women belonging to 195 families: a "European Community Alport-syndrome Concerted Action" study. J Am Soc Nephrol 14, 2603-10

Jofre R, Lopez-Gomez JM, Moreno F, Sanz-Guajardo D, Valderrabano F (1998): Changes in quality of life after renal transplantation. Am J Kidney Dis $\underline{32}$, 93100

Kashtan CE (1998): Alport-syndrome and thin glomerular basement membrane disease. J Am Soc Nephrol $\underline{9}, 1736-50$

Kashtan CE (2006): Renal transplantation in patients with Alport-syndrome. Pediatr Transplant 10, 651-7

Kashtan CE (2007): Alport-syndrome and the $X$ chromosome: implications of a diagnosis of Alport-syndrome in females. Nephrol Dial Transplant $\underline{22}, 1499-$ 505

Kashtan CE, Michael AF (1996): Alport-syndrome. Kidney Int 무, 1445-63

Kashtan CE, McEnery PT, Tejani A, Stablein DM (1995): Renal allograft survival according to primary diagnosis: a report of the North American Pediatric Renal Transplant Cooperative Study. Pediatr Nephrol $\underline{9}$, 679-84

Kashtan CE, Ding J, Gregory M, Gross O, Heidet L, Knebelmann B, Rheault M, Licht C (2012): Clinical practice recommendations for the treatment of Alport- 
syndrome: a statement of the Alport-syndrome Research Collaborative. Pediatr Nephrol 28, 5-11

Kasiske BL (1998): Hyperlipidemia in patients with chronic renal disease. Am J Kidney Dis $\underline{32}, 142-56$

Kasiske BL, Snyder JJ, Gilbertson D, Matas AJ (2003): Diabetes mellitus after kidney transplantation in the United States. Am J Transplant $\underline{3}, 178-85$

Kawai S, Nomura S, Harano T, Harano K, Fukushima T, Osawa G (1996): The COL4A5 gene in Japanese Alport-syndrome patients: spectrum of mutations of all exons. The Japanese Alport Network. Kidney Int 499, 814-22

KDOQI (2006): II. Clinical practice guidelines and clinical practice recommendations for anemia in chronic kidney disease in adults. Am J Kidney Dis 47, 16-85

Kimak E, Solski J, Janicka L, Zagojska M (1999): Lipid and lipoprotein ratios as risk factors of atherosclerosis in patients with chronic renal insufficiency (CRI). Int Urol Nephrol 31, 263-7

Kleppel MM, Fan W, Cheong HI, Michael AF (1992): Evidence for separate networks of classical and novel basement membrane collagen. Characterization of alpha 3(IV)-alport antigen heterodimer. J Biol Chem 267, 4137-42

Leahy TJ, Sullivan MJ, Slingeneyer A, Mion C (1980): The efficiency of microbial retention by peritoneal dialysis filters. Trans Am Soc Artif Intern Organs $\underline{26}$, 225-30

LeRoy EC, Trojanowska MI, Smith EA (1990): Cytokines and human fibrosis. Eur Cytokine Netw 1, 215-9

Levey AS, Beto JA, Coronado BE, Eknoyan G, Foley RN, Kasiske BL, Klag MJ, Mailloux LU, Manske CL, Meyer KB et al. (1998): Controlling the epidemic of cardiovascular disease in chronic renal disease: what do we know? What do we need to learn? Where do we go from here? National Kidney Foundation Task Force on Cardiovascular Disease. Am J Kidney Dis 32, 853-906

Levey AS, Coresh J, Balk E, Kausz AT, Levin A, Steffes MW, Hogg RJ, Perrone RD, Lau J, Eknoyan G (2003): National Kidney Foundation practice guidelines for chronic kidney disease: evaluation, classification, and stratification. Ann Intern Med 139, 137-47

Lewis EJ, Hunsicker LG, Bain RP, Rohde RD (1993): The effect of angiotensinconverting enzyme inhibition on diabetic nephropathy. N Engl J Med $\underline{329}$, 1456-62

Lindeman RD, Tobin J, Shock NW (1985): Longitudinal studies on the rate of decline in renal function with age. J Am Geriatr Soc $\underline{33}, 278-85$

Martini S, Peters H: Glomeruläre Erkrankungen; in: Harrisons Innere Medizin, Band 2, 17. Auflage, hrsg. v. Dietel M, Suttorp N, Zeitz M; ABW-Wissenschaftsverlag, Berlin 2009, 2199-2217

Mettang T: Peritonealdialyse; in: Nephrologie. Pathophysiologie-Klinik-Nierenersatzverfahren, 5. Auflage, hrsg. v. Kuhlmann U, Walb D, Böhler J, Luft FC; Georg Thieme Verlag, Stuttgart 2008, 582-618

Milliner DS, Pierides AM, Holley KE (1982): Renal transplantation in Alport's syndrome: anti-glomerular basement membrane glomerulonephritis in the allograft. Mayo Clin Proc $\underline{57}$, 35-43

Miner JH, Sanes JR (1996): Molecular and functional defects in kidneys of mice lacking collagen alpha 3(IV): implications for Alport-syndrome. J Cell Biol 135, 1403-13

Mochizuki T, Lemmink HH, Mariyama M, Antignac C, Gubler MC, Pirson Y, VerellenDumoulin C, Chan B, Schroder CH, Smeets HJ et al. (1994): Identification of 
mutations in the alpha $3(\mathrm{IV})$ and alpha 4(IV) collagen genes in autosomal recessive Alport-syndrome. Nat Genet $\underline{8}, 77-81$

Mojahedi MJ, Hekmat R, Ahmadnia H (2007): Kidney transplantation in patients with alport-syndrome. Urol J $\underline{4}, 234-7$

Mokdad AH, Bowman BA, Ford ES, Vinicor F, Marks JS, Koplan JP (2001): The continuing epidemics of obesity and diabetes in the United States. JAMA $\underline{286}$, $1195-200$

NAPRTCS $(2008)=$ North American Pediatric Renal Trials and Collarobative Studies. 2008 Annual Report, Renal Transplantation, Dialysis, Chronic Renal Insufficiency verfügbar: https://web.emmes.com/study/ped/annlrept/Annual\%20Report\%20-2008.pdf

National Kidney Foundation (2002): K/DOQI Clinical Practice Guidelines for Chronic Kidney Disease: Evaluation, Classification and Stratification. Am J Kidney Dis $\underline{39}, 1-266$

Ninomiya Y, Kagawa M, Iyama K, Naito I, Kishiro Y, Seyer JM, Sugimoto M, Oohashi T, Sado Y (1995): Differential expression of two basement membrane collagen genes, COL4A6 and COL4A5, demonstrated by immunofluorescence staining using peptide-specific monoclonal antibodies. J Cell Biol 130, 1219-1229

Nowack R, Birck R, Weinreich T: Dialyse und Nephrologie für Fachpersonal. 3. Auflage; Springer, Heidelberg 2009

Ojo AO, Leichtman AB, Punch JD, Hanson JA, Dickinson DM, Wolfe RA, Port FK, Agodoa LY (2000): Impact of pre-existing donor hypertension and diabetes mellitus on cadaveric renal transplant outcomes. Am J Kidney Dis $\underline{36}, 153-9$

Perico N, Codreanu I, Caruso M, Remuzzi G (2005): Hyperuricemia in kidney transplantation. Contrib Nephrol 147, 124-31

Perrin D, Jungers P, Grunfeld JP, Delons S, Noel LH, Zenatti C (1980): Perimacular changes in Alport's syndrome. Clin Nephrol $\underline{13}, 163-7$

Pescucci C, Mari F, Longo I, Vogiatzi P, Caselli R, Scala E, Abaterusso C, Gusmano R, Seri M, Miglietti N et al. (2004): Autosomal-dominant Alport-syndrome: natural history of a disease due to COL4A3 or COL4A4 gene. Kidney Int $\underline{65}$, 1598-603

Pirson Y (1999): Making the diagnosis of Alport's syndrome. Kidney Int $\underline{56}, 760-75$

Pochet JM, Bobrie G, Landais P, Goldfarb B, Grunfeld JP (1989): Renal prognosis in Alport's and related syndromes: influence of the mode of inheritance. Nephrol Dial Transplant $\underline{4}, 1016-21$

Popovich RP, Moncrief JW, Nolph KD, Ghods AJ, Twardowski ZJ, Pyle WK (1978): Continuous ambulatory peritoneal dialysis. Ann Intern Med 8ㅇ, 449-56

Proesmans W, Van Dyck M (2004): Enalapril in children with Alport-syndrome. Pediatr Nephrol 19, 271-5

Rowe JW, Andres R, Tobin JD, Norris AH, Shock NW (1976): The effect of age on creatinine clearance in men: a cross-sectional and longitudinal study. J Gerontol 31, 155-63

Ruggenenti P, Fassi A, llieva AP, Bruno S, lliev IP, Brusegan V, Rubis N, Gherardi G, Arnoldi F, Ganeva M et al. (2004): Preventing microalbuminuria in type 2 diabetes. N Engl J Med 351, 1941-51

Sadeghi M, Daniel V, Weimer R, Wiesel M, Hergesell O, Opelz G (2003): Differential early posttransplant cytokine responses in living and cadaver donor renal allografts. Transplantation $\underline{75}, 1351-5$

Savige J, Gregory M, Gross O, Kashtan C, Ding J, Flinter F (2013): Expert guidelines for the management of Alport-syndrome and thin basement membrane nephropathy. J Am Soc Nephrol 24, 364-75 
Sayers R, Kalluri R, Rodgers KD, Shield CF, Meehan DT, Cosgrove D (1999): Role for transforming growth factor-beta1 in alport renal disease progression. Kidney Int $\underline{56}, 1662-73$

Shlipak MG, Heidenreich PA, Noguchi H, Chertow GM, Browner WS, McClellan MB (2002): Association of renal insufficiency with treatment and outcomes after myocardial infarction in elderly patients. Ann Intern Med 137, 555-62

Smith HW: Comparative physiology of the kidney; in: The Kidney: Structure and Function in Health and Disease. Oxford University Programm, New York 1951, 520-74

Stallone G, Infante B, Schena A, Battaglia M, Ditonno P, Loverre A, Gesualdo L, Schena FP, Grandaliano G (2005): Rapamycin for treatment of chronic allograft nephropathy in renal transplant patients. J Am Soc Nephrol 16, 375562

Temme J, Kramer A, Jager KJ, Lange K, Peters F, Muller GA, Kramar R, Heaf JG, Finne P, Palsson R et al. (2012a): Outcomes of Male Patients with Alportsyndrome Undergoing Renal Replacement Therapy. Clin J Am Soc Nephrol $\underline{7}$, 1969-76

Temme J, Peters F, Lange K, Pirson Y, Heidet L, Torra R, Grunfeld JP, Weber M, Licht C, Muller GA et al. (2012b): Incidence of renal failure and nephroprotection by RAAS inhibition in heterozygous carriers of $X$ chromosomal and autosomal recessive Alport mutations. Kidney Int $\underline{81}, 779$ 83

Vajdic CM, McDonald SP, McCredie MR, van Leeuwen MT, Stewart JH, Law M, Chapman JR, Webster AC, Kaldor JM, Grulich AE (2006): Cancer incidence before and after kidney transplantation. JAMA 296, 2823-31

Valtin H, Budde K, Hepburn H: Dialyse zur Behandlung des Nierenversagens; in: Harrisons Innere Medizin, Band 2, 17. Auflage, hrsg. v. Dietel M, Suttorp N, Zeitz M; ABW-Wissenschaftsverlag, Berlin 2009, 2182-2188

Vollert JO, Möckel M, Dietz R: Herzinsuffizienz und Cor pulmonale; in: Harrisons Innere Medizin, Band 2, 17. Auflage, hrsg. v. Dietel M, Suttorp N, Zeitz M; ABW-Wissenschaftsverlag, Berlin 2009,1778-1791

Wenzel U, Dominiak P, Neumayer HH, Wolf G (2003): Hemmung der Progression von chronischen Nierenerkrankungen-Therapie durch Blockierung des ReninAngiotensin-Systems. Dtsch Arztebl 100, 2072-2079

Wolf G (2005): The renin-angiotensin-aldosterone system -- more complex as previously thought. Med Klin (Munich) $\underline{100}$, 471-7

Wühl E, Mehls O, Schaefer F (2004): Antihypertensive and antiproteinuric efficacy of ramipril in children with chronic renal failure (ESCAPE-Study). Kidney Int $\underline{66}$, 768-76

Wühl E, Trivelli A, Picca S, Litwin M, Peco-Antic A, Zurowska A, Testa S, Jankauskiene A, Emre S, Caldas-Afonso A et al. (2009): Strict blood-pressure control and progression of renal failure in children. N Engl J Med 361, 1639-50

Yusuf S, Sleight P, Pogue J, Bosch J, Davies R, Dagenais G (2000): Effects of an angiotensin-converting-enzyme inhibitor, ramipril, on cardiovascular events in high-risk patients. The Heart Outcomes Prevention Evaluation Study Investigators. N Engl J Med 342, 145-53

Zhang KW, Colville D, Tan R, Jones C, Alexander SI, Fletcher J, Savige J (2008): The use of ocular abnormalities to diagnose X-linked Alport-syndrome in children. Pediatr Nephrol $\underline{23}$, 1245-50 


\section{$7 \quad$ Anhang}

\subsection{Fragebogen}

Georg-August-Universität Göttingen

Universitätsklinikum, Abt. Nephrologie\&Rheumatologie

FAX +49-551-39-8906

\section{Fragebogen Alport Therapie-Register}

\section{Patient \\ GebDatum \\ Familie \\ Gruppe}

\section{Interner Gebrauch}

Datum

$\square$ erreicht

$\square$ nicht erreicht

\section{Endpunkte}

1. Dialyse

$\square$ nein

$\square$ ja (Datum)

$\square$ unbekannt

2. Aktuelle Nierenfunktion

Crea-Clearance

Proteinurie

$\mathrm{ml} / \mathrm{min}$ (Datum)

$\square$ unbekannt

g/Tag o. g/gCrea (Datum)

$\square$ unbekannt

3. Therapie

$\square$ nein
Wenn ja:

$\square$ ja (Substanz)

$\square$ unbekannt

4. Nebenwirkungen

$$
\begin{array}{ll}
\square \text { nein } & \square \text { ja (Datum) } \\
\text { Wenn ja: } \quad \square \text { Tod (Datum) } \\
\square \text { Hyperkaliämie (Datum, Therapie) } \\
\square \text { akutes Nierenversagen (Datum, Therapie) } \\
\square \text { Angioödem (Datum, Therapie) } \\
\square \text { Sonstiges (Datum, Therapie) }
\end{array}
$$

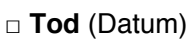

$\square$ unbekannt

$\square$ Husten $\square$ Hypotonie

$\square$ Katarrakt $\square$...........

\section{Diagnose: Mutation}

$$
\begin{aligned}
& \square \text { nein } \\
& \square \text { nein }
\end{aligned}
$$$$
\square \text { ja (Befund) }
$$$$
\square \text { ja (Befund) }
$$

$\square$ unbekannt

$\square$ Patient selbst $\square$ Verwandte 
Herzlichen Dank für Ihre Mithilfe!

Bitte zurücksenden an:

Kommentare

PD Dr. O. Gross, FASN

Abt. Nephrologie\&Rheumatologie Robert-Koch-Str. 40

37075 Göttingen

Germany

Tel. +49-551-39-8912 o. 6331

Fax +49-551-39-8906

gross.oliver@med.uni-goettingen.de

www.alport.de

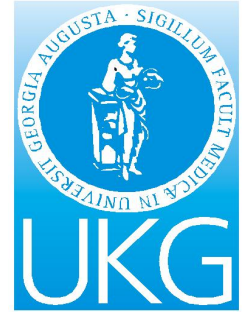




\section{Danksagung:}

Mein besonderer Dank gilt meinem Doktorvater Herrn Prof. Dr. med. Gross, der es mir über die Vergabe des Themas ermöglicht hat, einen Einblick in wissenschaftliches Arbeiten zu erlangen. Außerdem bedanke ich mich für die konstruktive Kritik und die Hilfeleistungen bei der Fertigstellung dieser Arbeit.

Außerdem bedanke ich mich bei Frau Dr. Katharina Lange, Wissenschaftliche Mitarbeiterin in der Abteilung Medizinische Statistik der Universitätsmedizin Göttingen, die mir bei der statischen Auswertung der Daten immer kompetent zu Seite stand. 


\section{Lebenslauf:}

Am 31.08.1984 wurde ich, Angela Irene Mathilde Assmann, geb. Coordes, als erstes Kind der Gynäkologin Irene Coordes und des Diplomkaufmanns Hinrich Coordes in Osnabrück geboren. Von 1991 bis 1995 besuchte ich die Grundschule Dom, von 1995 bis 1997 die Orientierungsstufe Dom, von 1997 bis 2004 das Gymnasium Ursulaschule in Osnabrück. In der 11. Klasse verbrachte ich ein Trimester als Austauschschülerin in England an der Westonbirt School in Tetbury, Gloucestershire (September bis Dezember 2001). Die Allgemeine Hochschulreife erhielt ich 2004 (Fächer: Latein, Englisch, Mathematik, Pädagogik). Von November 2004 bis Februar 2005 habe ich ein Vorsemester für Medizin am Rheinischen Bildungszentrum in Köln besucht, daraufhin habe ich mein Pflegepraktikum für das Medizinstudium am Klinikum Osnabrück abgeleistet und von November 2005 bis Februar 2006 habe ich eine Ausbildung zur Rettungssanitäterin gemacht. Im April 2006 begann ich mein Studium der Humanmedizin an der Georg-August-Universität zu Göttingen. Von Februar 2011 bis Januar 2012 habe ich das Praktische Jahr der medizinischen Ausbildung absolviert. Im Sommer 2012 bestand ich den Zweiten Abschnitt der Ärztlichen Prüfung mit der Note -gut-. Seit März 2013 arbeite ich als Ärztin in der Abteilung für Geburtshilfe und Gynäkologie des Krankenhaus Neu-Mariahilf in Göttingen.

Diese Arbeit fertigte ich zwischen 2010 und 2013 in der Klinik für Nephrologie und Rheumatologie unter der Leitung von Herrn Prof. Dr. med. O. Gross an. 